Florida International University FIU Digital Commons

$11-7-2017$

\title{
Evaluating High School Biology Modeling Instruction in South Florida: A Comparative Case Study
}

Feng Li

Florida International University, fli003@fiu.edu

DOI: $10.25148 /$ etd.FIDC004041

Follow this and additional works at: https://digitalcommons.fiu.edu/etd

Part of the Curriculum and Instruction Commons, Educational Assessment, Evaluation, and Research Commons, Educational Methods Commons, Science and Mathematics Education Commons, Secondary Education Commons, and the Secondary Education and Teaching Commons

\section{Recommended Citation}

Li, Feng, "Evaluating High School Biology Modeling Instruction in South Florida: A Comparative Case Study" (2017). FIU Electronic Theses and Dissertations. 3522.

https://digitalcommons.fiu.edu/etd/3522

This work is brought to you for free and open access by the University Graduate School at FIU Digital Commons. It has been accepted for inclusion in FIU Electronic Theses and Dissertations by an authorized administrator of FIU Digital Commons. For more information, please contact dcc@fiu.edu. 


\title{
FLORIDA INTERNATIONAL UNIVERSITY
}

Miami, Florida

EVALUATING HIGH SCHOOL BIOLOGY MODELING INSTRUCTION IN SOUTH FLORIDA: A COMPARATIVE CASE STUDY

\author{
A dissertation submitted in partial fulfillment of the \\ requirements for the degree of \\ DOCTOR OF PHILOSOPHY \\ in \\ CURRICULUM AND INSTRUCTION
}

by

Feng Li

2017 
To: Dean Michael R. Heithaus

College of Arts, Sciences and Education

This dissertation, written by Feng Li, and entitled Evaluating High School Biology Modeling Instruction in South Florida: A Comparative Case Study, having been approved in respect to style and intellectual content, is referred to you for judgment.

We have read this dissertation and recommend that it be approved.

$\begin{array}{r}\hline \text { Zahra Hazari } \\ \hline \text { Haiying Long } \\ \hline \text { George O'Brien } \\ \hline \text { Eric Brewe, Major Professor }\end{array}$

Date of Defense: November 7, 2017

The dissertation of Feng $\mathrm{Li}$ is approved.

Dean Michael R. Heithaus

College of Arts, Sciences and Education

Andrés G. Gil

Vice President for Research and Economic Development And Dean of the University Graduate School

Florida International University, 2017 


\section{ACKNOWLEDGMENTS}

I would like first to acknowledge the advice and support of my major professor Eric Brewe. His passion to work out of his comfort zone with me on a biology education research study is inspiring in my academic career. I would also like to acknowledge the support and valuable feedback of my other dissertation committee members: Zahra Hazari, Haiying Long, and George O’Brien.

I am also grateful for all kinds of contributions of the members of the Florida International University STEM Education Research Group, many of whom were willing to engage in conversation about biology education although were trained in STEM fields other than biology.

Manny Vilchez, David Jones, Caprila Almeida, and Octavio Visiedo deserve acknowledgements for their support in recruiting research participants. This dissertation project would even be difficult to start without their assistance through the recruitment process. I would like to particularly thank David Jones, who is currently having a hard time. Cheer up, DJ! You can make it!

I would also like to acknowledge my mother Quansheng Zhu, my father Shaoming Li, my sister Han Li, and my dog Wei-er back in China for their love and support. They have played critical roles in shaping me into the tenacious, courageous, and sympathetic person that I am today.

Last but definitely not least, I would like to acknowledge my wife Xuan Jiang, my daughter Tang Li, and my son Yan Li. My wife's support and inspiration 
throughout has made my Ph.D. journey more promising and enjoyable. My daughter and son just simply make me smile every day, which means everything to me. 


\section{ABSTRACT OF THE DISSERTATION \\ EVALUATING HIGH SCHOOL BIOLOGY MODELING INSTRUCTION IN \\ SOUTH FLORIDA: A COMPARATIVE CASE STUDY}

by

Feng Li

Florida International University, 2017

Miami, Florida

Professor Eric Brewe, Major Professor

The dissertation, with a collected papers approach, focused on evaluating the implementation of MI curriculum in high school Biology I classes in south Florida.

The dissertation included the development and validation of the Biology Identity and Persistence Survey (BIPS), the connection of instructors' teaching practices with students' biology identities, evolution identities, and career aspirations, and the connection of instructors' teaching practice with students' conceptual understanding in evolution. In the first part of the dissertation study, the BIPS was validated through expert review and student cognitive interviews for its face and content validity. Confirmatory factor analysis addressed the construct validity of the final version of the BIPS, after removing four problematic items. The Cronbach's alpha and test-retest reliability analysis indicated that the BIPS was a reliable instrument in terms of its internal reliability and stability. In the second part of the dissertation study, the comparison between the MI and non-MI classes indicated that there was 
no detectable significant difference between the MI classes and non-MI classes in students' development of biology identities and evolution identities, and shifts in career aspirations. Using the analysis of the MI and non-MI instructors' teaching practices, it was suggested that the use of intentional lack of inquiry closure, seeding, small-group collaboration, whole-class discussion, and Socratic questioning might contribute to students' biology/evolution identity development. In the third part of the dissertation study, the Evolution Concept Inventory was demonstrated as an invalid and unreliable research instrument. Qualitative analysis of instructors' teaching practices suggested that interactions between MI instructional materials and MI pedagogical techniques, including student-centered teaching, small-group collaboration, student-student interaction, whole-class discussion, and Socratic questioning, might contribute to students' gain of conceptual understanding in evolution. On the basis of the research findings, this dissertation provided suggestions for high school biology MI instructors and high school biology MI workshops. 


\section{TABLE OF CONTENTS}

CHAPTER

PAGE

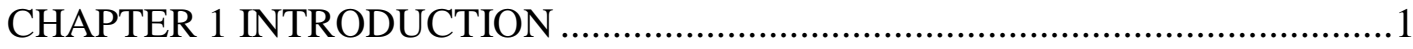

1.1 Project Motivation ..................................................................... 1

1.1.1 High School Biology Curriculum Reform .............................1

1.1.2 Modeling Instruction in High School Science Education.......2

1.1.3 Enhancing Students' Aspirations in Biology ..........................5

1.2 Literature Review and Theoretical Framework ................................6

1.2.1 Science/Biology Identity in High School Biology

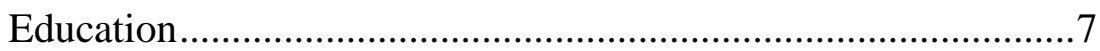

1.2.2 Science/Biology Identity Development ................................

1.2.3 Efficacy of Modeling Instruction in Science Education .......12

1.3 Overview of the Dissertation Research.........................................13

1.3.1 Purpose of the Dissertation Study and Research

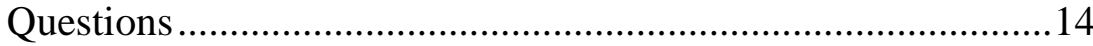

1.3.2 Dissertation Structure, Format, and Methodology.................16

1.3.3 Sampling Methods of the Dissertation Research ..................23

References (Chapter 1) ............................................................................25

\section{CHAPTER 2 DEVELOPING AND VALIDATING THE BIOLOGY IDENTITY}

AND PERSISTENCE SURVEY (BIPS) FOR USE IN HIGH

SCHOOLS IN SOUTH FLORIDA ….............................................. 30

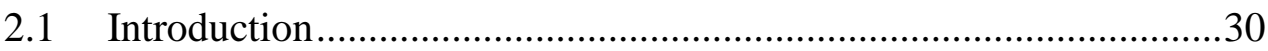

2.2 Science Identity Conceptual Framework ..........................................31

2.3 Instrument Design of the BIPS and Research Questions..................33

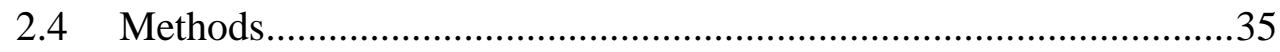

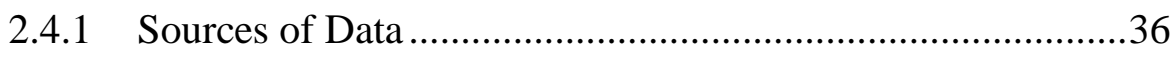

2.4.1.1 Qualitative Data....................................................36

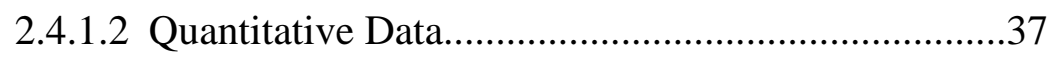

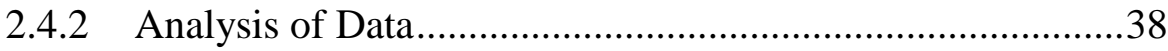

2.4.2.1 Qualitative Data Analysis.......................................38

2.4.2.2 Quantitative Data Analysis....................................39

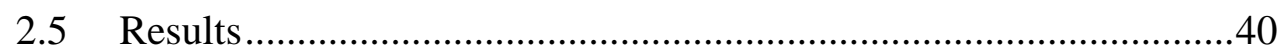

2.5.1 Evidence of Validity ........................................................40

2.5.1.1 Qualitative Aspect of Validity................................41

2.5.1.2 Quantitative Aspect of Validity................................43

2.5.2 Evidence of Reliability ......................................................48

2.5.2.1 Internal Consistency..............................................48

2.5.2.2 Test-retest Reliability.........................................49 


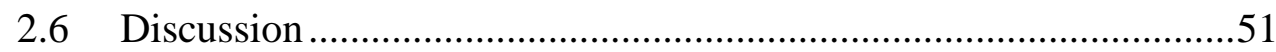

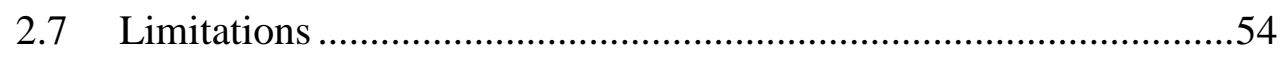

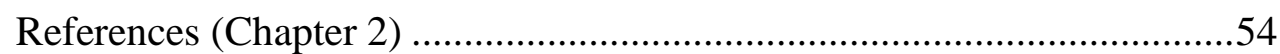

\section{CHAPTER 3 CONNECTING BIOLOGY MODELING INSTRUCTION}

PRACTICE, IDENTITY DEVELOPMENT, AND CAREER

ASPIRATIONS: A COMPARATIVE CASE STUDY .....................64

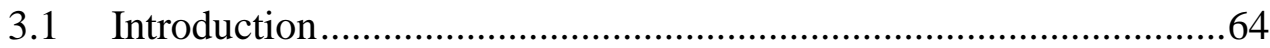

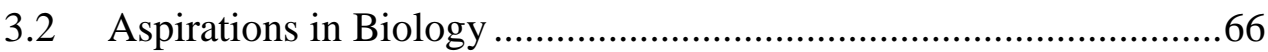

3.3 Biology and Evolution Identity Development ..............................67

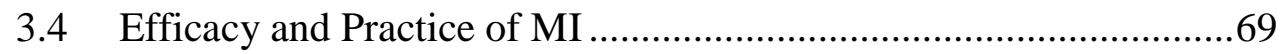

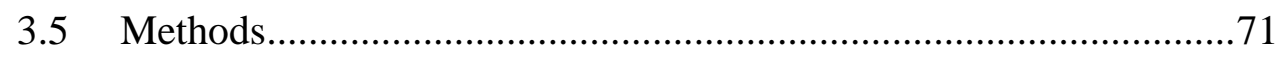

3.5.1 Participants.................................................................... 71

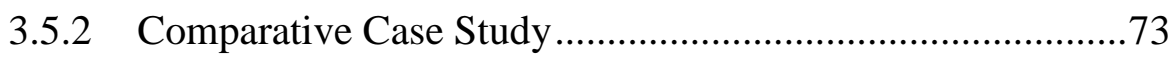

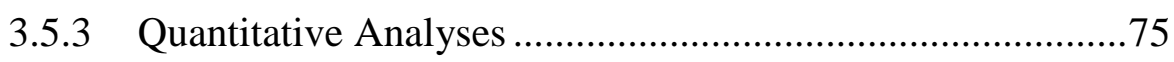

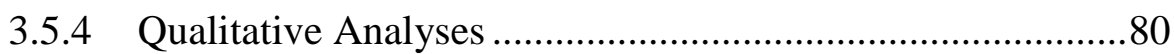

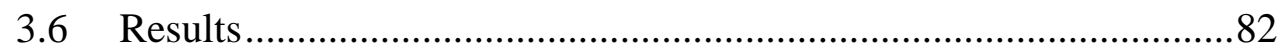

3.6.1 Students' Biology/Evolution Identities ...............................82

3.6.1.1 Students' Narrated Biology/Evolution Identities......83

3.6.1.2 Students' Performed Biology/Evolution

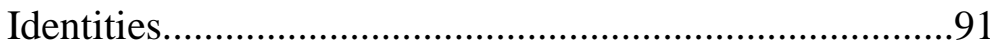

3.6.2 Students' Career Aspirations ................................................ 101

3.6.3 Students' Biology/Evolution Identities and Career

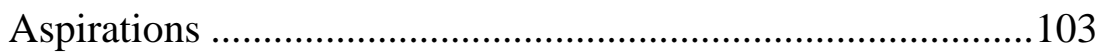

3.6.4 Implementation of MI Curriculum in Evolution..................104

3.6.5 Instructors' Teaching Practices, Students' Biology and

Evolution Identities, and Students' Biology Career

Aspirations

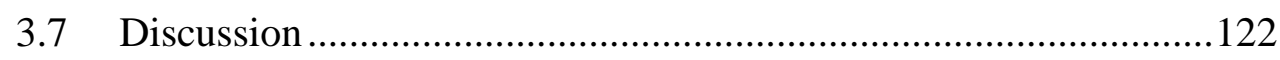

3.7.1 Students' Low Participation in Small-group

Collaboration....

3.7.2 High School Biology MI Curriculum, Workshops, and Instructors

3.7.3 Significant Gain of Evolution Identity in Non-MI

Classes

3.7.4 Performed Identity and Narrated Identity ..........................125

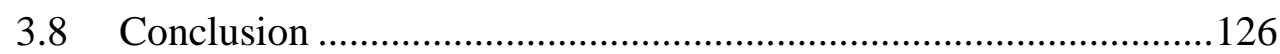

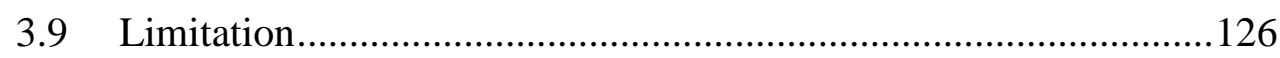

References (Chapter 3) .............................................................. 127 


\section{CHAPTER 4 CONNECTING BIOLOGY MODELING INSTRUCTION \\ PRACTICE AND EVOLUTION CONCEPTUAL \\ UNDERSTANDING: A COMPARATIVE CASE STUDY}

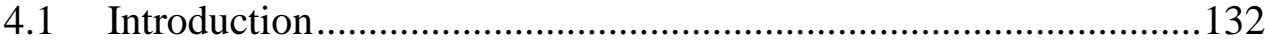

4.2 Efficacy and Practice of MI ........................................................ 133

4.3 Research Motivation and Research Questions..............................135

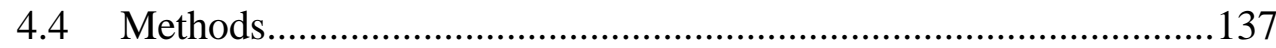

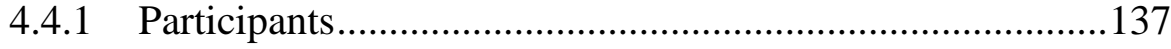

4.4.2 Comparative Case Study ...................................................139

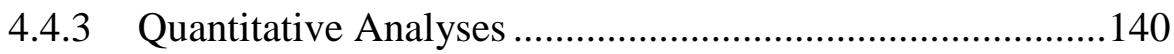

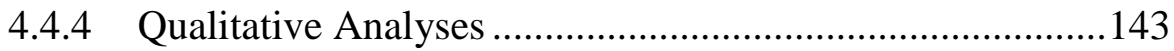

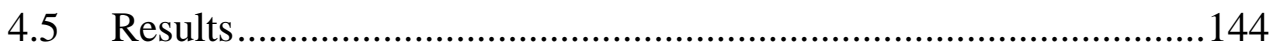

4.5.1 Validity and Reliability of the ECI ..................................144

4.5.2 Connection between Biology MI and Students' Evolution Conceptual Understanding ....................................................146

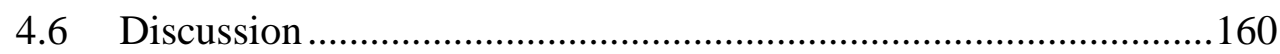

4.6.1 Validity and Reliability of the ECI .................................160

4.6.2 Extent of High School Biology MI Implementation and Conceptual Understanding ...................................................160

4.7 Limitation and Future Directions ...................................................161

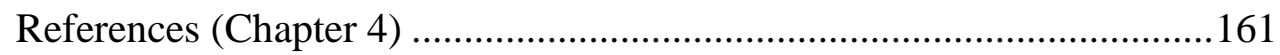

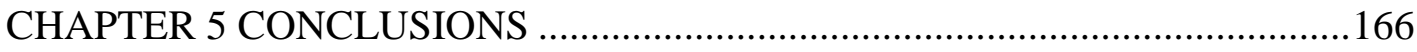

5.1 Summary of Research Findings ..................................................... 166

5.1.1 Validity and Reliability of the BIPS ..................................166

5.1.2 Connections between Teaching Practice, Biology and Evolution Identity, and Career Aspirations............................. 168

5.1.3 Connections between Teaching Practice and Conceptual Understanding in Evolution ................................................170

5.2 Implications of the Dissertation Research ..................................170

5.2.1 Implications for High School Biology MI Workshops........170

5.3 Directions for Future Work ...........................................................171

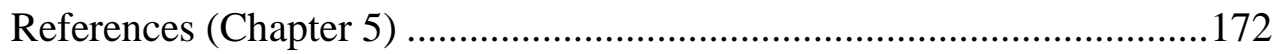

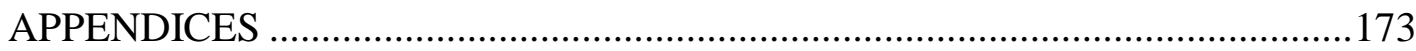

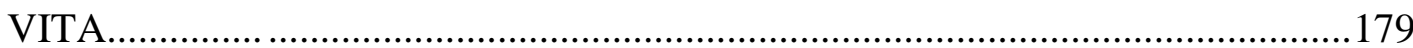




\section{LIST OF TABLES}

TABLE

PAGE

Table 1. CFA results about the identity models in the initial BIPS .44

Table 2. R-square of statements in the initial evolution identity model .45

Table 3. Chi-squared difference test for evolution identity model improvement .....47

Table 4. CFA results about the improvement of the evolution identity model .47

Table 5. Cronbach's alpha of biology identity and evolution identity statements ....49

Table 6. The test-retest stability of the final BIPS .50

Table 7. Students' Biology/Evolution Identity Indicators in MI and non-MI classes

Table 8. Regressions predicting students' biology/evolution identities by class type with controls .84

Table 9. Regressions predicting students' career aspirations in all biology-related fields by class type with controls.....

Table 10. Correlation of Students' Biology/Evolution Identities with Biology Career Aspirations 104

Table 11. MI and non-MI Biology Instructors' Teaching Practices 107 


\section{CHAPTER 1 INTRODUCTION}

\subsection{Project Motivation}

In order to maintain the United States' leadership position in science, technology, engineering, and math (STEM) fields and economic competitiveness, great effort has been put on increasing the number of students pursuing STEM majors and bachelor's degrees in the United States for more than a decade. To maintain the competitiveness of the United States in the STEM fields, pedagogic strategies have been called on for encouraging high school students to take more rigorous and advanced math and science courses in order to be adequately prepared for college science majors and science careers (National Science Board, 2012). Promoting high school students' interests in STEM fields and encouraging their aspirations to take more advanced science courses contributes to more students pursuing bachelor's degrees in STEM fields in colleges and universities (National Science Board, 2012). Evidence from previous research studies has indicated that students' interests and persistence in science could be promoted through their science identity development (Aschbacher, Li, \& Roth, 2010; Renninger, 2009).

\subsubsection{High School Biology Curriculum Reform}

The Committee on Conceptual Framework for the New K-12 Science

Education Standards of National Research Council (2012) argued that science education should emphasize not only science content knowledge but also scientific practices that are used to "establish, extend, and refine that knowledge" (pp. 2-3). It 
was further suggested that scientific practices that should be emphasized in the context of science education include modeling scientific theories, developing testable hypotheses from models, collecting and appraising data, modifying models if needed according to evidence from data, and evaluating and critiquing conclusions of others. One of the educational goals set by the Committee on Conceptual Framework for the New K-12 Science Education Standards of the National Research Council was that, by graduation, high school students should be able to quantify and present relationships between scientific concepts by scientific modeling. It was also argued that students' engagement in modeling facilitates them reflecting about their own science knowledge status and their perceptions of how science works (National Research Council, 2012).

\subsubsection{Modeling Instruction in High School Science Education}

Hestenes (1992) and Odenbaugh (2005) argued that models and modeling play a critical role in science. Hestenes further stated that "the great game of science is modeling the real world" (1992, pp. 732), which suggested modeling as a cross-disciplinary practice. As for the implementation of modeling in science teaching classrooms, Nersessian (1995) described constructive modeling, which was also described by Windschitl, Thompson and Braaten (2008) as model-based inquiry. Nersessian (1995) and Windschitl et al. (2008) argued for introducing and incorporating model-based inquiry (or constructive modeling) into science education as an authentic scientific practice across scientific disciplines. On the basis of the 
perception of models and modeling as critical components in scientific inquiry and science education, modeling theory of science was developed (Halloun, 2007; Hestenes, 1987, 1992). As for the role of models in scientific inquiry and science education, Halloun (2007) and Passmore, Stewart and Cartier (2009) argued that models work as mediators between theories and concepts, which allow stientists and science learners to understand "why something in the natural world works the way it does" (Passmore et al., 2009, pp. 395).

The Modeling theory of instruction (Brewe, 2008) was developed to introduce and apply modeling theory in science education classrooms. It suggested that science students should be engaged with modeling as the central classroom science learning activities as scientists do, and that students should be engaged in four components of the modeling cycle, which are building, validating, deploying, and revising of models. Modeling Instruction (MI), as a pedagogical approach of teaching and learning science, focuses on the development and application of conceptual models of scientific phenomena (Brewe, 2008; Jackson, Dukerich, \& Hestenes, 2008). Modeling Instruction encourages students to learn and work cooperatively in a group with support from their peer group members and the teacher. Students are also encouraged in an MI class to share and discuss their innovative ideas within their group. Theoretically, MI decreases students' passivity by engaging them to learn cooperatively in a supportive environment with real hands-on scientific modeling activities. The MI teachers have prior knowledge about 
the naïve conceptions students hold about the natural world. They help students develop appropriate models in MI classes to indirectly address their misconceptions rather than directly address those misconceptions through lectures. A teacher's role in an MI class is no longer that of an authority who delivers knowledge to students. Instead, an MI teacher acts as a facilitator to help students construct knowledge by themselves through experiencing a real modeling process as in an authentic scientific practice. At the end of each hands-on modeling activity, students present their models for explaining or predicting a given scientific phenomenon and evaluate models of peer classmates by comparing data and conclusions. Students are encouraged to use diagrams, maps, and pictorial and graphical representations in their models on whiteboard to demonstrate their ideas and/or findings to the entire class (National Research Council, 2012). During student whiteboard presentations, MI-trained teachers challenge students through Socratic questioning to press for students' deeper understanding and help students correct their misconceptions.

After the development and successful implementation of MI in physics education, biology education researchers and practitioners have designed, applied, and evaluated high school biology modeling instruction curricula to improve high school biology teaching and learning. For example, in the evolutionary biology section of a high school biology course, students are provided with background knowledge in evolution, introduced to Darwin's model of Natural Selection to explain evolution, and eventually are able to evaluate explanatory power of 
Darwin's model of Natural Selection with given data and make predictions based on Darwin's model of Natural Selection (Passmore \& Stewart, 2002).

From the MI perspective, teaching practice is designed and organized to engage students with specific scientific concepts or topics by developing models, applying and assessing models in real life situations. With this instructional strategy, students are encouraged and directed to design, build, and evaluate scientific models to predict and/or explain a biological phenomenon according to related concepts. Students should also be asked to use abstract models, such as diagrams, maps, pictorial and graphical representations to demonstrate their ideas or findings to others. Through the process of instructional modeling, activities of biological practices are conducted and replicated in classrooms or teaching labs so that the explicit nature of biological themes in curriculum is integrated and transferred to students.

\subsubsection{Enhancing Students' Aspirations in Biology}

Promoting high school students' interest in biology and aspiration for a biology career is a key way to maintain a "leakless" pipeline to increase the number of students choosing college majors and earning Bachelor's degrees in biological sciences. Unlike other STEM disciplines, biological sciences do not encounter gender imbalances in enrollment as around $60 \%$ of bachelor's degrees in biological sciences are awarded to female students (National Science Board, 2012, 2014). However, like other STEM disciplines, biological sciences still face low 
participation rates of historically underrepresented minorities (Hispanic/Latino, African American/Black, Native American, and Pacific Islander) in biological science majors in colleges and universities. The underrepresentation of minority students in biological sciences calls for more educational research studies to identify influential factors and solutions. Tai, Liu, Maltese and Fan (2006) demonstrated that adolescent students' aspiration for a science career is a strong predictor of their likelihood to choose science majors in colleges and universities. Their finding values the strategy of promoting high school students' interest and aspiration for a biology career in early stages to increase the likelihood of their intention of choosing a college major in biological sciences. It is also worthwhile to enhance high school students' aspiration for taking more advanced biology courses so that they are more likely to pursue college majors in biological sciences and earn degrees in corresponding fields (Chen \& Weko, 2009; National Center for Education Statistics, 2011). Therefore, it is important to utilize pedagogy in their introductory biology courses that improves high school students' interest in biology to increase the likelihood of them taking advanced biology courses in high school and pursuing college degrees in biological sciences later on.

\subsection{Literature Review and Theoretical Framework}

This section will review and summarize literature generally relevant to the dissertation project on research studies regarding science/biology identity and MI. 
Further extensive and specific literature reviews will be incorporated into each chapter of the dissertation.

\subsubsection{Science/Biology Identity in High School Biology Education}

Erikson (1968) described and used the term 'identity' as one's personal subjective sense of being and becoming. According to Burke (2003, pp. 1-2), the concept of identity lies in three bases: "the roles that one plays," "the social categories or groups to which one belongs," and "personal characteristics that are not necessarily shared with others." Identity in educational research realm was defined by Gee (2000, pp. 99) as what "certain kind of person in a given context" people think they are. Gee's definition allows that people may have multiple identities according to their performance in various social categories. Becoming a "certain kind of person" in a learning context requires students to negotiate the rationality of various identities to which they potentially belong to and to make decisions about what "certain kind of person" they would become. Science identity, which Brickhouse, Lowery and Schultz (2000) called for more research studies on, was described as who people think they are in terms of their relationship with science (Brickhouse et al., 2000). For example, an individual can identify as a biologist if he/she is engaging in biology research. A student can identify as a biology person if he/she is engaging in learning and doing biology.

Identity, as an emerging theory, has been part of science educational research for over a decade as a lens to explore students' relationship with science fields. 
Students' science identity was reported to be correlated with their engagement with science learning (Brickhouse et al., 2000) and commitment to science careers (Chemers, Zurbriggen, Syed, Goza, \& Bearman, 2011). Science-identity-based frameworks were employed in several studies, which demonstrated the influences of science identity on students' persistence in science (Aschbacher et al., 2010; Basu, 2008; Carlone \& Johnson, 2007; Cleaves, 2005; Gilmartin, Denson, Li, Bryant, \& Aschbacher, 2007; Shanahan, 2009). Increasing emphasis on science identity has made it necessary to explore not only science identity in general but also identity in specific science fields in terms of its development, fluctuation, and influence on students' learning (Kane, 2012). It is particularly important to have deeper and better understanding of students' identity in different science fields beginning in high school as this is the first time that science subjects are taught as separate courses. Students' identity development may be different between various science fields, and the effect of identity in each science field may also be different than others on enhancing students' performance and persistence in the particular science field. Knowledge of distinctions between different science disciplinary identities may contribute to better understanding of how science disciplinary identity mediates the fluctuation of students' aspirations for career in a specific science field, for example biological science in this study. As a result of increasing implementation of $\mathrm{MI}$ in high school biology education, it is worthwhile to evaluate any high school biology MI curriculum from an identity perspective. 


\subsubsection{Science/Biology Identity Development}

Lave and Wenger (1991) argued from perspectives of situated cognition that learning is a process of identity formation. Through any learning process, one negotiates and decides what kind of person one is and one's aspiration for the future. The National Research Council (2012) has suggested that students' science learning involves not only acquisition of scientific concepts but also construction of a science identity. Students' science identity is associated with high interest and motivation to learn more science and to become a competent science learner. Developing students' science identity through high school science teaching practices benefits students who would view themselves as scientists and would like to pursue science careers. On the other hand, developing science identity may also benefit those who do not intend to enter science professional fields. Developing science identity arms people with "the confidence, ability, and inclination to continue learning about issues, scientific and otherwise, that affect their lives and communities" (pp. 11-17). Embedding teaching strategies for developing students' science identity in high school biology curriculum is as important as teaching students scientific knowledge. Developing students' science identity particularly benefits students who feel neglected by traditional science instruction and discouraged from further science learning (National Research Council, 2012).

Students' science identity development is influenced by their sociocultural environment and their affiliation with specific cultural communities (National 
Research Council, 2009). The scope of culture can be as big as nationwide and as small as a classroom or even a study group. Culture is dynamic, which can both influence and be influenced by individuals in a specific cultural community. Individuals learn culturally valued knowledge and acquire identity from a specific cultural community while also influencing value and practices of the specific cultural group by bringing their own experiences and knowledge to a given cultural group (National Research Council, 2009). Evidence suggests that identity development takes place through interaction of individuals in a given cultural community (Holland, Skinner, Lachicotte, \& Cain, 1998; Hull \& Greeno, 2006). It happens both globally and locally, such as in a high school biology classroom. Identity can be shaped by prior experiences as well as by current activities, and it can also shape individuals' imaginations about what kind of person they want to be in the future (National Research Council, 2009). Because of the influence of culture shaping students' identity, data from educational research studies on racial/ethnic majority-dominant classrooms may not reflect the dynamics of science identity shift in classrooms in a minority-majority public school system like Miami-Dade County Public Schools (M-DCPS). The present dissertation project provides evidence about how science identity is developed for students in high school biology classrooms in a Hispanic-serving minority-majority public school system.

The dissertation project utilized an identity conceptual framework drawn from the work of Carlone and Johnson (2007), and Hazari, Sonnert, Sadler and Shanahan 
(2010). The framework includes a four component personal identity: interest, recognition, performance, and competence. Those four components work as critical contributors to students' biology identities. Students' interest in biology can shape their beliefs about themselves, which have far-reaching influence on their persistence in science. Students' recognition by others is critically important to how they see themselves. Performance has been reported for its influence on people's academic self-concept, which may affect people's future performance (Marsh, Hau, \& Kong, 2002). Students' science competence, which is their beliefs in ability to understand science content, also has influence on students' interest and beliefs about themselves. Evidence from previous studies (Barron, 2006; Nasir, 2002) indicates that an individual's social interactions and supports have significant influence on developing and sustaining one's interest in science. These findings suggested that high school science/biology teachers and classmates can help develop and maintain students' interest in learning science/biology and enhance their competence in science. Brickhouse and Potter (2001) demonstrated that students constructed their science identities largely depending on supports that they obtained from external environments. Boaler, William and Zevenbergen (2000) described students' mathematics identity development as students learned how to work, how to cope, how to act, how to think, and how to discuss as a mathematician in mathematics classes. According to self-determination theory, an autonomous learning environment, which is the typical class environment in MI classes, can meet the 
needs of school-age learners in terms of their identity development (Ryan \& Deci, 2000, 2003; Tsai, Kunter, Lüdtke, Trautwein, \& Ryan, 2008).

\subsubsection{Efficacy of Modeling Instruction in Science Education}

Dye, Cheatham, Rowell, Barlow and Carlton (2013) examined and compared students' academic achievement between teacher-centric traditional pedagogy context and student-centric MI pedagogy context with ACT science test scores and percentage of students graduating college ready in science. Results of their study indicated that students in high school science MI classes scored significantly higher academic achievement in science than their counterparts in traditional instructional classes regarding their ACT science scores and percentage of college readiness in science on average when graduating. The significant positive influence of MI on high school students' science academic achievement was also reported in two studies with measures from high school physics students' scores on the Force Concept Inventory (FCI) (Liang, Fulmer, Majerich, Clevenstine, \& Howanski, 2012; O’Brien \& Thompson, 2009). Beyond students' performance on the FCI, Malone (2008) examined students' problem-solving behaviors and their relationship with students' performance on the FCI. Malone's work suggested that students' scores in FCI could predict their level of problem-solving behaviors and that students in a modeling group employed more expert-like problem-solving skills. Brewe, Kramer and O'Brien (2009) found college students' positive attitudinal shifts on the Colorado Learning Attitudes about Science Survey (CLASS) in introductory physics modeling 
classes. By measuring students' academic achievement with FCI and their odds of success with the ratio of completing the introductory physics course and earning a passing grade, Brewe et al. (2010) reported that MI could enhance underrepresented students' academic achievement and participation in a college introductory physics class. The identity conceptual framework used in this dissertation project suggests that positive shift in any component of an individual's biology identity (interest, recognition, performance, and competence) may contribute to her or his biology identity development. Because of evidence from previous studies indicating positive influence of MI on students' attitude (particularly their interest and competence) towards science and their performance in science learning, it is safe to hypothesize that implementation of MI in high school science courses may contribute to positive shift in students' science identity. Therefore, it is worthwhile to examine the efficacy of $\mathrm{MI}$ in science education from a science identity perspective.

\subsection{Overview of the Dissertation Research}

The dissertation follows the "collected papers" approach, in which each of the data collection and analysis chapters (Chapters 2 - 4) were written in a research paper format that has been or will be submitted for publication to peer-reviewed journals. Guided by the "collected papers" dissertation format, each research paper chapter follow its specific methodology and literature related to each research study was reviewed and discussed specifically within each chapter. This section provides an overview of the dissertation with its overall structure along with specific research 
purpose, conceptual framework, data that were collected, and research methods in each chapter.

\subsubsection{Purpose of the Dissertation Study and Research Questions}

The purpose of this dissertation project is to evaluate the implementation of high school biology MI in south Florida by comparing MI and non-MI in high school biology classes. The comparison includes qualitative data on teachers' teaching strategies, in-class activities, learning environment, and students' performed biology identities, as well as quantitative data on students' biology identity, aspirations, and achievement in biology following a comparative case study research design. The first phase of the study is to develop and validate the Biology Identity and Persistence Survey (BIPS), which was used for collecting data on students' biology identity and aspirations in biology. The second phase of the study was divided into three parts. The first part collected qualitative data by in-class observation focusing on teachers' teaching strategies, in-class activities, learning environment, and students' performed biology identities in both MI and non-MI high school biology classes. The second part collected quantitative data with BIPS, focusing on students' shifts in biology identities and aspirations in biology, and an Evolution Concept Inventory (ECI), focusing on students' academic achievement in biology, in both MI and non-MI high school biology classes. The third part collected qualitative data by semi-structured interviews with voluntary students from both MI 
and non-MI classes, focusing on students' experiences from students' perspectives in both MI and non-MI high school biology classes.

The following research questions are addressed in this dissertation:

1. Is the BIPS valid and reliable for collecting data on high school biology students' biology identities, evolution identities, and career aspirations in south Florida?

2. Can taking evolution class sessions in MI or non-MI class predict students' biology identities? If so, how might high school biology instructors' teaching in MI or non-MI classes predict students' biology identities?

3. Can taking evolution class sessions in MI or non-MI class predict students' evolution identities? If so, how might high school biology instructors' teaching in MI or non-MI classes predict students' evolution identities?

4. Can taking evolution class sessions in MI or non-MI class predict students' career aspirations? If so, how might high school biology instructors' teaching in MI or non-MI classes predict students' career aspirations?

5. Do students' biology/evolution identities correlate with their biology career aspirations?

6. Can taking evolution class sessions in MI or non-MI class predict students' evolution conceptual understanding? If so, how might high school biology instructors' teaching in MI or non-MI classes predict students' evolution conceptual understanding? 


\subsubsection{Dissertation Structure, Format, and Methodology}

This dissertation is written according to the "Collected Papers" format used by the School of Education and Human Development in Florida International University. It includes two chapters (Chapter 1 and Chapter 5) that have been exclusively written for the dissertation, and a series of three related papers that have been or will be submitted for publication to peer-reviewed journals. Each of the papers developed through the dissertation project has a standalone research methodology that is able to provide deeper understanding of the optimal ways of implementing MI in high school biology classrooms.

Chapter 2 addresses the validity and reliability of the BIPS, which was designed and developed as the research instrument that was used for collecting quantitative data on high school students' biology identity and aspirations for persisting in biology. Chapter 2 reviews literature according to a biology identity conceptual framework regarding items constructing the biology identity proxy and provide information on the designing procedure of BIPS. In addition, Chapter 2 reports the evaluation of the validity and reliability of BIPS through expert reviews, cognitive interviews with high school students, and statistical evidence from a pilot study of field test and retest. Chapter 2 was submitted to CBE-Life Science Education, which requires Council of Biology Editors Style Manual format.

Chapter 2 of the dissertation describes how items of BIPS have been developed by referring to survey questionnaires with items regarding people's interest, 
recognition, performance, and competence in biology, which are four components of people's biology identity, as well as people's aspirations for persisting in biology. I reviewed those items for their applicability in BIPS and modified accordingly to constitute BIPS. The survey questionnaire then was validated through expert reviews. The survey items were reviewed by an expert in science/biology education and science/biology identity to validate constructs employed in BIPS about their capabilities to collect precise and accurate data by measuring what they are supposed to measure. The survey questionnaire was also reviewed by experts in questionnaire design to provide suggestions on wordings, questionnaire structure, question order, questionnaire instruction, response alternatives, and so on. After expert reviews and cognitive interviews with voluntary participating high school students, problematic items were modified and/or removed accordingly. In order to address the reliability of the BIPS, a pilot study was then conducted to implement the BIPS survey in ten high school physics classes in south Florida with a test and then a retest four weeks after. According to the Teacher in Residence in the Physics Education Research Group at Florida International University, a rate of $10 \%$ or fewer high school students in MDCPS take both physics and advanced biology courses concurrently in the same semester. I also added a question "Are you taking any biology course in this semester?" at the very beginning of the BIPS to filter out those who were taking any biology course in the same semester. Thus, those who were not filtered out were much less likely to shift in their biology identities and 
aspirations in biology during the period of pilot study, which was one of the reasons that I selected high school physics students to participate in the pilot study. The other reason was that they were almost the same age as high school biology students (approximately a two-year difference). Pilot data then were collected and statistically analyzed. Confirmatory factor analysis was conducted to statistically validate that survey items about students' interest, recognition, competence, and performance load into each of corresponding categories. Students' responses in the test and retest were analyzed with Pearson's $r$ to provide information about the consistency of measures from one test to the next. Cronbach's alpha was employed to assess the internal consistency of items in the same category (e.g., interest, recognition, competence, and performance) in measuring the same construct. Potential items in BIPS with high missing data, outliers, inconsistencies, and little variance was then identified and removed if necessary. Chapter 2 was focused on and answered research question 1 of the dissertation project.

Chapter 3 addresses the following four research questions: Can taking evolution class sessions in MI or non-MI class predict students' biology identities? If so, how might high school biology instructors' teaching in MI or non-MI classes predict students' biology identities? (Research Question 2); Can taking evolution class sessions in MI or non-MI class predict students' evolution identities? If so, how might high school biology instructors' teaching in MI or non-MI classes predict students' evolution identities? (Research Question 3); Can taking evolution class 
sessions in MI or non-MI class predict students' career aspirations? If so, how might high school biology instructors' teaching in MI or non-MI classes predict students' career aspirations? (Research Question 4); Do students' biology/evolution identities correlate with their biology career aspirations? (Research Question 5). Chapter 3 focuses on comparing high school MI and non-MI biology classes on their influence on students' biology identities and aspirations in persisting in biology. Chapter 3 integrates data on biology/evolution identities and aspirations in biology together in one paper because previous research studies, following science-identity-based frameworks, demonstrated significant strong correlation of students' science identities with their persistence in science (e.g., Aschbacher et al., 2010; Carlone \& Johnson, 2007), which may contribute to their subsequent choice of pursuing science degrees in college. Therefore, biology identity would be a useful lens to evaluate the implementation of high school biology MI in this research project. To be specific, Chapter 3 employed a biology identity conceptual framework to evaluate the implementation of MI in high school biology classrooms in south Florida by examining students' shifts in biology identities and aspirations in biology and how MI and non-MI biology classes influence on those shifts. Chapter 3 reviewed literature regarding science/biology identity and persistence/aspiration in science/biology. The chapter provides quantitative results through statistical analysis of data from BIPS to demonstrate the efficacy of high school biology MI from the perspectives of biology identity and aspirations in biology. Then the chapter utilized 
qualitative results through analysis of data from in-class observations and semi-structured interviews about students' in-class experiences to compare and interpret why students' biology identities and aspirations in biology shifted differently, if any, in MI and non-MI biology classes, and how MI can be implemented better in high school biology classes. Chapter 3 is intended for submission to CBE-Life Science Education, which requires Council of Biology Editors Style Manual format.

Chapter 3 of the dissertation includes both quantitative data from BIPS and qualitative data from in-class observations and after-class interviews. Data were collected from the same level of biology I classes in public high schools in south Florida, U.S. The validated BIPS questionnaire reported in Chapter 2 was employed as the instrument to collect quantitative data on students' biology identities and aspirations in biology. The BIPS survey was implemented two times in both high school MI and non-MI classes: the pre-test in the Fall semester of 2016-2017 academic year in the first class session of evolution and the post-test in the last class session of evolution. Data collected from pre-test provided information to establish a baseline for the sample of students in this study. Data collected from the post-test provided information on students' gain of biology identities and aspirations in biology throughout the entire teaching period for evolution.

After all quantitative data on students' biology identity and aspiration in biology were collected with BIPS, a confirmatory factor analysis was conducted to 
statistically assess the fit of biology/evolution identity model with students' biology/evolution interest, recognition, competence, and performance with collected data. Multiple linear regression was used to analyze and compare the shifts of students' biology/evolution identities between high school MI and non-MI biology classes in south Florida by controlling students' demographic information and pre-test scores in biology/evolution identities on the BIPS. Multiple linear regression was also used to analyze and compare students' aspirations in pursuing biology career between high school MI and non-MI biology classes in south Florida by controlling students' demographic information and pre-test scores in aspirations in biology on the BIPS.

In order to collect qualitative data to compare and interpret differences, if any, between high school MI and non-MI biology classes in terms of students' biology/evolution identities and aspirations in biology and provide better ways of implementing MI in high school biology classes, I selected one optimal MI class and one optimal non-MI class, according to the results of short teachers' survey, to conduct in-class observations. I observed the instructors' teaching styles, class environment, in-class activities, and students' performed biology/evolution identities. I also interviewed voluntary participants from MI and non-MI classes about their in-class experiences and their perceptions about their instructors' teaching styles, class environment, in-class activities, and so on. Interviews were audio-recorded. Qualitative data regarding differences between high school biology MI and non-MI 
classes in students' biology identities and aspirations in biology were transcribed, coded, and analyzed to find out patterns that could be used to interpret the differences between high school biology MI and non-MI classes that contributed to the difference, if any, between high school MI and non-MI biology classes in students' shifts in biology/evolution identities and aspirations in biology.

Chapter 4 focuses on addressing the difference between high school biology MI and non-MI classes in students' academic achievement in evolution with quantitative data collected from ECI and qualitative data collected from in-class observations and following semi-structured interviews with participating students. Chapter 4 reviewed literature regarding relationship between students' academic achievement in science/biology in MI classrooms, provided theoretical foundation supporting the argument, and presented the findings. Chapter 4 answered Research Question 4 to provide information on the difference between high school biology MI and non-MI classes in terms of students' academic achievement in biology. The manuscript is intended for submission to CBE-Life Science Education, which requires Council of Biology Editors Style Manual format.

Chapter 4 includes both quantitative data from ECI and qualitative data from in-class observations and after-class interviews. The ECI collected quantitative data on students' academic achievement in evolution. The ECI was adopted from the Modeling Biology Concept Inventory with questions about evolution. The validity and reliability of the ECI with high school biology students were addressed by 
conducting item analysis for its difficulty and discrimination and conducting

Cronbach's alpha analysis for its internal consistency.

After quantitative data on students' evolution conceptual understanding were collected with the ECI, multiple linear regression was used to analyze and compare the difference between high school biology MI and non-MI classes in students' academic achievement in evolution by controlling students' demographic information and ECI pre-test scores. Qualitative data regarding the difference between high school biology MI and non-MI classes in terms of students' academic achievement in evolution were also collected through in-class observations and semi-structured interviews with voluntary participants. Data from the in-class observations and after-class interviews were used to compare and interpret difference, if any, between high school MI and non-MI biology classes in terms of students' academic achievement in evolution. Qualitative data regarding difference between high school biology MI and non-MI classes in students' achievement in biology were transcribed, coded, and analyzed to find out patterns that could be used to interpret the differences between high school MI and non-MI biology classes that contributed to students' achievement gains in evolution.

\subsubsection{Sampling Methods of the Dissertation Research}

In the pilot study to address the reliability of the BIPS, I worked with the Teacher in Residence in the Physics Education Research Group at Florida International University who had connections with high school physics teachers in 
MDCPS. I asked him to help me recruit four high school physics teachers in MDCPS to implement the BIPS with a test and then a retest four weeks after. The reason that I selected high school physics students to participate in the pilot study was that they were almost the same age as high school biology students (about two-years difference) and that their biology/evolution identities and aspirations in biology were much less likely to shift during the period of pilot study since most of them (more than 90\%) were not taking any biology course in that semester.

In order to build connections with biology-MI-trained high school biology teachers, I attended biology MI workshops for Miami-Dade County public high school biology teachers at Florida International University in the summer of 2015 and 2016 respectively and talked with biology-MI-trained teachers in the workshops. I recruited high school biology MI instructors from the workshop in the summer of 2016 to participate in my dissertation project. I talked with them about how they were going to use MI in their biology classes. Using their teaching plans and self-efficacy in implementing high school biology MI curriculum, I selected two participating high school biology MI instructors and evolution as the topic that all participating biology-MI-trained teachers were confident to teach with MI. I asked participating biology-MI-trained teachers to introduce one non-biology-MI-trained biology instructors in their school to participate in this study, who could help me collect data from non-MI biology classes. 


\section{References (Chapter 1)}

Aschbacher, P. R., Li, E., \& Roth, E. J. (2010). Is science me? High school students' identities, participation and aspirations in science, engineering, and medicine. Journal of Research in Science Teaching, 47, 564-582.

Barron, B. (2006). Interest and self-sustained learning as catalysts of development: A learning ecology perspective. Human Development, 49(4), 193-224.

Basu, S. J. (2008). How students design and enact physics lessons: Five immigrant Caribbean youth and the cultivation of student voice. Journal of Research in Science Teaching, 45, 881-899.

Boaler, J., William, D., \& Zevenbergen, R. (2000). The construction of identity in secondary mathematics education. In Second International Conference on Mathematics Education and Society (pp. 192-202). Montechoro, Portugal.

Brewe, E. (2008). Modeling theory applied: Modeling Instruction in introductory physics. American Journal of Physics, 76, 1155-1160.

Brewe, E., Kramer, L., \& O’Brien, G. (2009). Modeling instruction: Positive attitudinal shifts in introductory physics measured with CLASS. Physical Review Special Topics - Physics Education Research, 5(1), 1-5.

Brewe, E., Sawtelle, V., Kramer, L. H., O’Brien, G. E., Rodriguez, I., \& Pamelá, P. (2010). Toward equity through participation in Modeling Instruction in introductory university physics. Physical Review Special Topics - Physics Education Research, 6(1), 10106.

Brickhouse, N. W., Lowery, P., \& Schultz, K. (2000). What kind of girl does science? The construction of school science identities. Journal of Research in Science Teaching, 37, 441-458.

Brickhouse, N. W., \& Potter, J. T. (2001). Young women's scientific identity formation in an urban context. Journal of Research in Science Teaching, 38, 965-980.

Burke, P. J. (2003). Introduction. In P. J. Burke, T. J. Owens, R. T. Serpe, \& P. A. Thoits (Eds.), Advances in identity theory and research (pp. 1-7). New York, NY: Kluwer Academic Publisher. 
Carlone, H. B., \& Johnson, A. (2007). Understanding the science experiences of successful women of color: Science identity as an analytic lens. Journal of Research in Science Teaching, 44, 1187-1218.

Chemers, M. M., Zurbriggen, E. L., Syed, M., Goza, B. K., \& Bearman, S. (2011). The role of efficacy and identity in science career commitment among underrepresented minority students. Journal of Social Issues, 67, 469-491.

Chen, X., \& Weko, T. (2009). Students who study science, technology, engineering, and mathematics (STEM) in postsecondary education. Washington, DC: National Center for Education Statistics.

Cleaves, A. (2005). The formation of science choices in secondary school. International Journal of Science Education, 27, 471-486.

Dye, J., Cheatham, T., Rowell, G. H., Barlow, A., \& Carlton, R. (2013). The impact of modeling instruction within the inverted curriculum on student achievement in science. Electronic Journal of Science Education, 17(2), 1-19.

Erikson, E. H. (1968). Identity: Youth and crisis. New York, NY: Norton.

Gee, J. P. (2000). Identity as an analytic lens for research in education. Review of Research in Education, 25(1), 99-125.

Gilmartin, S., Denson, N., Li, E., Bryant, A., \& Aschbacher, P. (2007). Gender ratios in high school science departments: The effect of percent female faculty on multiple dimensions of students' science identities. Journal of Research in Science Teaching, 44, 980-1009.

Hake, R. R. (1998). Interactive-engagement versus traditional methods: A six-thousand-student survey of mechanics test data for introductory physics courses. American Journal of Physics, 66(1), 64.

Halloun, I. A. (2007). Modeling theory in science education. Dordrecht, Netherlands: Springer.

Hazari, Z., Sonnert, G., Sadler, P. M., \& Shanahan, M.-C. (2010). Connecting high school physics experiences, outcome expectations, physics identity, and physics career choice: A gender study. Journal of Research in Science Teaching, 47, 978-1003. 
Hestenes, D. (1987). Toward a modeling theory of physics instruction. American Journal of Physics, 55, 440-454.

Hestenes, D. (1992). Modeling games in the Newtonian World. American Journal of Physics, 60, 732.

Holland, D., Skinner, D., Lachicotte, W., \& Cain, C. (1998). Identity and agency in cultural worlds. Cambridge, MA: Harvard University Press.

Hull, G. A., \& Greeno, J. G. (2006). Identity and agency in nonschool and school worlds. In Z. Bekerman, N. Burbules, \& D. S. Keller (Eds.), Learning in places: The informal education reader (pp. 77-97). New York, NY: Peter Lang.

Jackson, J., Dukerich, L., \& Hestenes, D. (2008). Modeling Instruction : An effective model for science education. Science Educator, 17(1), 10-17.

Kane, J. M. (2012). Young African American children constructing academic and disciplinary identities in an urban science classroom. Science Education, 96, 457-487.

Klymkowsky, M. W., Underwood, S. M., \& Garvin-Doxas, R. K. (2010). Biological Concepts Instrument (BCI): A diagnostic tool for revealing student thinking. arXiv: $1012.4501 \mathrm{v} 1$.

Lave, J., \& Wenger, E. (1991). Situated learning: Legitimate peripheral participation. Cambridge, UK: Cambridge University Press.

Liang, L. L., Fulmer, G. W., Majerich, D. M., Clevenstine, R., \& Howanski, R. (2012). The effects of a model-based physics curriculum program with a physics first approach: A causal-comparative study. Journal of Science Education and Technology, 21, 114-124.

Malone, K. L. (2008). Correlations among knowledge structures, force concept inventory, and problem-solving behaviors. Physical Review Special Topics Physics Education Research, 4(2), 1-15.

Marsh, W. H., Hau, K.-T., \& Kong, C.-K. (2002). Multilevel causal ordering of academic self-concept and achievement: Influence of language of instruction (English compared With Chinese) for Hong Kong students. American Educational Research Journal, 39, 727-763. 
Merriam, S. B. (1998). Qualitative research and case study applications in education. San Francisco, CA: Jossey-Bass.

Mountz, D. K. (2006). The effect of science core sequence reform on students' attitudes toward science. Immaculata University.

Nasir, N. S. (2002). Identity, goals, and learning: Mathematics in cultural practice. Mathematical Thinking and Learning, 4(2-3), 213-248.

National Center for Education Statistics. (2011). The nation's report card: Science 2009. Washington, DC: Institute of Education Sciences, U.S. Department of Education.

National Research Council. (2009). Learning science in informal environments: People, places, pursuits. Washington, DC: National Academies Press.

National Research Council. (2012). A framework for K-12 science education: Practices, crosscutting concepts, and core ideas. Washington, DC: National Academies Press.

National Science Board. (2012). Higher education in science and engineering. In Science and engineering indicators 2012 (pp. 1-39). Arlington, VA: National Academies Press.

National Science Board. (2014). Higher education in science and engineering. In Science and engineering indicators 2014. Arlington, VA: National Academies Press.

Nersessian, N. J. (1995). Should physicists preach what they practice? Science \& Education, 4(3), 203-226.

O'Brien, M. J., \& Thompson, J. R. (2009). Effectiveness of ninth-grade physics in Maine: Conceptual understanding. The Physics Teacher, 47(4), 234-239.

Odenbaugh, J. (2005). Idealized, inaccurate but successful: A pragmatic approach to evaluating models in theoretical ecology. Biology and Philosophy, 20, 231-255.

Passmore, C., \& Stewart, J. (2002). A modeling approach to teaching evolutionary biology in high schools. Journal of Research in Science Teaching, 39(3), 185-204. 
Passmore, C., Stewart, J., \& Cartier, J. (2009). Model-based inquiry and school science: Creating connections. School Science and Mathematics, 109, 394-402.

Renninger, K. A. (2009). Interest and identity development in instruction: An inductive model. Educational Psychologist, 44(2), 105-118.

Ryan, R. M., \& Deci, E. L. (2000). Self-determination theory and the facilitation of intrinsic motivation, social development, and well-being. The American Psychologist, 55(1), 68-78.

Ryan, R. M., \& Deci, E. L. (2003). On assimilating identities to the self: A self-determination theory perspective on internalization and integrity within cultures. In M. R. Leary \& J. P. Tangney (Eds.), Handbook of Self and Identity (pp. 253-272). New York, NY: Guilford.

Shanahan, M. (2009). Identity in science learning: Exploring the attention given to agency and structure in studies of identity. Studies in Science Education, 45(1), 43-64.

Tai, R. H., Liu, C. Q., Maltese, A. V, \& Fan, X. (2006). Planning early for careers in science. Science, 312, 1143-1144.

Tsai, Y.-M., Kunter, M., Lüdtke, O., Trautwein, U., \& Ryan, R. M. (2008). What makes lessons interesting? The role of situational and individual factors in three school subjects. Journal of Educational Psychology, 100, 460-472.

Windschitl, M., Thompson, J., \& Braaten, M. (2008). Beyond the scientific method: Model-based inquiry as a new paradigm of preference for school science investigations. Science Education, 92, 941-967. 


\section{CHAPTER 2 DEVELOPING AND VALIDATING THE BIOLOGY IDENTITY AND PERSISTENCE SURVEY (BIPS) FOR USE IN HIGH SCHOOLS IN SOUTH FLORIDA}

\subsection{Introduction}

For more than a decade, researchers and practitioners have been making strong calls to promote high school biology education to maintain pathways from high school biology classes to college biology majors (National Research Council, 2012; National Science Board, 2012). To maintain the biology pipeline, a considerable amount of effort has been put in refining and reforming curriculum and teaching methods for encouraging high school students to learn biology (National Science Board, 2012). Students' persistence in biology is one of the major goals of the charge to improve pathways for students from high school biology classes through college biology majors to biology related careers in the future (National Science Board, 2012). To achieve this goal, previous research studies have suggested that students' persistence in biology could be improved through their biology identity development (Aschbacher et al., 2010; Carlone \& Johnson, 2007; Cleaves, 2005;

Gilmartin et al., 2007; Renninger, 2009; Shanahan, 2009).

Identity has been part of science education research for nearly twenty years as a lens to explore students' relationships with science fields. The definition of identity in educational research was clarified by Gee (2000, p. 99) as what "kind of person in a given context" people think they are. Science identity was described as who people think they are in terms of their relationship with science (Brickhouse et al., 2000). 
Increasing emphasis on science identity has encouraged exploration of not only science identity in general but also identity in specific science disciplines in terms of its development, fluctuation, and influence on students' learning (Kane, 2012). Knowledge of distinctions between different science disciplinary identities can contribute to better understanding of how science disciplinary identity mediates the fluctuation of students' aspirations for a career in a specific science field.

To understand the influence of students' biology identity on their biology learning and persistence, it is important to design research instruments to assess students' biology identities as one of the outcomes of their biology learning experiences. The development of research instruments for assessing students' identities in a specific discipline is particularly critical because many innovative educational curricula and pedagogies are designed to improve students' conceptual understanding but not necessarily promote students' identity development and persistence in the discipline as well (Adams et al., 2006; Perkins, Adams, Pollock, Finkelstein, \& Wieman, 2005; Redish, Saul, \& Steinberg, 1998).

\subsection{Science Identity Conceptual Framework}

To assess science identity, it first needs to be clarified that identity is a complex construct in the sense that it is complicated to describe identity and that identity fluctuates and is influenced by various factors throughout its development (Hazari et al., 2010). Science identity is a latent variable, which cannot be measured directly, and can only be measured through its observable indicators that are hypothesized by 
theory developed by qualitative research. Carlone and Johnson (2007) proposed a conceptual framework for science identity that can be characterized into three domains: recognition, competence, and performance. Hazari, Sonnert, Sadler, and Shanahan (2010) identified and added interest as another domain into this science identity conceptual framework, which they believe can critically affect a student's conception of what kind of person the student is and wants to be seen as. In this science identity conceptual framework, recognition refers to recognition by others as a good science student or a "science person." Whether others see a student as a good science learner or as being scientifically oriented as a person is critically important to how the student recognizes her/himself as well as to her/his subsequent choice in terms of her/his relationship with science. Science competence refers to an individual's belief in her/his ability to understand science concepts, which also exerts an impact on the individual's interest in science and belief about her/himself. Science performance refers to an individual's belief in her/his ability to complete science tasks. A student's belief in performance has an influence on her/his academic self-concept, which in turn can further affect the student's future performance (Marsh et al., 2002). Science interest refers to an individual's desire to think about and learn science. A student's interest in science can shape her/his science-related beliefs about her/himself, which can further affect the student's persistence in science. These four components (recognition, competence, performance, and interest) work as critical contributors in shaping an individual's science identity. 


\subsection{Instrument Design of the BIPS and Research Questions}

The Biology Identity and Persistence Survey (BIPS) was designed and developed as a research instrument for collecting data on high school students' biology identities and aspirations in biology. As a result of the challenges in teaching evolution (Alters \& Nelson, 2002; Lovely \& Kondrick, 2008; Nadelson \& Nadelson, 2010; Rutledge \& Mitchell, 2002), a section that includes statements about identities related to evolution was also developed and included in the BIPS questionnaire. On the basis of the science identity conceptual framework employed in the instrument design, the first section about biology identity in the BIPS is composed of statements about recognition, competence, performance, and interest in biology; the second section about how students see themselves with respect to evolution is composed of statements about recognition, competence, performance, and interest related to evolution. The third section of the survey is about their future career aspirations, comprising statements about students' aspirations in pursuing careers related to biology, science in general, and non-science fields. Respondents are asked to rate their agreement to each survey statement (e.g., "I am confident that I can understand biology outside of class") on an anchored five-point Likert scale ("Not at all" to "Very much so") in the biology identity and evolution identity sections, and on an eleven-point Likert scale ("Not at all likely" to "Very likely") in the career aspiration section. At the end of the survey, students were also asked to report demographic and background information (e.g., gender, race, ethnicity, parental education, year in 
school, home environment support). The original version of the BIPS with all statements about biology identity, evolution identity, and career aspirations, and questions about demographic information is attached in the supplemental material. It usually takes about 10 minutes for respondents to complete the entire survey.

The BIPS biology identity statements were initially adapted from the physics and mathematics identity statements from a survey study on the mathematics and physics identities of college students (Godwin, Potvin, Hazari, \& Lock, 2016). Three statements about physics recognition, six statements about physics competence/performance, and two statements about physics interest were adapted to address biology recognition, competence/performance, and interest in the BIPS with some minor modifications (e.g., the recognition statement "My parents/relatives/friends see me as a physics person" was separated into two statements and modified to be "My family sees me as a biology person" and "My friends/classmates see me as a biology person"). One statement about self-recognition (I see myself as a biology person) and one statement about biology interest (Topics in biology excite my curiosity) were added into the BIPS because of new versions of the physics identity instrument (Scott, Hazari, Potvin, Sadler, \& Sonnert, 2014). Some of the biology identity statements (particularly competence, performance, and interest items) were adapted to address students' identities with respect to evolution, specifically for the evolution identity section. Additional items were added to appropriately reflect students' recognition with respect to evolution to 
better fit high school students' experiences with evolution conceptions. The validity and reliability of BIPS is the focus of this paper with the following driving questions:

1) Is the BIPS valid in measuring high school students' biology identities, evolution identities, and career aspirations? 2) Is the BIPS reliable in measuring high school students' biology identities, evolution identities, and career aspirations?

\subsection{Methods}

To address the validity and reliability of the BIPS, both qualitative and quantitative data were collected. Qualitative data, including expert reviews and student cognitive interviews, were employed to provide the validity evidence of the BIPS based on content. Quantitative data were employed to statistically address one aspect of validity and two aspects of reliability: 1) the validity evidence based on structure of biology identity and evolution identity measurement models in the BIPS, 2) the internal consistency of biology identity statements in measuring biology identity and evolution identity statements in measuring evolution identity, and 3) the stability of biology identity and evolution identity constructs from one test to another. 


\subsubsection{Sources of Data}

\subsubsection{Qualitative Data}

The first part of the qualitative data in this study were collected through expert reviews. During the development of the BIPS, the questionnaire was first reviewed several times by an expert in science education, who was a faculty member in a university in southeast of the U.S. and had research expertise in science identity. The expert provided suggestions on the adaptation of identity statements, rephrasing of evolution recognition statements, and some wording issues of questions about demographic information, which were recorded with field notes or through email communications. After modifications were made accordingly after each review by the expert in science identity, the BIPS was then reviewed by an expert in survey questionnaire design. This expert, who was also a faculty member in a university in southeast of the U.S., reviewed the BIPS questionnaire once with the first author face-to-face and provided suggestions about questionnaire structure and wordings based on her expertise in educational measurement.

The second part of the qualitative data in the study were collected through student cognitive interviews. The first interviewee was recruited from a sample known to the author. Then a snowball sampling method was used by asking the first interviewee to invite more high school students to participate in the cognitive interviews. Two more interviewees were recruited in this way. The first interviewee was a female Asian American $10^{\text {th }}$ grader. The second interviewee was a female 
Hispanic $11^{\text {th }}$ grader, and the third interviewee was a male White $10^{\text {th }}$ grader. The author conducted cognitive interviews respectively with each interviewee. During each cognitive interview, students were first asked to complete the BIPS survey and turn it in to the interviewer. They were then asked to review each of the statements and verbally provide their responses along with an explanation of how they arrived at their response for each statement. Each interview was audio-recorded, and the data were transcribed thereafter. All interviewees were asked and encouraged to provide their thoughts and comments on every statement.

\subsubsection{Quantitative Data}

Quantitative data were collected through the implementation of the BIPS in the pilot study conducted in four public high schools in south Florida. The pilot version of the BIPS was administered to students in 11 high school physics I classes at four participating public high schools, six classes from three of the high schools (two classes from each school) and five classes from the fourth high school $(n=243)$. A follow-up re-test was conducted in the same six classes in the first three high schools after about four weeks, in which the BIPS was administered again $(n=113$, the final sample size for test-retest reliability analysis). The reasons to collect quantitative data in high school physics classes are: 1) high school physics students are almost at the same age as biology students, i.e., they are in the same developmental stage, and 2) in participating high schools, students' usually take Biology I in $9^{\text {th }}$ or $10^{\text {th }}$ grade while taking physics in $11^{\text {th }}$ or $12^{\text {th }}$ grade. Therefore, high school physics students 
are much less likely to be taking biology in the same data collection period.

Collecting data in high school physics classes ensures the ability to test how stable the items are with minimal influence of new biology experiences (see reliability section for more details), i.e., it minimizes shifts in biology/evolution identities and aspirations associate with taking biology courses. However, a few physics students were taking advanced biology courses in the same semester so these students were removed from the test-retest stability analysis because of their responses to the question added to the pilot version of the BIPS: “Are you taking any biology course in this semester?"

\subsubsection{Analysis of Data}

\subsubsection{Qualitative Data Analysis}

Data from expert reviews were analyzed by breaking down into some suggestions for specific modifications, which were then sent back to the corresponding expert to confirm that their suggestions were taken into action appropriately. Data from student cognitive interviews were first transcribed from audio-recording. Then the data were coded for suggestions for modifications. Every suggestion was considered carefully, particularly those mentioned by at least two of the interviewees. Then a list of suggestions for modifications were sent to all interviewees for review to confirm that their suggestions were understood correctly. 


\subsubsection{Quantitative Data Analysis}

Confirmatory Factor Analysis. On the basis of the science identity conceptual framework, I categorized the statements in Section One into biology recognition, biology competence/performance, and biology interest for the biology identity model, and categorized the statements in Section Two into evolution recognition, evolution competence/performance, and evolution interest for the evolution identity model. I categorized competence and performance as one construct taken from previous studies on STEM identity (Cass, Hazari, Cribbs, Sadler, \& Sonnert, 2011; Godwin, Potvin, Hazari, \& Lock, 2013; Hazari et al., 2010), which demonstrated that competence and performance were not clearly differentiable constructs for students (i.e., competence and performance items statistically loaded into one category in factor analysis).

I conducted confirmatory factor analysis (CFA) with R (R Core Group 2017), which is an open source software system for statistical data analysis, on students' responses to statistically validate survey statements about biology identity (recognition, performance/competence, and interest) and evolution identity (recognition, performance/competence, and interest) in measuring each specific construct to fit the biology identity model or evolution identity model respectively, based on the science identity conceptual framework.

Cronbach's Alpha. Cronbach's alpha was employed to assess the internal consistency of statements in the same category for measuring the associated 
construct in the final BIPS. In this study, I used R to calculate Cronbach's alpha of a group of statements respectively about each single construct: biology recognition, biology performance/competence, biology interest, evolution recognition, evolution performance/competence, and evolution interest. The Cronbach's alpha of all statements for the latent variable of biology identity and evolution identity was also calculated respectively.

Pearson's $\boldsymbol{r}$. To assess the repeatability/stability of the final BIPS in measuring each construct, the BIPS was administrated twice with a four-weeks interval with students in the same six physics classes of three physics teachers from three different public high schools in south Florida $(\mathrm{n}=113)$. Students' responses in the test-retest study were analyzed with Pearson's correlation coefficients (Pearson's r) for the consistency of measures from one test to the next. First, the measures for each construct (biology recognition, biology competence/performance, biology interest, biology identity, evolution recognition, evolution competence/performance, evolution interest, and evolution identity) were calculated by averaging the Likert scale scores of items measuring the same construct in the model. Then the Pearson's $r$ of each construct measure between the first and second administration was calculated to assess the test-retest reliability of the BIPS in measuring each construct. The Pearson's $r$ was also calculated for the test-retest stability of each single statement about students' career aspirations. 


\subsection{Results}

\subsubsection{Evidence of Validity}

Face and content validity for statements in the BIPS was established through expert reviews and high school student cognitive interviews. The validation step helped in modifying, adding, and dropping items, using feedback from the expert reviews and results of the student interviews. Construct validity was established through a pilot study which employed confirmatory factor analysis (CFA) to test whether the items mapped to the theorized conceptual framework.

\subsubsection{Qualitative Aspect of Validity}

Face and Content Validity - Expert Reviews. After the original version of the BIPS was developed, it was validated first through expert reviews. The survey statements about biology identity, evolution identity, career aspirations, and demographic information were reviewed by an expert in science education, with research expertise in science identity, to provide face and content validity for what those survey statements are supposed to measure. Some statements about evolution recognition were rephrased, considering relevant experiences that high school students have that relate to answering those questions. For example, I rephrased "I see myself as an evolution (biology) person" as "I see myself as an advocate for evolution" because high school students usually do not use "evolution person" to describe their recognition of themselves in terms of the relationship with evolution. Some new statements about evolution recognition (e.g., "evolution fits in my 
worldview," which was rephrased again later according to feedback from student cognitive interviews) were added to the BIPS to better describe high school students' recognition of themselves in terms of the relationship with evolution with words easier to understand for answering the question. The BIPS was then reviewed by an expert in educational research instrument design to provide suggestions about the order of the questions in the BIPS, the use of the Likert scale, and some wording issues that might cause ambiguity to high school students. Some minor modifications were then made accordingly. For example, in Question 10 about the highest education level of parents/guardians, the fifth item was changed from "master's degree or higher" to be "graduate/professional degree" to make it easier for high school students to understand what kind of degree this item asks about.

Face and Content Validity - Student Cognitive Interviews. Because the target population of this instrument is high school students, cognitive interviews were conducted with three high school students in the spring of 2016 to verify that high school students can clearly understand the wording and meaning of individual statements, and that students' verbal explanations of each statement were consistent with their Likert-scale responses. In general, interviewees could provide explanations consistent with most of their responses. For example, when I asked Laura (pseudonym) what she thought the statement "Topics in biology excite my curiosity" asks about, she said "I think it is asking like how I feel about topics in the biology course and if I like learning biology...it's about my enjoyment and interests 
in learning biology.” Another example is when I asked Jack (pseudonym) what he thought the statement "I see myself as an advocate for evolution" is about, he said "I think this is like how well you accept evolution...or support evolution.” However, in some cases, a few statements were identified by two or three of the interviewees as ambiguous in meaning. Those statements were revised. For example, all interviewees declared that, in the statement "My biology instructors/teachers see me as a biology person," they were thinking of whether "instructors" and "teachers" refer to different individuals or the same ones. After careful consideration, the word "instructors" was removed from this statement because students in high school found the language "teachers" more understandable (note that the instrument that BIPS was adapted from was designed for college students). Another example is the statement "Evolution fits in my worldview," which two interviewees explained that they were not quite sure what the word "worldview" refers to. As a result, this statement was modified to be "Evolution fits in how I see the world."

\subsubsection{Quantitative Aspect of Validity}

Quantitative data provided statistical evidence of the validity of the BIPS from a pilot study in high school physics classes in south Florida. In terms of validity, the data were used to conduct confirmatory factor analyses to establish construct validity for the instrument.

Construct Validity - Confirmatory Factor Analysis. In accordance with Brown (2006) and Kline (2005), the root mean square error of approximation (RMSEA), 
standardized root mean square residual (SRMR), comparative fit index (CFI), and Tucker-Lewis index (TLI) were employed as model fit indices in CFA to assess how well the biology identity model and evolution identity model fit the data using the theoretical science identity conceptual framework described earlier. The biology identity model and evolution identity model are composed of statements about students' recognition, competence, performance, and interest in biology or evolution, which were developed to measure the biology identity or evolution identity construct. The RMSEA, which is a parsimony correction index, evaluates how well the complexity of the model reasonably fits the population (Harrington, 2009). The SRMR, which is an absolute fit index, assess the discrepancy between the correlations in the sample covariance matrix and the correlations in the model covariance matrix. The CFI and TLI, which are both comparative fit indices, examine the discrepancy between the model and a more restricted baseline model (Harrington, 2009).

Students' responses about biology identity and evolution identity were analyzed respectively to assess the biology identity model and the evolution identity model. The CFA results for the initial version of the biology identity model and evolution identity model in the BIPS are reported in Table 1.

Table 1. CFA results about the identity models in the initial BIPS

\begin{tabular}{lcccc}
\hline & RMSEA & SRMR & CFI & TLI \\
\hline Biology Identity & 0.075 & 0.051 & 0.968 & 0.960 \\
Evolution Identity & 0.132 & 0.109 & 0.889 & 0.861 \\
\hline
\end{tabular}


The acceptable model fit indices suggested by Brown (2006) are RMSEA close to or less than 0.06 , SRMR close to or less than 0.08 , CFI close to or greater than 0.95, and TLI close to or greater than 0.95. According to Brown's criteria, the biology identity model in the BIPS fits well with the data, except the RMSEA which is greater than 0.06. However, the criteria are not rigid. According to Kline (2005), RMSEA value between 0.05 and 0.08 indicates an acceptable error of approximation, which supports the biology identity model in the BIPS as an acceptable fit model.

Table 2. R-square of statements in the initial evolution identity model

\begin{tabular}{lc}
\hline \multicolumn{1}{c}{ Statement } & R-square \\
\hline I see myself as an advocate for evolution & 0.777 \\
Evolution fits in how I see the world & 0.774 \\
People have come to me with questions about evolution & 0.177 \\
My biology teachers recognize my understanding of evolution & 0.241 \\
I am confident that I can understand evolution in class & 0.769 \\
I am confident that I can understand evolution outside of class & 0.672 \\
I can do well on exams in evolution & 0.690 \\
I understand concepts I have studied in evolution & 0.762 \\
I can overcome setbacks in evolution & 0.530 \\
Others ask me for help in evolution & 0.175 \\
I am interested in learning more about evolution & 0.806 \\
Topics in evolution excite my curiosity & 0.862 \\
I enjoy learning about evolution & 0.880 \\
\hline
\end{tabular}

The initial evolution identity model in the BIPS does not fit well with the data, according to the criteria of both Brown (2006) and Kline (2005), with RMSEA greater than 0.10 , SRMR greater than 0.10 , CFI less than 0.90 , and TLI less than 0.95. To improve the evolution identity model, I first calculated the coefficients of determination (R square, Table 2) of each statement with regards to their statistical fits with the initial evolution identity model. The R square value assesses how close 
each variable fits the regression model. Considering the $\mathrm{R}$ square value of each statement along with reviewing results for any ambiguity in the meaning of statements in the initial evolution identity model, I dropped some problematic statements with low R square values. When modifying the evolution identity model by dropping potentially problematic statements to improve the model fit, the statement "Others ask me for help in evolution" was first dropped because of its low coefficient of determination $(\mathrm{R}$-square $=0.175)$ with regards to its fit with the model. The CFA result was still not acceptable (RMSEA > 0.1, TLI < 0.95) after dropping. Then the statement "People have come to me with questions about evolution" was dropped $(\mathrm{R}$-square $=0.177)$ to generate a CFA result that was still not acceptable (RMSEA $>0.1$, TLI $<0.95$ ). The third dropped statement was "My biology teachers recognize my understanding of evolution" $(\mathrm{R}$-square $=0.241)$, which produced a CFA result approaching acceptability $(0.08<$ RMSEA $<0.1)$. According to Kline (2005), RMSEA value between 0.05 and 0.08 indicates acceptable error of approximation, and RMSEA value greater than 0.1 suggests poor model fit. In the case, the RMSEA value between 0.08 and 0.1 is not poor but still not acceptable. To enhance the validity of the evolution identity model, I decided to keep modifying it by dropping the statement "I can overcome setbacks in evolution" $(\mathrm{R}$-square $=0.530)$, which resulted in an acceptable CFA with RMSEA lower than 0.08, SRMR lower than 0.08, CFI greater than 0.95, and TLI greater than 0.95 . 


\begin{tabular}{lccc}
\hline \multicolumn{4}{c}{ Table 3. Chi-squared difference test for evolution identity model improvement } \\
\hline & Chi-square & d.f. & Critical Value \\
\hline Evolution Identity & 321.159 & 62 & \\
q2j dropped & 192.975 & 51 & 19.675 \\
q2c q2j dropped & 117.874 & 41 & 18.307 \\
q2c q2d q2j dropped & 87.284 & 32 & 16.919 \\
q2c q2d q2i q2j dropped & 58.256 & 24 & 15.507 \\
\hline d.f.: degree of freedom & & & \\
q2j: "Others ask me for help in evolution" & \\
q2c: "People have come to me with questions about evolution" \\
q2d: "My biology teachers recognize my understanding of evolution" \\
q2i: "I can overcome setbacks in evolution" \\
\hline
\end{tabular}

The modification by dropping problematic statements was done one by one per the

Chi-squared difference test for significance of model improvement, i.e., the statements that fit the model least were removed first (Table 3). If the obtained Chi-squared difference between the parent and nested models is greater than the critical value for the test of the degree of freedom difference between the parent and nested models, I can conclude that the modification of the model resulted in a significant improvement in model fit (Harrington, 2009). The CFA results of the evolution identity models after each modification are reported in Table 4.

Table 4. CFA results about the improvement of the evolution identity model

\begin{tabular}{lcccr}
\hline & RMSEA & SRMR & CFI & TLI \\
\hline Evolution Identity & 0.132 & 0.109 & 0.889 & 0.861 \\
q2j dropped & 0.107 & 0.087 & 0.935 & 0.916 \\
q2c q2j dropped & 0.104 & 0.085 & 0.949 & 0.932 \\
q2c q2d q2j dropped & 0.084 & 0.048 & 0.973 & 0.961 \\
q2c q2d q2i q2j dropped & 0.077 & 0.038 & 0.981 & 0.972 \\
\hline q2j: "Others ask me for help in evolution" & & & & \\
q2c: "People have come to me with questions about evolution" & & \\
q2d: "My biology teachers recognize my understanding of evolution" & & \\
q2i: "I can overcome setbacks in evolution" & & & \\
\hline
\end{tabular}


The final evolution identity model includes nine statements: two statements about evolution recognition (two problematic statements dropped from the initial model), four statements about evolution competence/performance (two problematic statements dropped from the initial model), and three statements about evolution interest. The final version of the BIPS is different from the initial version with the initial evolution identity section substituted by the modified evolution identity section. In the final version of the BIPS, about the biology identity model, RMSEA is less than 0.08 (RMSEA $=0.075)$, SRMR is less than $0.08(\mathrm{SRMR}=0.051), \mathrm{CFI}$ is greater than $0.95(\mathrm{CFI}=0.968)$, and TLI is greater than $0.95(\mathrm{TLI}=0.960)$; about the evolution identity model, RMSEA is less than 0.08 (RMSEA $=0.077)$, SRMR is less than $0.08(\mathrm{SRMR}=0.038), \mathrm{CFI}$ is greater than $0.95(\mathrm{CFI}=0.981)$, and TLI is greater than $0.95(\mathrm{TLI}=0.972)$. The statistical results indicated that the final version of the BIPS is valid for measuring biology identity and evolution identity.

\subsubsection{Evidence of Reliability}

The reliability of the final version of the BIPS was assessed in two ways:

1) Cronbach's alpha, which assesses internal consistency of each single construct, and 2) test-retest stability of responses for the same student sample between two administrations with a four-week interval.

\subsubsection{Internal Consistency}

A Cronbach's alpha that is close to or greater than 0.9 is considered to be an indication of excellent internal consistency with a 0.7 considered acceptable (Kline, 
2000). The Cronbach's alpha for each construct in the conceptual framework relative to biology and evolution identity is presented in Table 5 .

Table 5. Cronbach's alpha of biology identity and evolution identity statements

\begin{tabular}{lc}
\hline & Cronbach's Alpha \\
\hline Biology Recognition & 0.93 \\
Biology Competence/Performance & 0.91 \\
Biology Interest & 0.92 \\
Biology Identity & 0.94 \\
Evolution Recognition & 0.89 \\
Evolution Competence/Performance & 0.91 \\
Evolution Interest & 0.94 \\
Evolution Identity & 0.91 \\
\hline
\end{tabular}

The Cronbach's alpha for biology recognition statements is 0.93 , for biology

competence/performance statements is 0.91 , for biology interest statements is 0.92 ,

and for all biology identity statements is 0.94 . As to the evolution identity construct, the Cronbach's alpha for evolution recognition statements is 0.89 , for evolution competence/performance statements is 0.91 , for evolution interest statements is 0.94 , and for all evolution identity statement is 0.91 . The results demonstrate an excellent internal consistency for the final version of the BIPS (alpha ranges from 0.89 to $0.94)$.

\subsubsection{Test-retest Reliability}

A Pearson's $r$ that is close to or greater than 0.7 is considered an indication of acceptable test-retest stability of the measures of each single construct (George \& Mallery, 2003). The biology identity model and evolution identity model in the final BIPS were reliable (Pearson's $r>0.7$ ) when implemented with the same student sample in a test-retest study with a 4-week interval. The results in Table 6 
demonstrate a satisfactory test-retest reliability of the measures of all constructs in the biology identity model and the evolution identity model in the final version of the BIPS ( $\mathrm{r}$ ranges from 0.75 to 0.86 ). The results of the test-retest stability analysis for career aspirations indicate that the measures for career aspirations towards being a medical professional, health professional, and biologist were very stable between the test and retest ( $\mathrm{r}$ is $0.89,0.84,0.75$ respectively). However, high school students' career aspirations towards being earth/environmental scientists, other biology-related fields, other science-related fields, and non-science-related fields were not as stable according to the results of the test-retest reliability analysis ( $\mathrm{r}$ is $0.59,0.66,0.66,0.63$ respectively).

Table 6. The test-retest stability of the final BIPS

\begin{tabular}{lc}
\hline & Pearson's r \\
\hline Biology Recognition & $0.82^{* * *}$ \\
Biology Competence/Performance & $0.81^{* * *}$ \\
Biology Interest & $0.79^{* * *}$ \\
Biology Identity & $0.86^{* * *}$ \\
Evolution Recognition & $0.75^{* * *}$ \\
Evolution Competence/Performance & $0.77^{* * *}$ \\
Evolution Interest & $0.78^{* * *}$ \\
Evolution Identity & $0.82^{* * *}$ \\
Career Aspirations & \\
Medical Professional & $0.89^{* * *}$ \\
Health Professional & $0.84^{* * *}$ \\
Biologist & $0.75^{* * *}$ \\
Earth/Environmental Scientist & $0.59^{* * *}$ \\
Other Biology-Related Field & $0.66^{* * *}$ \\
Other Science-Related Field & $0.66^{* * *}$ \\
Non-Science-Related Field & $0.63^{* * *}$ \\
\hline ***: Pearson's r is significant at the 0.001 level. & \\
\hline
\end{tabular}




\subsection{Discussion}

The BIPS has been developed, assessed, and modified for evaluating high school students' biology identity, evolution identity, and career aspirations in various areas, biology-related or non-biology-related. The validity of statements in the BIPS for measuring each proposed construct based on the conceptual framework was verified through expert reviews by an expert in science identity and an expert in instrument design. The clarity and explanation of how responses were conceived by students for each instrument statement were verified through cognitive interviews with three high school students.

The validity of the biology identity model and evolution identity model in measuring the latent variable of biology identity and evolution identity respectively was assessed through CFA and verified after dropping several problematic statements in the initial evolution identity model. The dropped statements "Others ask me for help in evolution" and "I can overcome setbacks in evolution" have low coefficients of determination ( $\mathrm{R}$-square $=0.175$ and 0.530 respectively) with regards to their fit with the model. The similar statements about physics and mathematics identity in a survey study on the mathematics and physics identities of college students, from which I adapted identity statements, also had relatively low coefficients of determination compared to other physics and mathematics identity statements in the same survey (Godwin et al., 2016). The statement "People have come to me with questions about evolution" was another problematic statement that 
was dropped. The possible reason might be that, to high school students, the meaning of this evolution recognition statement is close to another problematic competence/performance statement "Others ask me for help in evolution," which might confuse them when they conceive answers to each of these two statements. Another possible reason is that participants of the pilot study might not be able to explicitly recall whether someone came to her/him with questions particularly about evolution because, as public high school physics students in south Florida, they took biology about two years ago. For the similar reason, the participants of the pilot might also not be able to clearly recall whether their biology teachers in about two years ago recognized their understanding of evolution particularly. Therefore, after dropping four problematic statements, I finalized the evolution identity section in the BIPS with two evolution recognition statements, four evolution competence/performance statements, and three evolution interest statements (see the supplemental material for more details).

As for the reliability of the final BIPS, Cronbach's alpha results indicated excellent internal consistency (Cronbach's alpha $\geq 0.9$ ) in measuring each single construct. The one exception is the Cronbach's alpha of evolution recognition statements (0.89), which was lower than but very close to 0.9 . Therefore, with a Cronbach's alpha of 0.94 for all the biology identity statements and 0.91 for all the evolution identity statements, it is safe to conclude that the biology identity model and evolution identity model in the final BIPS both had excellent internal 
consistency. The similar physics and mathematics

interest/recognition/performance/competence statements in the survey, which I adapted identity statements from, also had good internal consistency (Godwin et al., 2016).

When I put together all statements about aspirations in biology-related careers (“medical professional," "health professional," "biologist," "earth/environmental scientists," and "other biology-related field") and assessed the test-retest stability, the Pearson's r (0.87) was greater than 0.7, which suggested that the final BIPS was reliable in evaluating students' aspirations in biology-related careers. As for the relatively low test-retest reliability of aspiration statements in non-biology-related fields ("other science-related field," Pearson's $r=0.66$; "non-science-related field," Pearson's $r=0.63$ ), the possible reason for the low test-retest reliability might be that I only ensured that students were not exposed to biology courses, by removing responses from those who were taking any biology course, during the four-week interval but all participating students were taking physics and could also have been exposed to other science and non-science courses and experiences of note, which might contribute to their shifts of career aspirations towards "other science-related field" and "non-science-related field" and hence lower the correlations.

I presented a newly developed and validated research instrument, the BIPS, which can be implemented in high school biology classes to assess students' identity development in biology and evolution, as well as their aspirations towards 
biology-related careers. The BIPS can be used to correlate students' biology identity and aspirations with their conceptual understanding and other student characteristics related to biology learning to better understand the influence of biology identity on students' academic achievement and persistence in biology. Moreover, the BIPS can be employed to evaluate innovative biology interventions and programs in terms of the impact on students' biology identity and persistence.

\subsection{Limitations}

The BIPS was tested with high school students in south Florida because this instrument was developed for a dissertation project, which targeted on high school students in south Florida. To broaden the application of the BIPS in biology education, it needs to be further tested with college students. It could also better address the validity and reliability of the BIPS and widen its application to further test the BIPS national-wide with national representative sample.

\section{References (Chapter 2)}

Adams, W. K., Perkins, K. K., Podolefsky, N. S., Dubson, M., Finkelstein, N. D., \& Wieman, C. E. (2006). New instrument for measuring student beliefs about physics and learning physics: The Colorado Learning Attitudes about Science Survey. Physical Review Special Topics - Physics Education Research, 2(1).

Alters, B. J., \& Nelson, C. E. (2002). Perspective: Teaching evolution in higher education. International Journal of Organic Evolution, 56, 1891-1901.

American Association for the Advancement of Science. (1993). Benchmarks for science literacy: A project 2061 report. New York, NY: Oxford University Press. 
American Modeling Teachers Association. (2016). High school biology modeling workshop participant materials. Miami, FL: American Modeling Teachers Association.

Aschbacher, P. R., Li, E., \& Roth, E. J. (2010). Is science me? High school students' identities, participation and aspirations in science, engineering, and medicine. Journal of Research in Science Teaching, 47, 564-582.

Barron, B. (2006). Interest and self-sustained learning as catalysts of development: A learning ecology perspective. Human Development, 49(4), 193-224.

Basu, S. J. (2008). How students design and enact physics lessons: Five immigrant Caribbean youth and the cultivation of student voice. Journal of Research in Science Teaching, 45, 881-899.

Black, A. E., \& Deci, E. L. (2000). The effects of instructors' autonomy support and students' autonomous motivation on learning organic chemistry: A self-determination theory perspective. Science Education, 84, 740-756.

Boaler, J., William, D., \& Zevenbergen, R. (2000). The construction of identity in secondary mathematics education. In Second International Conference on Mathematics Education and Society (pp. 192-202). Montechoro, Portugal.

Breakwell, G. M., \& Beardsell, S. (1992). Gender, parental and peer influences upon science attitudes and activities. Public Understanding of Science, 1(2), 183-197.

Brewe, E. (2008). Modeling theory applied: Modeling Instruction in introductory physics. American Journal of Physics, 76, 1155-1160.

Brewe, E., Kramer, L., \& O’Brien, G. (2009). Modeling instruction: Positive attitudinal shifts in introductory physics measured with CLASS. Physical Review Special Topics - Physics Education Research, 5(1), 1-5.

Brewe, E., Sawtelle, V., Kramer, L. H., O’Brien, G. E., Rodriguez, I., \& Pamelá, P. (2010). Toward equity through participation in Modeling Instruction in introductory university physics. Physical Review Special Topics - Physics Education Research, 6(1), 10106.

Brickhouse, N. W., Lowery, P., \& Schultz, K. (2000). What kind of girl does science? The construction of school science identities. Journal of Research in Science Teaching, 37, 441-458. 
Brickhouse, N. W., \& Potter, J. T. (2001). Young women's scientific identity formation in an urban context. Journal of Research in Science Teaching, 38, 965-980.

Brown, T. A. (2006). Confirmatory factor analysis for applied research. New York, NY: The Guilford Press.

Burke, P. J. (2003). Introduction. In P. J. Burke, T. J. Owens, R. T. Serpe, \& P. A. Thoits (Eds.), Advances in identity theory and research (pp. 1-7). New York, NY: Kluwer Academic Publisher.

Caldas, S. J., \& Bankston, C. (1997). Effect of school population socioeconomic status on individual academic achievement. The Journal of Educational Research, 90(5), 269-277.

Carlone, H. B., \& Johnson, A. (2007). Understanding the science experiences of successful women of color: Science identity as an analytic lens. Journal of Research in Science Teaching, 44, 1187-1218.

Cass, C. A. P., Hazari, Z., Cribbs, J., Sadler, P. M., \& Sonnert, G. (2011). Examining the impact of mathematics identity on the choice of engineering careers for male and female students. In Frontiers in Education Conference (p. F2H-1). Rapid City, SD: IEEE.

Chemers, M. M., Zurbriggen, E. L., Syed, M., Goza, B. K., \& Bearman, S. (2011). The role of efficacy and identity in science career commitment among underrepresented minority students. Journal of Social Issues, 67, 469-491.

Chen, X., \& Weko, T. (2009). Students who study science, technology, engineering, and mathematics (STEM) in postsecondary education. Washington, DC: National Center for Education Statistics.

Cleaves, A. (2005). The formation of science choices in secondary school. International Journal of Science Education, 27, 471-486.

Davis-Kean, P. E. (2005). The influence of parent education and family income on child achievement: The indirect role of parental expectations and the home environment. Journal of Family Psychology, 19(2), 294-304.

Desbien, D. M. (2002). Modeling discourse management compared to other classroom management styles in university physics. Arizona State University. 
Dobzhansky, T. (1973). Nothing in biology makes sense except in the light of evolution. The American Biology Teacher, 35(3), 125-129.

Dukerich, L. (2015). Applying modeling instruction to high school chemistry to improve students' conceptual understanding. Journal of Chemical Education, 92, $1315-1319$.

Durden, J., Brewe, E., \& Kramer, L. H. (2011). “Seeding”: Understanding discourse management in modeling. Jacksonville, FL: AmericanAssociation of Physics Teachers National Meeting.

Dye, J., Cheatham, T., Rowell, G. H., Barlow, A., \& Carlton, R. (2013). The impact of modeling instruction within the inverted curriculum on student achievement in science. Electronic Journal of Science Education, 17(2), 1-19.

Erikson, E. H. (1968). Identity: Youth and crisis. New York, NY: Norton.

Gard, A. (2015). Modeling instruction in high school biology. Miami, FL: American Modeling Teachers Association.

Gee, J. P. (2000). Identity as an analytic lens for research in education. Review of Research in Education, 25(1), 99-125.

George, D., \& Mallery, P. (2003). SPSS for Windows step by step: A simple guide and reference. Boston, MA: Allyn \& Bacon.

Gilmartin, S., Denson, N., Li, E., Bryant, A., \& Aschbacher, P. (2007). Gender ratios in high school science departments: The effect of percent female faculty on multiple dimensions of students' science identities. Journal of Research in Science Teaching, 44, 980-1009.

Godwin, A., Potvin, G., Hazari, Z., \& Lock, R. (2013). Understanding engineering identity through structural equation modeling. In Proceedings - Frontiers in Education Conference, FIE (pp. 50-56).

Godwin, A., Potvin, G., Hazari, Z., \& Lock, R. (2016). Identity, critical agency, and engineering: An affective model for predicting engineering as a career choice. Journal of Engineering Education, 105(2), 312-340. 
Grolnick, W. S., \& Ryan, R. M. (1987). Autonomy in children's learning: An experimental and individual difference investigation. Journal of Personality and Social Psychology, 52, 890-898. http://doi.org/10.1037/0022-3514.52.5.890

Halloun, I. A. (2007). Modeling theory in science education. Dordrecht, Netherlands: Springer.

Harrington, D. (2009). Confirmatory Factor Analysis. New York, NY: Oxford University Press.

Hazari, Z., Cass, C., \& Beattie, C. (2015). Obscuring power structures in the physics classroom: Linking teacher positioning, student engagement, and physics identity development. Journal of Research in Science Teaching, 52, 735-762.

Hazari, Z., Sonnert, G., Sadler, P. M., \& Shanahan, M.-C. (2010). Connecting high school physics experiences, outcome expectations, physics identity, and physics career choice: A gender study. Journal of Research in Science Teaching, 47, 978-1003.

Hestenes, D. (1987). Toward a modeling theory of physics instruction. American Journal of Physics, 55, 440-454.

Hestenes, D. (1992). Modeling games in the Newtonian World. American Journal of Physics, 60, 732.

Hodapp, V. (1982). Causal inference from nonexperimental research on anxiety and educational achievement. Series in Clinical \& Community Psychology: Achievement, Stress, \& Anxiety, 355-372.

Holland, D., Skinner, D., Lachicotte, W., \& Cain, C. (1998). Identity and agency in cultural worlds. Cambridge, MA: Harvard University Press.

Hughes, J., \& Kwok, O. (2007). Influence of student-teacher and parent-teacher relationships on lower achieving readers' engagement and achievement in the primary grades. Journal of Educational Psychology. Hughes, Jan: 701 Harrington Building, 4225 TAMU, College Station, TX, US, 77843-4225, jhughes@tamu.edu: American Psychological Association. http://doi.org/10.1037/0022-0663.99.1.39 
Hull, G. A., \& Greeno, J. G. (2006). Identity and agency in nonschool and school worlds. In Z. Bekerman, N. Burbules, \& D. S. Keller (Eds.), Learning in places: The informal education reader (pp. 77-97). New York, NY: Peter Lang.

Jackson, J., Dukerich, L., \& Hestenes, D. (2008). Modeling instruction : An effective model for science education. Science Educator, 17(1), 10-17.

Johnson, D. W., Johnson, R. T., \& Holubec, E. J. (1994). Coorperative learning in the classroom. Alexandria, VA: Association for Supervision and Curriculum Development.

Kane, J. M. (2012). Young African American children constructing academic and disciplinary identities in an urban science classroom. Science Education, 96, 457-487.

Kline, P. (2000). The handbook of psychological testing (2nd ed.). London, UK: Routledge.

Kline, R. B. (2005). Principles and practice of structural equation modeling (2nd ed.). New York, NY: The Guilford Press.

Lave, J., \& Wenger, E. (1991). Situated learning: Legitimate peripheral participation. Cambridge, UK: Cambridge University Press.

Lavigne, G. L., Vallerand, R. J., \& Miquelon, P. (2007). A motivational model of persistence in science education: A self-determination theory approach.

European Journal of Psychology of Education, 22, 351-369. http://doi.org/10.1007/BF03173432

Lawrence Jr., S. W. (1962). The effects of anxiety, achievement motivation, and task importance upon performance on an intelligence test. Journal of Educational Psychology, 53(3), 150-156. http://doi.org/10.1037/h0045204

Lee, O., \& Fradd, S. H. (1998). Science for all, including students from non-English-language backgrounds. Educational Researcher, 27(4), 12-21.

Li, F., Brewe, E., Hazari, Z., O’Brien, G. E., \& Long, H. (2017). Connecting biology modeling instruction practice, identity development, and career aspirations: A comparative case study. Unpublished Manuscript. 
Li, F., \& Hazari, Z. (2017). Developing and validating the Biology Identity and Persistence Survey (BIPS) for use in high schools in south Florida. Manuscript Submitted for Publication.

Liang, L. L., Fulmer, G. W., Majerich, D. M., Clevenstine, R., \& Howanski, R. (2012). The effects of a model-based physics curriculum program with a physics first approach: A causal-comparative study. Journal of Science Education and Technology, 21, 114-124.

Lovely, E. C., \& Kondrick, L. C. (2008). Teaching evolution: Challenging religious preconceptions. Integrative and Comparative Biology, 48, 164-174.

Malone, K. L. (2008). Correlations among knowledge structures, force concept inventory, and problem-solving behaviors. Physical Review Special Topics Physics Education Research, 4(2), 1-15.

Manthey, S., \& Brewe, E. (2013). Toward university modeling instruction-biology: Adapting curricular frameworks from physics to biology. CBE Life Sciences Education, 12, 206-214.

Marsh, W. H., Hau, K.-T., \& Kong, C.-K. (2002). Multilevel causal ordering of academic self-concept and achievement: Influence of language of instruction (English compared With Chinese) for Hong Kong students. American Educational Research Journal, 39, 727-763.

Mayr, E. (1982). The growth of biological thought. Cambridge, MA: Harvard University Press.

Merriam, S. B. (1998). Qualitative research and case study applications in education. San Francisco, CA: Jossey-Bass.

Nadelson, L. S., \& Nadelson, S. (2010). K-8 educators perceptions and preparedness for teaching evolution topics. Journal of Science Teacher Education, 21, 843-858.

Nasir, N. S. (2002). Identity, goals, and learning: Mathematics in cultural practice. Mathematical Thinking and Learning, 4(2-3), 213-248.

National Academy of Science. (1998). Teaching about evolution and the nature of science. Washington, DC: National Academies Press. 
National Association of Biology Teachers. (2000). Statement on teaching evoluton. In Voices for Evolution (p. 154). National Center for Science Education.

National Center for Education Statistics. (2011). The nation's report card: Science 2009. Washington, DC: Institute of Education Sciences, U.S. Department of Education.

National Research Council. (1996). National science education standards. Washington, DC: National Academies Press.

National Research Council. (2009). Learning science in informal environments: People, places, pursuits. Washington, DC: National Academies Press.

National Research Council. (2012). A framework for K-12 science education: Practices, crosscutting concepts, and core ideas. Washington, DC: National Academies Press.

National Science Board. (2012). Higher education in science and engineering. In Science and engineering indicators 2012 (pp. 1-39). Arlington, VA: National Academies Press.

National Science Board. (2014). Higher education in science and engineering. In Science and engineering indicators 2014. Arlington, VA: National Academies Press.

Nersessian, N. J. (1995). Should physicists preach what they practice? Science \& Education, 4(3), 203-226.

O'Brien, M. J., \& Thompson, J. R. (2009). Effectiveness of ninth-grade physics in Maine: Conceptual understanding. The Physics Teacher, 47(4), 234-239.

Odenbaugh, J. (2005). Idealized, inaccurate but successful: A pragmatic approach to evaluating models in theoretical ecology. Biology and Philosophy, 20, 231-255.

Papanastasiou, C. (2002). School, teaching and family influence on student attitudes toward science: Based on TIMSS data for Cyprus. Studies in Educational Evaluation, 28(1), 71-86.

Passmore, C., \& Stewart, J. (2002). A modeling approach to teaching evolutionary biology in high schools. Journal of Research in Science Teaching, 39(3), 185-204. 
Passmore, C., Stewart, J., \& Cartier, J. (2009). Model-based inquiry and school science: Creating connections. School Science and Mathematics, 109, 394-402.

Perkins, K. K., Adams, W. K., Pollock, S. J., Finkelstein, N. D., \& Wieman, C. E. (2005). Correlating student beliefs with student learning using the Colorado learning attitudes about science survey. In AIP Conference Proceedings (Vol. 790, pp. 61-64).

Redish, E. F., Saul, J. M., \& Steinberg, R. N. (1998). Student expectations in introductory physics. American Journal of Physics, 66(3), 212.

Reichardt, C. S., \& Cook, T. D. (1979). Quantitative and qualitative methods in evaluation research. In C. S. Reichardt \& T. D. Cook (Eds.), Beyond Qualitative versus Quantitative Methods. Thousand Oaks, CA: SAGE.

Renninger, K. A. (2009). Interest and identity development in instruction: An inductive model. Educational Psychologist, 44(2), 105-118.

Rutledge, M. L., \& Mitchell, M. A. (2002). High school biology teachers' knowledge structure, acceptance and teaching of evolution. The American Biology Teacher, 64(1), 21-28.

Ryan, R. M., \& Deci, E. L. (2000). Self-determination theory and the facilitation of intrinsic motivation, social development, and well-being. The American Psychologist, 55(1), 68-78.

Ryan, R. M., \& Deci, E. L. (2003). On assimilating identities to the self: A self-determination theory perspective on internalization and integrity within cultures. In M. R. Leary \& J. P. Tangney (Eds.), Handbook of Self and Identity (pp. 253-272). New York, NY: Guilford.

Schneider, B., \& Lee, Y. (1990). A Model for academic success: The school and home environment of East Asian students. Anthropology \& Education Quarterly, 21(4), 358-377.

Schuchardt, A. M., \& Schunn, C. D. (2015). Modeling scientific processes with mathematics equations enhances student qualitative conceptual understanding and quantitative problem solving. Science Education, 100(2), 290-320.

Schwarz, C., \& Passmore, C. (2012). Preparing for NGSS: Developing and using models. Retrieved May 2, 2017, from 
http://learningcenter.nsta.org/products/symposia_seminars/ngss/files/Preparingfo rNGSS--DevelopingandUsingModels_9-25-2012.pdf

Scott, T. D., Hazari, Z., Potvin, G., Sadler, P. M., \& Sonnert, G. (2014). Interdisciplinary affinity: Definitions and connections to physics identity. In 2014 Physics education research conference (pp. 235-238). Minneapolis, MN: American Association of Physics Teachers.

Shanahan, M. (2009). Identity in science learning: Exploring the attention given to agency and structure in studies of identity. Studies in Science Education, 45(1), $43-64$.

Sherman, R. R., \& Webb, R. B. (1988). Qualitative research in education. London, UK: Routledge.

Song, I.-S., \& Hattie, J. (1984). Home environment, self-concept, and academic achievement: A causal modeling approach. Journal of Educational Psychology, 76, 1269-1281.

Strauss, A., \& Corbin, J. (1990). Basics of qualitative research (2nd ed.). Newbury Park, CA: SAGE.

Tai, R. H., Liu, C. Q., Maltese, A. V, \& Fan, X. (2006). Planning early for careers in science. Science, 312, 1143-1144.

Tsai, Y.-M., Kunter, M., Lüdtke, O., Trautwein, U., \& Ryan, R. M. (2008). What makes lessons interesting? The role of situational and individual factors in three school subjects. Journal of Educational Psychology, 100, 460-472.

Windschitl, M., Thompson, J., \& Braaten, M. (2008). Beyond the scientific method: Model-based inquiry as a new paradigm of preference for school science investigations. Science Education, 92, 941-967.

Yin, R. K. (2014). Case study research: Design and methods (5th Editio). Thousand Oaks, CA: SAGE. 


\section{CHAPTER 3 CONNECTING BIOLOGY MODELING INSTRUCTION PRACTICE, IDENTITY DEVELOPMENT, AND CAREER ASPIRATIONS: A COMPARATIVE CASE STUDY}

\subsection{Introduction}

High school biology Modeling Instruction (MI) curriculum has been under development for over a decade (Gard, 2015; Passmore \& Stewart, 2002; Schuchardt \& Schunn, 2015). The first complete high school biology MI curriculum was developed in a Physics-Chemistry-Biology sequence for $11^{\text {th }}$ graders (Gard, 2015). The development and adaptation of high school biology MI curriculum for $9^{\text {th }}$ and $10^{\text {th }}$ graders in a Biology-Chemistry-Physics sequence was initiated in 2010 (Gard, 2015). Substantial effort has been made in developing biology MI materials and integrating MI into high school biology classes. The high school biology MI curriculum materials have been evaluated for several years at high schools in the U.S. (Gard, 2015); however, attention has yet been paid to monitoring, evaluating, and promoting high school biology instructors' teaching practices with MI curriculum.

Although I advocate MI as optimal strategy for science teaching and learning (Brewe et al., 2009; Dukerich, 2015; Jackson et al., 2008; O’Brien \& Thompson, 2009), it still highly relies on science instructors' effective teaching practice.

Teachers' appropriate teaching practice is essential in implementing biology MI curriculum effectively in high school biology classrooms. In light of the concern 
about the effectiveness of MI instructors' teaching practice, the comparative case study, by focusing on the evolution class sessions in high school Biology I course in south Florida, aimed to decipher and compare high school biology instructors' teaching practices in MI and non-MI classes. The comparative case study also aimed to identify and understand the connection between instructors' teaching practices and students' identities with biology and evolution and aspirations in biology-related careers. Because of its relatively younger age compared to the longer developing period of high school physics and chemistry MI curricula, there are still very limited number of published research studies on high school biology MI curriculum. Even among previous research studies on secondary MI in physics or chemistry, many of them focused on students' conceptual understanding (e.g., Dukerich, 2015; O'Brien \& Thompson, 2009). The present study focused on students' development of biology and evolution identities. Science identities have been demonstrated to be able to predict students' persistence in science (Aschbacher et al., 2010; Carlone \& Johnson, 2007; Cleaves, 2005; Gilmartin et al., 2007; Renninger, 2009; Shanahan, 2009), and their aspirations in science-related careers. I employed a comparative case study research design, with both qualitative and quantitative data, to examine teaching strategies that participating MI and non-MI high school biology instructors used in their evolution classes and how their teaching practices related to students' biology and evolution identity development and shifts of aspirations in biology-related 
careers. The results in turn inspired our thinking of how high school biology MI could be implemented better.

\subsection{Aspirations in Biology}

In order to maintain a "leakless" pipeline in biology education, it is critical to promote high school students' aspirations to learn more biology, earn biology degrees, and pursue biology-related careers. Unlike other STEM disciplines, biological sciences do not encounter gender inequity in enrollment as around $60 \%$ of bachelor's degrees in biological sciences are earned by female students (National Science Board, 2012, 2014). However, like other STEM disciplines, biological fields still confront low participation rates of historically underrepresented minorities (Hispanic, African American/Black, Native American, and Pacific Islander) in biological science majors in colleges and universities. The underrepresentation of minority students in biological fields calls for more attention and more studies to identify or develop effective solutions/interventions. Tai, Liu, Maltese and Fan (2006) reported that adolescent students' aspirations for a science career significantly predicted the likelihood of their pursuing science majors in colleges and universities. Their finding supports the strategy of promoting high school students' aspirations for biology careers in an early stage to increase the likelihood of their choosing college majors in biological sciences. 


\subsection{Biology and Evolution Identity Development}

Science identity was described as who people think they are in terms of their relation with science (Brickhouse et al., 2000). An individual's science identity is influenced by the social environment she/he is affiliated with (National Research Council, 2009). Evidence from prior studies suggests that identities are developed through interaction of an individual with others in a given social setting (Holland et al., 1998; Hull \& Greeno, 2006). While negotiating and acquiring identity in a certain social setting, an individual also brings her/his own experiences and values into the given social community to influence values and practices of others in the specific social community (National Research Council, 2009).

To examine students' learning outcomes in both MI and non-MI Biology I classes during the course unit of evolution, I employed "biology identity" and "evolution identity" as two aspects of their learning outcomes. By using the two terms "biology identity" and "evolution identity," I mean how students see themselves with respect to biology/evolution according to their experiences in learning biology/evolution as a high school student. An individual's biology/evolution identity can be conceptualized in two constructions: 1) internalized perception of one's role with respect to the relation with biology/evolution, which is narrated by the individual and may be observed through external social performance, and 2) external social performance of one's role in learning biology/evolution, which can be observed through what an individual does 
or says and may not be perceived by the individual her/himself and not be narrated (Hazari, Cass, \& Beattie, 2015). In the present study, I identified students’ observed/performed construction of biology/evolution identities through in-class observation. To construct internalized designation of biology/evolution identities, I employed the science identity conceptual framework drawn from the work of Carlone and Johnson (2007), and Hazari, Sonnert, Sadler and Shanahan (2010). With this framed conceptualization of students' biology/evolution identities, I measured students' internalized designation of biology/evolution identities as their perceptions of recognition, competence, performance, and interest in biology/evolution. These four components work as essential contributors to students' biology/evolution identities. Evidence from Brickhouse and Potter (2001) indicates that students construct their science identities primarily drawing on supports from and interactions with external environment. Boaler, William and Zevenbergen (2000) demonstrated that students' mathematics identities develop through their learning how to work, how to cope, how to act, how to think, and how to discuss as a mathematician in mathematics classes. According to self-determination theory, an autonomous and self-directed learning environment, the typical class environment of MI classes, can satisfy the needs of school-age learners in developing their disciplinary identities (Ryan \& Deci, 2000, 2003; Tsai et al., 2008). 


\subsection{Efficacy and Practice of MI}

Malone (2008) indicated that students in a modeling group employed more expert-like problem-solving skills than their counterparts in a non-modeling group. Beyond students' performance in science, Brewe, Kramer and O'Brien (2009) reported that college students in introductory physics MI class had positive attitudinal shifts towards physics, measured by the Colorado Learning Attitudes about Science Survey. It was also reported that MI improved underrepresented students' academic achievements, odds of success, and participation in college introductory physics class (Brewe et al., 2010). The science identity conceptual framework employed in this study suggests that positive shifts in any component of an individual's biology/evolution identity (recognition, performance, competence, and interest) could contribute to one's biology/evolution identity development. According to the evidence demonstrating positive influence of MI on students' attitude (particularly interest and competence) towards science and their performance in science learning, it is worthwhile to explore high school biology MI instructors' teaching practice in terms of its relationship with students' biology/evolution identity development and career aspirations.

Biology MI teaching practice is not only supported by prior research studies but also conceptualized by Modeling Theory of Science (MTS), Modeling Theory of Instruction (MTI), and Modeling Discourse Management (MDM; Manthey \& Brewe, 2013). The MTS articulates that scientific disciplines, including biology, progress 
through an ongoing process of model construction, validation, implementation, and modification (Halloun, 2007). It was argued that scientists employ models to connect scientific theory and related concepts to understand and conceptualize science (Halloun, 2007; Hestenes, 1987). Serving as a framework for applying the MTS, the MTI suggests that students, when learning science, should be involved in similar scientific activities as scientists use in constructing, validating, implementing, and modifying models (Brewe, 2008). The MTI argues for a student-centered classroom environment and encourages students to learn science through student-student interactions (Brewe, 2008). Along with authentic scientific practices established by MTS and MTI, it is also critical to support MI instructors' teaching practices with structured discourse, which is shaped by MDM with a set of discourse management tools (Manthey \& Brewe, 2013). These discourse management tools include small-group collaboration, entire-class discussion, intentional lack of inquiry closure, seeding (Desbien, 2002), and Socratic questioning, which is used during students' whiteboard presentations. Seeding refers to introducing a new concept/question to a group for them to construct their own idea and interpretation about the concept/question and then present to the entire class (Durden, Brewe, \& Kramer, 2011). Because the idea is presented by students rather than the instructor, it is easier to generate an in-class discussion within students, which eventually leads to solutions developed by students. According to Schwarz and Passmore (2012), a scientific model must be developed to explain and predict natural phenomena, and 
help answer how and/or why a natural phenomenon happens. From the MI perspective, teaching practice should be designed and organized to engage students with specific scientific topics by developing, applying, and assessing models in real-life situations. With biology MI methods, the instructor should encourage and direct students to design, build, and evaluate scientific models to predict and/or explain biological phenomena according to related concepts. The instructor should also guide students to use abstract models, including diagrams, maps, pictorial and graphical representations to demonstrate their data and findings to the class.

Through the process of instructional modeling, students conduct and replicate activities of real biological practices in classrooms so that the explicit nature of biological topics in curriculum can be integrated and delivered to students.

\subsection{Methods}

\subsubsection{Participants}

This study is a part of a dissertation project in evaluating the implementation of high school biology MI curriculum under a Biology-Chemistry-Physics sequence in south Florida. In order to meet and recruit biology MI teachers from local high schools, the primary researcher attended two-week-long high school biology MI workshops in the summers of 2015 and 2016. After talking with all teachers in the workshops and collecting their background information with a short teacher survey, I recruited two high school biology MI teachers from the workshop in the summer of 2016 based on their willingness and criteria from the short survey data, including the 
likelihood of using MI in Biology I course in the following academic year, and their self-efficacy in applying biology MI in their classes. Then the two MI teachers were asked to introduce two non-MI biology teachers in their own school, who were going to teach the same level of biology course (Biology I) as the two MI biology teachers would, to minimize potential differences between MI and non-MI teachers caused by school characteristics, and to make the biology MI and non-MI teachers within the same boundary for this case study. After talking with all participating teachers and carefully considering their potential capabilities to optimally teach Biology I, with either MI or non-MI methods, in their own classes, I selected one MI and one non-MI biology teachers in the same high school to collect qualitative data on their teaching practice. Furthermore, I asked each MI and non-MI teacher in this school to recommend one optimal class of their own, according to students' grades in the most recent biology exam and the teacher's perception of students' performance, to collect qualitative data through in-class observation and student interviews. Quantitative data were collected in eight Biology I classes of all four participating teachers, two classes from each teacher, with the Biology Identity and Persistence Survey (BIPS).

The school, where I collected both quantitative and qualitative data, was opened less than one decade ago with total enrollment of over 1500 students, including about 35\% White non-Hispanic, 33\% Hispanic of any race, 32\% Black/African American, and less than 1\% other races. The other participating high 
school, where I collected only quantitative data, was an urban school serving a low-income population in a historically Black neighborhood with total enrollment of about 1000 students, including about 91\% Black/African American, 8\% Hispanic of any race, and $1 \%$ White non-Hispanic.

The MI biology teacher in the first school was Amy (pseudonym), who was a female Hispanic science teacher. She had a master's degree in education and had had ten years of school teaching experience. She had one-year experience with modeling methods in teaching chemistry before participating in this study, and had taught biology in high school for four years. The non-MI biology teacher in the same school was Mia (pseudonym), who was a female Hispanic science teacher. She earned a bachelor's degree in a Spanish-speaking country. The MI biology teacher in the second school was Bill (pseudonym), who was a male White science teacher. He had a Ph.D. in biology and one-year experience in teaching high school biology before participating in this study. He had no classroom experience with MI in science teaching practice before participating in this study. The non-MI biology teacher in the same school was Grace (pseudonym), who was a female Hispanic science teacher. Both MI biology instructors attended a high school biology MI workshop in the summer of 2016.

\subsubsection{Comparative Case Study}

This study aimed to evaluate MI (vs. non-MI) in high school Biology I classes in south Florida, and answer how and/or why the targeted students' learning 
outcomes, biology/evolution identity development and shifts of career aspirations, happened in both MI and non-MI classes. In this sense, case study is typically advantaged in answering the "how" and/or "why" questions (Yin, 2014). It was also argued by Merriam (1998) that case study could be the best strategy when “investigating complex social units consisting of multiple variables of potential importance in understanding the phenomenon" (p. 41). With respect to the purpose of evaluating high school biology MI as an educational intervention in this study, Reichardt and Cook (1979) argued that case study is an especially appropriate design because of its function in "describing the context and population of the study, discovering the extent to which the treatment or program has been implemented, providing immediate feedback of a formative type, and the like" and "discovering or confirming the process by which the treatment had the effect that it did" (p. 21). I employed a comparative case study approach in this study in order to not only provide rich description of each single case but also decipher the relation between cases to answer such question as why a phenomenon happened in one class different (or not different) than in another. A comparative case study with variation across cases can provide compelling interpretation, help understand how, where, and why a phenomenon happens in a single case, and enhance the precision, validity, and stability of research findings (Merriam, 1998). To minimize the impact of the researcher's bias in this study, I employed multiple data sources to increase the reliability and validity. 


\subsubsection{Quantitative Analyses}

The BIPS was administered at the beginning and the end of the teaching period of evolution in all eight participating Biology I classes to statistically assess students' biology identities, evolution identities, and career aspirations across MI and non-MI classes. The BIPS is a research instrument developed by Li and Hazari (2017) for collecting data about biology identities, evolution identities, and aspirations in biology-related or non-biology-related careers.

The data collected with the BIPS were employed to provide statistical evidence about students' biology/evolution identities across MI and non-MI classes. Biology/evolution identity was conceptually constructed with four components: recognition, competence, performance, and interest in biology/evolution (Carlone \& Johnson, 2007; Hazari et al., 2010). Because competence and performance items were demonstrated statistically loading as one construct in factor analysis (Cass et al., 2011; Godwin et al., 2013; Hazari et al., 2010), I developed the biology/evolution identity proxy combining three components or sub-constructs: recognition, competence/performance, and interest in biology/evolution. To gauge students' biology/evolution identity development and career aspiration shift, I first conducted paired-sample t-test to compare students' biology identity proxies, evolution identity proxies, and career aspirations in the pre- and post-test of the BIPS at the beginning and the end of evolution teaching sessions. The biology recognition indicator was assessed with the average of four items in the BIPS 
(pre-test as the co-variable and post-test as the outcome) collected from sample students reporting their extent of agreement with "I see myself as a biology person," "My family sees me as a biology person," "My friends/classmates see me as a biology person," and "My biology teachers see me as a biology person" on a five-point Likert scale with each from "0-Not at all" to "4-Very much so." Two items in the BIPS were averaged for the evolution recognition indicator, which reported students' extent of agreement with "I see myself as an advocate for evolution" and "Evolution fits in how I see the world" each on the same Likert scale. I averaged six items in the BIPS for the biology competence/performance indicator reporting students' extent of agreement with "I am confident that I can understand biology in class," "I am confident that I can understand biology outside of class," "I can do well on exams in biology," "I understand concepts I have studied in biology," "I can overcome setbacks in biology," and "Others ask me for help in biology" each on the same Likert scale. I averaged four items in the BIPS for the evolution competence/performance indicator reporting students' extent of agreement with "I am confident that I can understand evolution in class," "I am confident that I can understand evolution outside of class," "I can do well on exams in evolution," and "I understand concepts I have studied in evolution" each on the same Likert scale. The biology/evolution interest indicator was assessed by averaging three items in the BIPS reporting students' extent agreement with "I am interested in learning more about biology/evolution," "Topics in biology/evolution excite my curiosity," and "I 
enjoy learning about biology/evolution" each on the same Likert scale. I gauged the biology/evolution identity proxy by averaging the three sub-constructs (recognition, competence/performance, and interest in biology/evolution) each on a five-point Likert scale.

I employed paired-sample t-tests to gauge whether students had significant gain of biology identities, evolution identities, and career aspirations in various fields in MI and non-MI classes. Then I employed linear regression to examine whether taking evolution class sessions in either MI or non-MI classes can predict students' biology identities, evolution identities, and career aspirations in various fields by controlling students' prior biology identities, evolution identities, and career aspirations at the beginning of evolution class sessions and students' demographic information as covariances.

I conducted multiple linear regression analyses about students' biology identities and evolution identities with class type (MI or non-MI) as the predictor, biology/evolution identity proxy as the outcome, and prior biology/evolution identity and some demographic background information as controlled covariates that might also affect students' biology/evolution identities. The reason to control these covariates is to control the potential effect of these variables on students' biology/evolution identities so as to fairly compare across MI and non-MI classes. The covariates in the initial biology/evolution identity linear regression models included: 1) students' biology/evolution identity indicators in the pre-test of the 
BIPS before learning evolution in their classes (constructed with items about students' recognition, competence, performance, and interest in biology/evolution, the same as those in the post-test, which were used as outcomes);2) students' perceived extent of home environment supporting for science (an item on a five-point Likert scale from "not at all" to "very much so"); 3) the total and the highest of female and male parents'/guardians' highest level of education (HLE: less than high school diploma, high school diploma/GED, associate degree, bachelor's degree, graduate/professional degree, or N/A) as an indicator of socioeconomic status (if either mother's or father's HLE was missing, the total and highest of parents'/guardians' HLE was set to missing; if both mother's and father's HLE were N/A, the total and highest of parents'/guardians' HLE was set to missing; if either mother's or father's HLE was N/A, the total and highest of parents'/guardians' HLE was set to the value of the other variable); 4) primary spoken language in household (English or non-English); 5) students' grade levels (ninth grade, tenth grade, eleventh grade, and twelfth grade); and 6) other demographic information such as gender (female or male), ethnicity (Hispanic or non-Hispanic), and race (dummy variable for White/Caucasian, Black/African American, Asian, American Indian, Pacific Islander, or other). The first controlled co-variable was to control for students' initial biology identities, evolution identities, and career aspirations at the beginning of the data collection period, which might have significant influence on students' biology identities, evolution identities, and career aspirations as the 
outcomes at the end of the data collection period. The second controlled for students' home environment in supporting science, which might have significant influence on students' science attitudes (Breakwell \& Beardsell, 1992; Hazari et al., 2010; Papanastasiou, 2002). The third controlled for parental education as an indicator of students' household socioeconomic status, which is another potential influential factor on students' science attitudes (Hazari et al., 2010; Papanastasiou, 2002). The fourth controlled for students' primary speaking language because some students were English Language Learners (ELLs; i.e., students may have higher level of engagement and participation in learning biology in class if their primary speaking language is English). The fifth controlled for students' standing in high school (most of the students were tenth graders; a few of the students were of other grades). The sixth controlled for students' demographic background such as gender, ethnicity, and race in case potential group differences exists.

With the BIPS data, I also statistically examined the connection between course type (MI vs. non-MI) and students' career aspirations in biology-related fields and non-biology-related fields. Students' career aspirations were evaluated by seven items, each on an eleven-point Likert scale from " 0 -Not at all likely" to "10-Very likely," about the likelihood of they choosing a career as a medical professional, health professional, biologist, earth/environmental scientist, or in other biology-related filed, other science-related field, or non-science-related field. I employed a regression model to predict students' career aspirations in each listed 
field after taking the evolution class sessions with class type (MI or non-MI) as potential predictor by controlling for students' initial career aspirations at the beginning of the evolution class sessions, home environment supporting for science, parental education level, household primary spoken language, grade level, and demographic information such as gender, ethnicity, and race.

\subsubsection{Qualitative Analyses}

After discussing with Amy (MI biology instructor) and Mia (non-MI biology instructor in the same school), I selected one optimal class from Amy's MI Biology I classes and one optimal class from Mia’s non-MI Biology I classes for collecting qualitative data including in-class observation and semi-structured interviews with students. Due to the interruption of a higher standard test, scheduled earlier release, and teaching of other topics, Amy spent nine class sessions to complete teaching evolution, while Mia spent four class session to complete teaching evolution. The actual time they spent in teaching evolution was about ten class hours in the MI class and five and a half class hours in the non-MI class. The primary researcher observed all class sessions of evolution in both MI and non-MI Biology I classes, during which he employed video-recording and field notes to collect observational data. Five students from the MI class and four students from the non-MI class were interviewed respectively about their experiences in learning biology/evolution, and their perceptions of their biology instructors' teaching practices after the instruction of evolution had completed. Interview participants were selected based on their 
willingness, which is a limitation of the study. The primary researcher interviewed each participating student 15 to 30 minutes after class in their school. All interviews were audio-recorded.

The interview data were transcribed for further analysis. The video data were viewed and interview transcripts and field notes were read several times to identify themes of differences in students' biology/evolution identities across the MI and non-MI Biology I classes. Students' narrated identities were identified through interview data and quantitative data collected with the BIPS. Students' performed identities were identified through observational data as supplement to their narrated identities, which they did not perceive and could not tell. I coded both performed identities (e.g., answering questions, taking the lead in group work, talking to others about biology/evolution, applying effort to problem solving, helping others in problem solving) and narrated identities (e.g., expressing interest in biology/evolution, being confident in learning/completing tasks in biology/evolution, feeling of recognition by others and/or her/himself). I also observed and identified instructors' teaching practice, including in-class activities and discourse management, as another emergent theme of differences across MI and non-MI classes. Based on in-class observation and student interview data, an emerging theme was noticed, which led to the emerging hypothesis that the instructors' teaching practices were related to students' identities with biology/evolution. The interview protocol was developed after coding some observational data so that 
relevant questions, according to emerging themes, could be asked in the interviews to collect data as reflections of themes coded from observational data. The coded themes from instructors' in-class activities and discourse management tools in both MI and non-MI classes were then compared to high school MI materials (American Modeling Teachers Association, 2016) and discourse management tools suggested for MI courses to help understand students' biology/evolution identity development and shifts of career aspirations across MI and non-MI classes. With a constant comparative approach (Sherman \& Webb, 1988; Strauss \& Corbin, 1990), I compared emerging themes to understand the differences across the MI and non-MI classes as well as with suggested MI curriculum.

\subsection{Results}

\subsubsection{Students' Biology/Evolution Identities}

Students' biology/evolution identities were examined in two forms. One is narrated identity and the other is performed identity. Students' narrated biology/evolution identities were assessed based on quantitative data collected with the BIPS and detected through qualitative data collected in student interviews. Students' performed biology/evolution identities were discerned by analyzing interview transcription and observational video and notes.

I present detailed examples of these narrated and performed biology/evolution identity indicators detected in both the MI and non-MI classes through in-class observation and student interviews. All evidence of students' biology/evolution 
identities were presented and employed for comparing the MI and non-MI classes

rather than describing both MI and non-MI classes one at a time. In Table 7, I

summarized the differences of students' biology/evolution identity indicators

between the MI and non-MI instructors for easy comparison.

\begin{tabular}{lcc}
\hline \multicolumn{3}{l}{ Table 7. Students' Biology/Evolution Identity Indicators in MI and non-MI classes } \\
\hline Identity Indicators & Ms. Amy (MI) & Ms. Mia (non-MI) \\
\hline Narrated Identity & + & + \\
Expressing interest & + & $\mathrm{n}$ \\
Being confident & + & + \\
Feeling of recognition & & \\
Performed Identity & ++ & + \\
Answering questions & + & $\mathrm{n}$ \\
Applying effort & + & $\mathrm{n}$ \\
Taking the lead & + & $\mathrm{n}$ \\
Helping others & ++ & + \\
Being praised & + & $\mathrm{n}$ \\
Talking to others & + & \\
\hline
\end{tabular}

n: none or little; +: very a few isolated instances; ++: several repeated instances

\subsubsection{Students' Narrated Biology/Evolution Identities}

I first conducted paired-sample t-test to evaluate whether there was any

difference between the pre- and post-test in students' biology identities and

evolution identities in both MI and non-MI classes. I present details about students'

biology/evolution identities in Figure 1 with bar charts representing the raw means

of students' biology/evolution identities. It is indicated in Figure 1 that the only

significant identity difference discovered between the pre- and post-test was the

positive evolution identity development of students in the non-MI classes $(t=2.255$,

$\mathrm{p}<0.05)$. There were no significant differences between the pre- and post-test in

non-MI students' biology identities $(\mathrm{t}=0.282, \mathrm{p}>0.05)$, MI students' biology 
identities ( $\mathrm{t}=-0.097, \mathrm{p}>0.05)$, and MI students' evolution identities $(\mathrm{t}=0.744$, $\mathrm{p}>0.05)$. To further examine sub-constructs of biology/evolution identities, there were no significant differences between the pre- and post-test in MI students' biology recognition $(t=0.080, p>0.05)$, biology competence/performance $(t=-0.765, p>0.05)$, biology interest $(t=0.069, p>0.05)$, evolution recognition $(t=0.638, p>0.05)$, evolution competence/performance $(t=0.594, p>0.05)$, evolution interest $(\mathrm{t}=0.112, \mathrm{p}>0.05)$, and non-MI students' biology recognition $(t=1.261, p>0.05)$, biology competence/performance $(t=-0.924, p>0.05)$, biology interest $(\mathrm{t}=-0.210, \mathrm{p}>0.05)$, evolution recognition $(\mathrm{t}=0.911, \mathrm{p}>0.05)$, evolution competence/performance $(t=1.241, p>0.05)$, evolution interest $(t=1.673, p>0.05)$.

Table 8. Regressions predicting students' biology/evolution identities by class type with controls

\begin{tabular}{|c|c|c|c|c|c|c|}
\hline \multirow[b]{2}{*}{ Predictor } & \multicolumn{3}{|c|}{ Biology Identity } & \multicolumn{3}{|c|}{ Evolution Identity } \\
\hline & $\mathrm{B}$ & $\mathrm{SE}$ & $\mathrm{t}$ & $\mathrm{B}$ & SE & $\mathrm{t}$ \\
\hline Intercept & -0.968 & 0.854 & -1.133 & -0.187 & 1.093 & -0.171 \\
\hline $\begin{array}{c}\text { Pre-test Bio/Evo } \\
\text { Identity }^{\mathrm{a}}\end{array}$ & 0.872 & 0.088 & $9.879^{* * *}$ & 0.715 & 0.109 & $6.535^{* * *}$ \\
\hline Class Type (MI/non-MI) & 0.020 & 0.148 & 0.132 & 0.054 & 0.189 & 0.286 \\
\hline Adjusted $\mathrm{R}^{2}$ & 0.542 & & & 0.378 & & \\
\hline $\begin{array}{l}{ }^{* * *} \mathrm{p}<0.001 \\
\text { aThe only significant col }\end{array}$ & & & & & & \\
\hline
\end{tabular}

I conducted multiple linear regression to examine the predictive power of class curriculum (MI vs non-MI) along with some other potential covariances on students' biology identities or evolution identities. From statistically analyzing the quantitative data collected with the BIPS in all four MI and four non-MI classes in the pre- and post-test, students' narrated biology and evolution identities were 
gauged and compared between the MI and non-MI classes. The linear regression results were presented in Table 8. By comparing students' biology and evolution identity development in both MI and non-MI classes, no significant difference was found. The regression results about predicting sub-constructs of students biology/evolution identities by class type also indicated that there weren't any significant differences between MI and non-MI classes on predicting students' biology recognition $(t=0.712, p>0.05)$, biology competence/performance $(t=0.679$, $\mathrm{p}>0.05)$, biology interest $(\mathrm{t}=-1.040, \mathrm{p}>0.05)$, evolution recognition $(\mathrm{t}=-0.362$, $\mathrm{p}>0.05)$, evolution competence/performance $(\mathrm{t}=-0.136, \mathrm{p}>0.05)$, and evolution interest $(\mathrm{t}=-0.224, \mathrm{p}>0.05)$.

Figure 1. Students' Biology and Evolution Identities in Pre- and Post-test

\section{Biology and Evolution Identity}

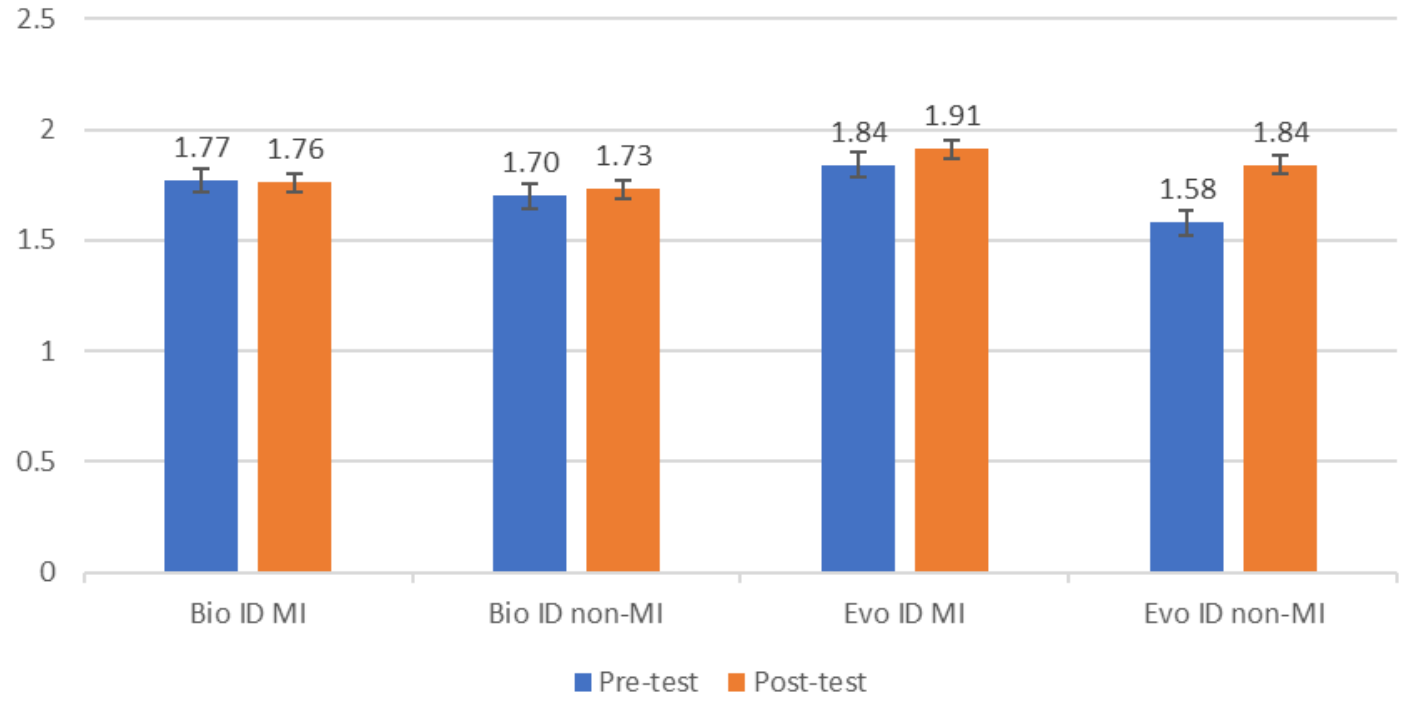

To deeper explore students' narrated biology/evolution identity, I qualitatively analyzed data from student interviews and discovered three categories of indicators 
of narrated biology/evolution identities through coding interview transcription. The narrated biology/evolution identity indicators that I discovered were:

- expressing interest in learning biology/evolution: stating that one was interested in learning biology/evolution (the indicator of interest: demonstrating one's desire to understand biology/evolution).

- being confident in understanding biology/evolution and completing tasks in biology/evolution: expressing that one could understand biology/evolution and complete specific biology/evolution tasks (the indicator of performance: demonstrating one's belief in the ability to complete specific biology/evolution tasks, and the indicator of competence: demonstrating one's belief in the ability to understand biology/evolution).

- feeling of recognition by others: mentioning that other students asked for help from her/him (the indicator of recognition: demonstrating recognition by others as being good at biology/evolution).

Expressing Interest in Learning Biology/Evolution. This narrated biology/evolution identity indicator refers to students' interest, as one component of biology/evolution identity, in learning biology/evolution. I demonstrated students' interest in learning biology and/or evolution mainly through their verbal expression during interviews.

Eva (White Hispanic female $10^{\text {th }}$ grader), in Ms. Amy's MI class, expressed her interest in biology at the end of the interview: 
"I like biology. It catches a lot of my attention. We're always learning something new. It's not something that we (have) already known and we're just learning a little bit more about it. It's about life. It gives you detail about life. You learn about it."

She stated that she was interested in and attracted by biology because it is new to her. When it came to evolution, she explained: "Evolution, I little like it. It doesn't attract me that much as biology but I like it." It indicated that Eva was a little bit interested in evolution but not as interested as in biology in general. Another student in Ms. Amy's MI class, Noah (White Hispanic male $10^{\text {th }}$ grader ELL), expressed his interest in biology as well by saying that "it's just exciting, I mean, all the labs we're doing." He declared that he liked learning biology by engaging in hands-on activities. When being asked about whether he was more or less interested in biology or stayed the same, compared to his interest in biology at the beginning of the semester, Noah said that "Yeah, I'm interested." He further explained that "I wasn't prepared for this class in the beginning, but then she (Ms. Amy) did everything for me to learn even more." He affirmed his positive gain of interest in learning biology in this MI class.

During my interview with Norman (White non-Hispanic male $10^{\text {th }}$ grader), the student in Ms. Mia's non-MI class, he expressed his strong interest in biology and evolution: 
"I think what I like the most is just like learning about the different life forms and how they all come from one common ancestor. I find that to be very interesting... Because it's very cool to think that everything that alive nowadays could have possibly come from one organism...Yeah, that knowledge is very interesting to me."

He specifically illustrated his strong interest in evolution with detailed reasons, which also suggested his advocacy of evolution. Carl (White Hispanic male $10^{\text {th }}$ grader), another student in Ms. Mia's non-MI class, expressed his interest in learning biology, particularly evolution and classification, as well:

"I like so much the things that we see, like, classification...I like that so much. It's so interesting about how natural selection, classification, evolution...I love it. I like it so much."

However, students' expressions about interest in biology and/or evolution were superficial without enough further supportive details, so I am conservative about their extent of interest in biology and/or evolution.

In comparison, both MI and non-MI classes had some students (Eva and Noah in the MI class; Norman and Carl in the non-MI class) expressing interest in biology/evolution and some students (Sara, Mark, and Anna in the MI class; Adam and John in the non-MI class) not expressing interest in biology/evolution. Noah in the MI class expressed the improvement in his interest in biology; while no interviewee in the non-MI class explicitly declared positive gain of interest in 
biology. In terms of interviewees' specific interest in evolution, Eva in the MI class expressed her interest in evolution with reservations; while Norman and Carl in the non-MI class expressed interests in evolution. However, all interviewees' expressions about interest in biology and/or evolution were superficial, which, therefore, was not convincing.

Being confident in understanding biology/evolution and completing tasks in biology/evolution. This narrated biology/evolution indicator suggested students' competence and performance, as the components of biology/evolution identity, in learning biology/evolution. I demonstrated students' confidence in understanding biology/evolution and completing biology/evolution tasks mainly through their verbal expression during interviews.

Mark (White non-Hispanic male 10th grader ELL), in the MI class, expressed and explained the positive gain in his confidence in learning biology:

"At the beginning, I was kind of lost. Not lost, but I wasn't sure of what I was doing...but then I went to learn what it means and how you can use it to do other stuff, then you feel confident and you know what to do."

This indicated his positive gain of confidence in learning biology, which could contribute to his biology identity development.

Mark was the only interviewee declaring confidence, particularly positive gain of confidence, in learning biology/evolution in the MI class. No interviewee from 
the non-MI class mentioned confidence, let alone gain of confidence, in learning biology/evolution.

Feeling of recognition by others. Students' feeling of recognition means that they are recognized by others as being good at biology/evolution. I illustrated this indicator primarily through one's verbal expression, during interview, of other students asking her/him for help to solve biology/evolution problems.

Adam (White non-Hispanic male $10^{\text {th }}$ grader), in the non-MI class, mentioned that "they (other students) ask you for work...they ask you to do all the work for them...they come up to you and start asking you." He perceived that other students recognized him as a good student in biology and asked him to solve problems and complete tasks for them. However, he also declared that "they (other students) never work... and it distracts you a lot." His complaint suggested that, according to Adam's perception, he did not like to answer questions from other students or do others' jobs.

Adam was the only interviewee mentioning about being asked for help from other students. No interviewees from the MI class mentioned anything about recognition by other students or the instructor as being good at biology/evolution. Even though Adam mentioned being asked for help but he did not perceive recognition by others as a positive factor on his biology/evolution learning, which was in contrast with the science identify conceptual framework employed in this study. Therefore, this contrast suggested that recognition as one component of 
science identity development is context-based, which means people may perceive recognition by others differently (either positively or negatively) in different context.

Summary. No much narrated science identity components were detected in this study. Some interviewees made statements of interest in biology and/or evolution; however, since their statements were all superficial, I was not convinced by their statements. The one who mentioned recognition did not appreciate recognition by others and was even annoyed by the recognition. There was only one interviewee said something about confidence in learning biology/evolution, which was not mentioned by any other interviewees. In general, very limited statements about positive science identity components were detected, most of which were either not convincing or even negatively influential. I did not identify much narrated positive science identity indicators based on our data.

\subsubsection{Students'Performed Biology/Evolution Identities}

From viewing the videos several times, and coding the class notes and interview transcriptions, I also discovered six categories of indicators of performed biology/evolution identities in both MI and non-MI classes, which were:

- Answering questions: actively answering questions from the instructor (the indicator of competence: demonstrating one's belief in one's ability in understanding biology/evolution content).

- Applying effort to problem solving: putting effort to solve problems and complete assigned tasks, particularly when having questions and/or having 
no support from peers in group work (the indicator of performance:

demonstrating one's belief in one's ability to complete specific

biology/evolution tasks).

- Taking the lead in group work: leading and managing the group in in-class activities to complete tasks, and/or assigning specific roles to other group members (the indicator of performance: demonstrating one's belief in one's ability to complete specific biology/evolution tasks).

- Helping others in problem solving: responding to questions from other students, and/or actively helping other students to complete tasks (the indicator of recognition and performance: demonstrating recognition by others as being good at biology/evolution and one's belief in one's ability to complete specific biology/evolution tasks).

- Being praised by the instructor for achievements in learning biology/evolution: being praised by the instructor for completing biology/evolution tasks, and/or correctly answering biology/evolution questions (the indicator of recognition: demonstrating one's recognition by the instructor as being good at biology/evolution).

- Talking to others about biology/evolution: talking about topics related to biology/evolution, and/or explaining biology/evolution topics to others (the indicator of interest and competence: demonstrating one's desire to think 
about and understand biology/evolution and belief in one's ability to understand biology/evolution content).

Answering questions. Answering the instructor's questions suggested students' confidence in their knowledge in biology/evolution, which reflected students' competence as one component of biology/evolution identity. I demonstrated students' competence through coding students' performance from the videos recorded in class, notes taken during in-class observation, and students' description of their performance in class in interviews.

In many cases, some MI students actively answered questions from the instructor, raising or without raising hands. In a few cases when no one actively answered the instructor's questions, she rephrased the question and/or provided some clues to help students think and find the answers. When sometimes she appointed a student to answer, in very few cases, the appointed student did not answer her questions, and in most other cases, the appointed students answered her questions passively though.

In most cases, non-MI students did not actively answer the instructor's questions, even not paying attention to her questions in some cases. Therefore, she had to repeat, not rephrase, the questions louder and slower to attract students' attention, which worked in most cases and could get some students to passively answer her questions. 
In comparison, the MI instructor asked students more questions than the non-MI instructor did. MI students were more active in answering questions from their instructor than their counterparts did in the non-MI class.

Applying effort to problem solving. Applying efforts to problem solving indicated students' confidence in their abilities to complete biology/evolution tasks by themselves, even without assistance and/or support from peer group members. I detected this performed biology/evolution indicator from students' expression of their performance in class during interviews as well as through coding students' performance from videos recorded and notes taken during in-class observation.

Some MI students tended to ask the instructor for help whenever they had questions in completing the tasks. In most cases, the instructor replied to students promptly with more details or further explanation. However, in a few cases, the instructor just asked the student to try her/his best to find the answers. Eva explained her strategies when not getting meaningful assistance from the instructor for her questions: "It's fine. I guess she wants me to just see what I think or what I know about it. So, it doesn't bother me. It's just, 'Okay, I'll try my best'” Then she further explained the strategies that she employed to find the answers

"With keywords. Looking for keywords that can help me...Keywords in the question. Like some words that have to do with the question so that helps me find my answer...if I don't know the answer to it, I just 
re-read the question and what they're most, what they're asking me for. So, that's how I try my best."

Lack of collaborations from peer group members was another challenge some MI students encountered during group activities. Not all students were engaged in group activities. Some students just passively did tasks assigned by the group "leader" or active group members, and a few students did not participate at all. In these cases, active group members would have to put efforts to do most or even almost all work to complete group tasks. There were usually one or two students in each group taking the lead to apply efforts in completing group tasks. When her peer group members not only did not participate but also had "destructive behavior," which made it "kind of hard to concentrate," Eva explained her strategy as "It's fine. I mean, I don't really have a problem with them...I try my best to like and then just work with them...it's my grade so I try my best for it...I just try my best and I tell them what to do...I'm gonna do my job."

She mentioned several times that, no matter how distracting the class environment was and whether her peer group members did their jobs or not, she would do her best to complete the tasks. There was one and only one group in the MI class that almost all group members were engaged and participating in every group activity. Almost all group members in this group played their roles and put efforts in completing every group task. Students in this group discussed about their tasks, took 
active roles to work on a specific task assigned to each one of them, and helped a group member to put their data and related information on the whiteboard.

In the non-MI class, except students in the first row adjacent to the front desk, very few students asked the instructor questions when they did in-class activities. In many cases, when in trouble to complete the tasks, many students tended to ask neighbors for help. However, due to the lack of supportive environment, usually no students helped others. Therefore, most of those in trouble then just stopped working and then chatted with neighbors, played with smartphones, or just did something off-task. When realizing this situation, the instructor would ask for attention from students and try to explain the activity again more explicitly, but usually it did not work very well.

In comparison, MI students applied more efforts than their counterparts in the non-MI class in completing in-class activities. When getting in trouble or having questions, many MI students, first tended to ask for help from their instructor; while less non-MI student tried to find assistance from the instructor. Some MI students asked for help from peer group members, usually the group "leader," and the "leader" usually helped other group members to complete the tasks, no matter willingly or not. Fewer non-MI students asked classmates for help even when they were struggling to complete the tasks. Even if peer group members were not collaborative and supportive in completing group tasks, at least one or two students in each group in the MI class still put efforts to complete the tasks; while fewer 
non-MI students put efforts in completing the tasks. Instead, many non-MI students just waited for the instructor to provide more assistance without actively asking for help, which suggested not only their low confidence in complete biology/evolution tasks but also their low interest to understand more about biology/evolution.

Talking to others about biology/evolution, helping others in problem solving, and taking the lead in group work. This performed biology/evolution identity indicator referred to students' confidence in their abilities to understand biology/evolution, solve biology/evolution problems, and help others complete biology/evolution tasks. I demonstrated this indicator through coding students' performance in class from videos and observational notes; it was also identified from students' expression about their performance in interviews.

Group work was the basic structure of MI class when implementing activities. In this study, about two thirds of in-class activities in the MI class were group activities. In the MI class, students were allowed to freely form their own group of four or five students by sitting at the same desk at the beginning of each class session. During class, the instructor occasionally re-arranged groups by asking some students to move to another desk. In most cases, two or three active students in each group were engaged in group activities and actively put efforts toward completing group tasks. However, those active students did not necessarily always lead the group. In some cases, they did lead the group by explaining the activities to other group members, assigning specific roles to each group member, and leading 
discussion about some problems. In other cases, because other group members were not engaged or not participating at all, those active members had to find some ways to engage other group members. For example, Anna (White non-Hispanic female $10^{\text {th }}$ grader), in the MI class, said that, in order to engage her group members, "I would give them simple things, like, 'Can you cut this out?' 'Can you color this?'” If other group members were still not engaged, the active members had to complete all work by themselves, just like Anna said that "If they still didn't do it, I'm just like okay. I guess I'll do it.” There was only one out of five or six groups that almost all group members were engaged in group activities in most cases with one or two students working as group leaders, and helped each other in problem solving by discussing about tasks and solutions, providing suggestions, and helping others answer questions during whiteboard presentation. Especially for leading a group with ELLs, Sara (White Hispanic female $10^{\text {th }}$ grader) described what she did "Especially in my group, I always try...since I am a bilingual. I always try to tell them (ELLs) what's happening and get them to know what we were doing, not just sitting in the corner not doing anything and not knowing anything."

Only one of my non-MI interviewees, Norman, actively talked with neighbors about biology-evolution content. Since he always sat in the very first row adjacent to the instructor's desk, Norman sometimes even actively talked with the instructor about biology/evolution topics that the instructor just taught the whole class. 
Although group work was not purposely required by the non-MI instructor, some non-MI students in some cases still tried to form an informal group with neighbors to work on in-class activities. According to interviewees from the non-MI class, some students formed a group actively in order to obtain assistance from or even reply on others to complete specific tasks for them. For example, Adam mentioned that "They never work and then they ask you to do all the work for them...they come up to you and start asking you." Very few students in the non-MI class were willing to complete all the work of an activity for others. In some other cases, some students formed groups passively due to the class environment, in which students tended to talk with others nearby. John (White Hispanic male $10^{\text {th }}$ grader ELL) explained his experience and feeling in this class environment "It's a bit harder to concentrate, because you kind of have an urge to work or talk to another classmate like, 'I'll help you out'... There could be a group table, but then there's other students around me, but we have to work individually. It's kind of hard to not look over and look up while you work to avoid asking a question. Because you can't ... you're not supposed to be talking during individual work. It's meant to be all in your head or you could talk out loud. It depends on the teacher really. But for me, I just have a hard time focusing on my own when there's a lot of distractions." 
As a result, no matter how the group was formed by students actively or passively, very few promotive interactions existed and no group leaders were observed in the non-MI class.

In comparison, due to different requirements of the instructors, fewer groups were formed in the non-MI class than in the MI class, no matter whether the groups were formal or informal. Some MI students worked as group leaders by assigning jobs and helping others complete their tasks, but, in many cases, those group leaders had to do all the jobs and complete tasks for other group members. No group leader was identified in the non-MI class and much less promotive interactions existed in the non-MI class than in the MI class.

Being praised by the instructor. Students being praised by the instructor for achievements in learning biology/evolution and/or completing biology/evolution tasks is a meaningful indicator of recognition by the instructor. In our data analysis, this indicator was primarily detected from video viewing and in-class notes coding.

Both instructors of the MI and non-MI classes praised their students when they answered questions correctly. The MI instructor also praised students when they performed well on certain in-class activities, which was not observed in the non-MI class. The MI instructor usually praised her students more specifically according to what they had just achieved, not just saying such general words as "Good" or "Good job," which were used more by the non-MI instructor. For example, when seeing a group successfully put a specific dinosaur bone in the right spot, she announced with 
passion that "Oh my God. The only people put that bone in the right spot." And used body language to encourage other students to look it at. This way of praising explicitly and passionately recognized this group of students as completing a great job. The MI instructor was much more appealing than the non-MI instructor when praising students. In general, instructors' praises, especially specific and passionate praises, meaningfully recognize students' achievements, which contribute to students' biology/evolution identity development.

\subsubsection{Students' Career Aspirations}

Table 9. Regressions predicting students' career aspirations in all biology-related fields by class type with controls

\begin{tabular}{lccc}
\hline Predictor & $\mathrm{B}$ & $\mathrm{SE}$ & $\mathrm{t}$ \\
\hline Intercept & -4.804 & 13.532 & -0.355 \\
Pre-test Biology Career Aspiration ${ }^{\mathrm{a}}$ & 0.586 & 0.116 & $5.042^{* * * *}$ \\
Class Type (MI/non-MI) & -0.346 & 2.485 & -0.139 \\
Adjusted $\mathrm{R}^{2}$ & 0.206 & & \\
\hline${ }^{* * * *} \mathrm{p}<0.001$ & & & \\
${ }^{\mathrm{a}}$ The only significant control & & & \\
\hline
\end{tabular}

I statistically analyzed data collected with the BIPS in all four MI and four non-MI high school Biology I classes in south Florida in pre- and post-test to examine and compare students' career aspirations in MI and non-MI classes. The regression results of taking MI or non-MI evolution class sessions predicting students' career aspirations in biology-related fields were presented in Table 9. Students' career aspirations and their shifts in biology-related, other-science-related, and non-science-related fields are illustrated in Figure 2 and Figure 3 with bar charts representing the raw means of students' career aspirations. 
Figure 2. MI Students' Career Aspirations in Pre- and Post-test

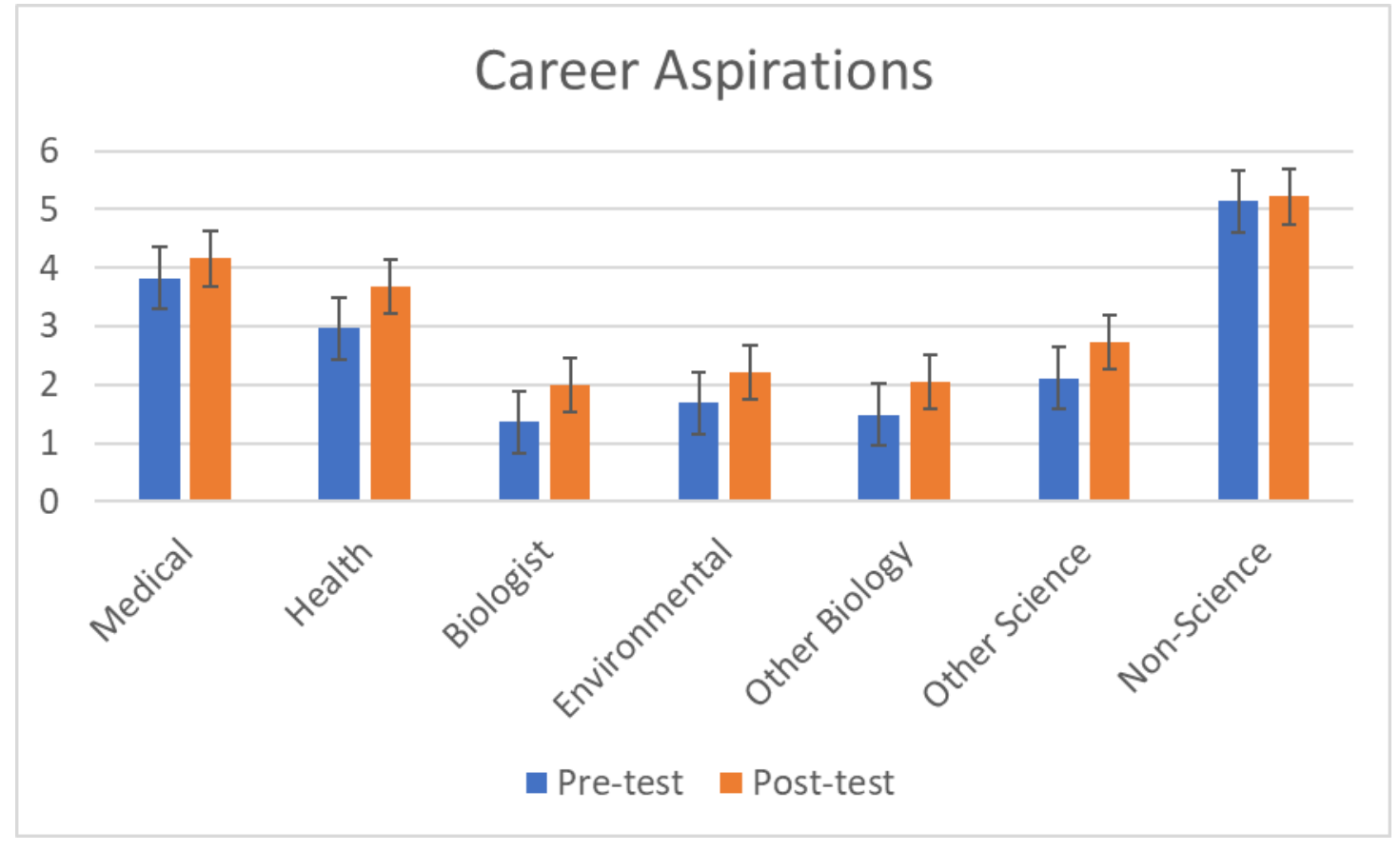

Figure 2 suggests that MI students gained significantly more aspirations in pursuing careers as a health professional or biologist during the class sessions of evolution. Figure 3. Non-MI Students' Career Aspirations in Pre- and Post-test

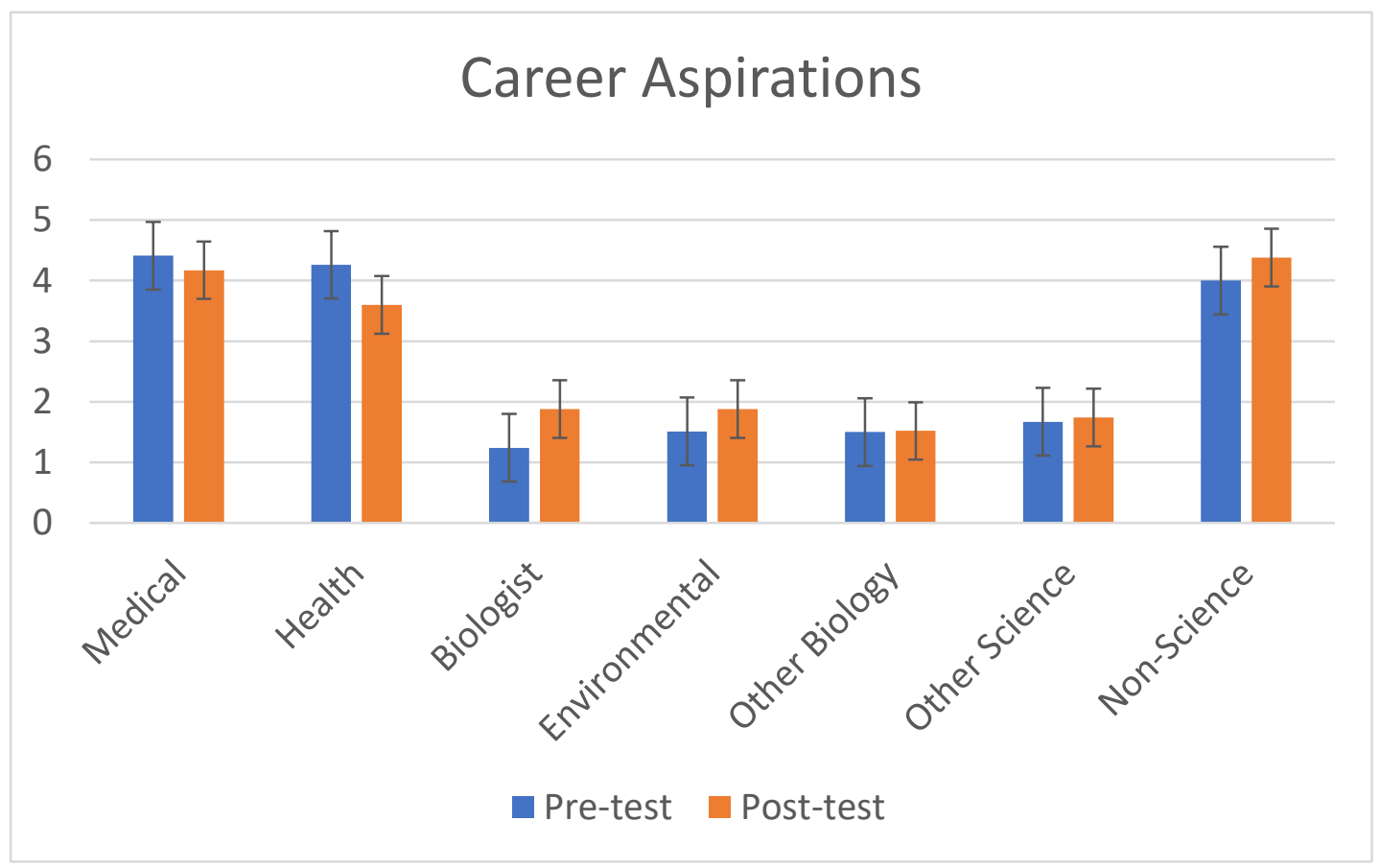


Figure 3 indicated that students in the non-MI class did not have any significant gains of career aspirations during the class sessions of evolution. However, students' gains of career aspirations in the fields of health professional or biologist in the MI class were still not significantly different than those in the non-MI class. In summary, no significant difference was found in students' gain of career aspirations in any fields between MI and non-MI classes.

\subsubsection{Students' Biology/Evolution Identities and Career Aspirations}

I employed Pearson's $r$ to statistically assess the correlation between students' biology identities and biology career aspirations, and between their evolution identities and biology career aspirations. I put results of students' aspirations in medical professions, health professions, biologists, earth/environmental scientists, and other biology-related fields together to create students' aspirations in all biology-related career. I analyzed data from both pre- and post-test. According to Table 10, students' biology career aspirations were significantly correlated with their biology identities in both pre- $(\mathrm{r}=0.223, \mathrm{p}<0.01)$ and post-test $(\mathrm{r}=0.507, \mathrm{p}<0.001)$; students' biology career aspirations were significantly correlated with their evolution identities in the post-test $(r=0.385, p<0.01)$ but not in the pre-test $(r=0.126$, $\mathrm{p}>0.05)$. The correlation between biology/evolution identity and biology career aspirations suggested that students' development in biology/evolution identity, particularly biology identity, could contribute to their likelihood to pursue a biology-related career. 
Table 10. Correlation of Students' Biology/Evolution Identities with Biology Career Aspirations

Pearson's r with Biology Career Aspirations

\begin{tabular}{lc}
\hline Pre-test & \\
Biology Identities & $0.223^{* *}$ \\
Evolution Identities & 0.126 \\
Post-test & \\
Biology Identities & $0.507^{* *}$ \\
Evolution Identities & $0.385^{* *}$ \\
\hline ** $\mathrm{p}<0.01$ & \\
\hline
\end{tabular}

\subsubsection{Implementation of MI Curriculum in Evolution}

Instructional materials employed. The MI instructor used her PowerPoint lecture and two articles to discuss with students about evidences of evolution and how those evidences support the theory of evolution. However, she did not employ student-centered and interactive activities about evidences of evolution suggested in high school biology MI instructional materials, which allow student to collaboratively work in groups to explore the theory of evolution. She employed Thirsty Bird simulation, an MI activity in which students used spoons, forks, knives, and pairs of straws to simulate different beaks of birds and explored how different beaks survived, based on their capabilities to take different kinds of food. However, due to the lack of MI activities used about evidence of evolution, it might be hard for students to understand and/or accept evolution.

The non-MI instructor also employed a modeling activity, in which students used red, orange, and yellow cards as beetles of different colors, determined the color of offspring according to six different combinations of parents in each generation based on given rules to simulate the process of genetic drift, and removed 
certain percentage of beetles with specific colors in each generation based on the preference of predators to beetles' colors to simulate the mechanism of natural selection. She used videos to explained evidences of evolution to students.

In comparison, the MI instructor failed to use MI activities with students to understand theory of evolution, which did not make difference with what the non-MI instructor did. Moreover, both the MI and non-MI instructors used modeling activities to help students explore natural selection as the mechanism of evolution. The failure of employing activities about evidence of evolution might make it hard for students to understand and/or accept evolution.

General description and comparison of teaching practices. Ms. Amy, the MI instructor, was very talkative and asked students a lot of questions in class. She walked around a lot in the classroom. In some cases, she asked the whole class a question. In some other cases, she just stood or sat by a table and asked a question to the student nearby during discussion with them. In Ms. Mia's non-MI class, the instructor stood behind the desk in the front of the classroom in most of time. She spoke slowly, particularly when speaking out the "key words."

According to the MTI and MDM. I deciphered and compared the observed MI and non-MI high school biology instructors' teaching practices according to the MTI and the MDM in order to evaluate the implementation of high school biology MI. Based on the MTI and the MDM, I coded the in-class observation and student 
interview data, and identified and compared the instructors' teaching practices in seven aspects, which were:

- Student-centered teaching: putting students in a critical role in constructing understanding from new content knowledge and prior experience (through allowing autonomy of students in learning and acknowledging students' voice).

- Student-student interactions: allowing students to interact with each other to construct the meaning of biology (through creating chance of interactive learning and encouraging group work).

- Small-group collaboration: encouraging a small group of students to work and learn together (through setting a group goal, assigning specific role to each group member, encouraging promotive interactions, allowing students to evaluate the work of the group and each individual as well).

- Whole-class discussion: encouraging the whole class to learn from others in discussion (through allowing students to discuss about a question and/or a topic, and question each other).

- Intentional lack of inquiry closure: leaving an inquiry open to students to explore more by themselves (through allowing students to further explore a concept inside and/or outside of class and then bring their new ideas to the class and construct their own understanding of the content knowledge). 
- Seeding: leaving a new concept to a group of students to learn by themselves (through allowing the group of students to design and conduct an investigation to explore around the concept and then present their findings and interpretations to the whole class).

- Socratic questioning: challenging students and probing deep thinking (through systematically opening up problems, revealing assumptions, and following logical implication of thought).

\begin{tabular}{lcc}
\hline \multicolumn{3}{l}{ Table 11. MI and non-MI Biology Instructors' Teaching Practices } \\
\hline Teaching Practices & Ms. Amy (MI) & Ms. Mia (non-MI) \\
\hline Student-centered teaching & ++ & $\mathrm{n}$ \\
Student-student interactions & + & $\mathrm{n}$ \\
Small-group collaboration & + & $\mathrm{n}$ \\
Whole-class discussion & + & $\mathrm{n}$ \\
Intentional lack of inquiry closure & $\mathrm{n}$ & $\mathrm{n}$ \\
Seeding & $\mathrm{n}$ & $\mathrm{n}$ \\
Socratic questioning & ++ & $\mathrm{n}$ \\
\hline
\end{tabular}
n: none or little; +: very a few isolated instances; ++: several repeated instances

I describe and present detailed examples of the MI and non-MI biology instructors' teaching practices identified through in-class observation and student interviews. The comparison of the MI and non-MI instructors' teaching practices was presented in Table 11. These evidences of instructors' teaching practices are presented and employed for comparing the MI and non-MI classes. I intend to decipher MI and non-MI instructors' teaching practices and connect the instructors' teaching practices with students' biology/evolution identity development.

Student-centered teaching. Brewe suggested, according to the MTI, that MI teachers should give students autonomy in classrooms to learn science, and 
articulated for the central role of students in learning science and constructing their own understanding of science (2008).

Ms. Amy, the MI instructor, usually provided students with autonomy in class activities. She usually explained an activity briefly to students and then allowed them to work together by themselves to complete the task. She encouraged students to discuss within group and work together on group activities. She particularly provided students with an open class environment so that students could freely move around and talk with others. However, sometimes some students were not participating in group activities and relied on other group member's work. In these cases, she would ask about those inactive students' task-completing progress and orally encourage them to collaborate with other group members. In a few cases, she even had to split a pair or group of off-task students by changing their groups. However, if she failed to involve inactive students in group activities with the strategies mentioned above, she did not have further effective strategies to promote students' participation in group activities. One possible reason for students' relatively low participation in group activities is that they were less-prepared and had low self-efficacy to complete group tasks, some of whom were even stressed out, and they were afraid of making mistakes in group activities. When students asked her questions, sometimes Ms. Amy gave direct answers but sometimes she just helped and encouraged students to find solutions by themselves. Sometimes, the MI instructor handed out an article for students to read and extract related content 
knowledge from the article by themselves. However, most students were not engaged in reading articles and did not answer related questions. Therefore, the MI instructor had to extract useful information and directly provide to her students. The situation was better when she showed videos to students, in which case students were more engaged and could relatively easily identify useful information from videos. Another remarkable example was the Thirsty Bird simulation (high school biology MI materials), in which the MI students used spoons, forks, knives, and pairs of straws to simulate different beaks of birds and explored how different beaks survived, based on their capabilities to take food, under natural selection. Students had the autonomy and were almost all engaged in this activity. However, many students still could not interpret the activity about how it relates to evolution and could not answer questions from the MI instructor.

Students had very little autonomy in Ms. Mia's non-MI class. Usually the instructor explained an activity to students and let them work on it individually. Then she stopped students after each step to explain the next step. She showed videos to students to help students understand a topic. She usually stopped a video whenever there was a concept that she would like to explain to students. Due to the distracting class environment, she used a lot of "shh" to draw attention of her students. She tended to take the control of the class to draw attention of her students. In comparison, the MI instructor provided students with more autonomy than the non-MI instructor did. The MI instructor tended to provide chances to students to 
explore and learn content knowledge by themselves although in some cases she had to take the control of the class in order to push the class and catch up with the pacing guide. The non-MI instructor tended to take the control of the class by explain every content knowledge by herself with details.

Student-student interactions and small-group collaboration. Student-student interaction is encouraged, according to MTI, in MI class to allow students to interact with peers and learn from each other through the interaction experiences. According to MDM, MI instructors are suggested to structure small groups in class and allow a group of students to sit and work close on their group activities. In collaborative leaning environments, students are encouraged to learn and work together by playing specific roles in each group activity, supporting other group members academically and personally, working as a group not individually, and evaluating works of the group and each other as well.

MI students were purposely required to form groups of four or five in the class to sit around the same desk. All MI activities that they did were developed intentionally for small-group collaboration. The MI instructor also asked students to do several non-MI activities, which were basically individual work. Only one group in the MI class did apply group collaborations. Student in this group assigned specific roles to each group member for each group activity. They discussed about each group activity, shared information with each other, and worked together to complete each group activity. In other groups in the MI class, usually one to three 
active group members tried to assign tasks to each group member for each group activity. In a few cases, some inactive group members passively did the jobs assigned by others, but, in most cases, those inactive group members worked on her/his assigned jobs without enough efforts or even did not work at all. In order to earn a good group grade, active group members would have to either push inactive group members to work step-by-step though passively or do all the work by themselves.

Very few meaningful student-student interactions were identified in the non-MI class. In most cases, the non-MI students interacted about off-topic things, which made the class very noisy and distracting to those who wanted to learn. Small-group collaboration was very rare in the non-MI class since the non-MI instructor usually did not require or encourage group collaboration and all but one in-class activities were individual work. The non-MI instructor employed one modeling activity about genetic drift and natural selection, which was the only group activity in the non-MI class and in which students used cards of three different colors as beetles of different colors. Students determined the color of offspring according to different combinations of parents in every generation based on given rules to simulate the process of genetic drift; students removed certain ratio of beetles with specific colors in every generation based on the preference of predators in terms of beetles' colors to simulate the mechanism of natural selection. Then she asked students to make group whiteboard and present as a group to the whole class their data, reasoning, and 
claims about how natural selection happens in the beetles' population. More meaningful student-student interactions and small-group collaborations were identified during this group activity in the non-MI class. Although the class structure of the non-MI class was similar to that of the MI class as students sitting around each desk, usually the non-MI instructor did not require students to work in a small group collaboratively. Instead, the non-MI instructor asked students to work individually in most activities. Some students tried to approach others to ask for help but very few of them got meaningful academic support from others. As Adam said

"They ask you for work. They never work and then they ask you to do all the work for them, and it distracts you a lot because they come up to you and start asking you."

He and most other students, who were asked for help, did not want to help others and only want to focus on their own tasks. As the results, very few meaningful collaborations were formed in the non-MI class, which were also not encouraged by the non-MI instructor.

In summary, MI students had more meaningful interactions than their counterparts in the non-MI class, particularly when MI students worked on their group activities. Small-group collaboration was encouraged in the MI class while not in the non-MI class. There were more small-group collaborations in the MI class than in the non-MI class. However, effective small-group collaboration in the MI class happened mostly in only one group and rarely in all other groups. 
Whiteboard presentation, whole-class discussion and Socratic questioning.

The MDM suggests MI instructors to encourage discussion about some topics among the whole class of students. Students are encouraged to discuss with and question others about a specific topic, and construct their own understanding of the topic through the whole-class discussion. Socratic questioning is one technique that instructors could employ to stimulate students thinking about a topic by opening up issues, following out students' logical implication of thought, and uncovering assumptions.

In this study, the MI instructor tried to lead whole-class discussion once during the group whiteboard presentation about evidence of evolution. However, during students' whiteboard presentation, not all group members actively participated in their group presentation. In most cases, only one or two members of a group orally presented their work and answered questions but other group members just stood in front of the class and did not talk or answer questions. The MI instructor did emphasize the accountability of all group member in oral presentation but, once one student took the initiative to talk, the instructor did not try to engage other group members in the oral presentation. After each group's whiteboard presentation, the instructor encouraged other students to ask questions for the group and allow the entire class to discuss around the group's work. The instructor also applied Socratic questioning during students' whiteboard presentation to stimulate their thinking about their work. Very few students in the MI class were engaged in whole-class 
discussion by negotiating with peers and discussing issues with the presenting group. Most students were not engaged in whole-class discussion, some of whom were just listening to the instructor and peers while a few of whom were off task by chatting or playing with smart phones. Most interactions were between the instructor and presenters. As to the Socratic questioning, usually only a few students could follow the instructor's questions to think deeper, explore the specific topic, and distinguish what they knew from what they did not know. Most other students failed to follow the instructor's Socratic questioning and could not answer the instructor's questions. For example, during one group's whiteboard presentation on analogous evidence of evolution, the MI instructor asked "Just because some things have the same function, does that mean that they have same common ancestor?" Some students answered "No." But students were quiet and no one answered this question when the instructor further asked "What else do you have to look at."

One possible reason for students' low levels of participation in whiteboard presentations and whole-class discussions is that most MI students did not actively participate in the group activities that led up to the presentations or discussion so that they did not have idea about what to talk about. Another possible reason for students' low participation in whiteboard presentation and whole-class discussion is that some students were ELLs, who were not confident to speak in English in public due to language barrier. I suggest that the instructor could provide ELLs with necessary vocabulary for a specific MI activity and related content knowledge so 
that ELLs would be equipped with enough language background so that they would feel more comfortable to talk in the class. A third plausible reason for students' low participation particularly in whiteboard presentation is that some students were introverted, who felt shy or even nervous to talk during presentation to the whole class. Eva explained why she talked very soft in group presentation by saying that "I don't really like going up and talking to the class so when evolution came and we had to explain it, I really didn't want to talk about it so I didn't try my best... I'm really shy so my personality has to do with it...I feel like I'm not a hundred percent know about everything about evolution so I try to not talk that much about it" I suggest that the instructor could avoid stimulate introverted students to talk during one's own group presentation but instead encourage them to talk more as audience during whole-class discussion, which might make introverted students less stressed.

The non-MI instructor tried to lead whole-class discussion a few times by providing questions for students to discuss about, but in most cases only one student was engaged in the discussion, who actively answered the instructor's questions and expressed his ideas. A few other students occasionally responded to the instructor by providing their own ideas about a question. In general, no matter it was the student who repeatedly answered the instructor's questions or a few others who occasionally answered the instructor's questions, they all only interacted with the instructor, not 
their peer classmates. Therefore, almost no whole-class discussion happened in the non-MI class.

In summary, most MI students were not engaged in the whole-class discussion, although very few students were. Whole-class discussion was also very rare in the non-MI class. In comparison, no difference in the frequency of whole-class discussion between the MI and non-MI classes. Although the MI instructor employed Socratic questioning during students' whiteboard presentation, in only a few cases some students followed the instructor to think deeper and more about the specific topic. In this sense, Socratic questioning did not stimulate more thinking of students in the MI class than those in the non-MI class.

Intentionally lack of inquiry closure and seeding. I tried to identify the intentionally lack of inquiry closure and seeding as two pedagogical techniques in both MI and non-MI classes, but I failed to detect any of them. Particularly in the MI class, although intentionally lack of inquiry closure and seeding are suggested by the MDM, the MI instructor did not employ them in her Biology I class.

Class environment. It was noisy most of the time in both the MI and non-MI classes. Students talked constantly very loudly. Some students moved around from desk to desk. In some cases, students talked and/or moved for academic purpose, e.g. discussing about a class topic or an activity, picking up activity materials from the instructor's desk. However, in many other cases, students were chatting off-topic or just walked to friends in other group for off-topic purpose. The noisy class 
environment in both MI and non-MI classes made it difficult for students to focus on the instructor or tasks assigned. Mark complained that "Sometimes it's a bit noisy. It's hard to concentrate." It was also complained by Eva that

"The students in the class that have destructive behavior like environment-- it's kind of hard to concentrate with them...I just don't like it when everyone like talks a lot. It's very hard to work." About the negative influence of noisy class environment, Norman explained that “The environment takes in a lot to what you're learning because if you don't have a good environment where you can concentrate, you really miss out on what you're trying to learn."

To conclude the influence of noisy class environment to all students, Adam said that "If you misbehave, because it doesn't affect only them, but it affects their peers around them." He argued that the distracting behaviors of those students impaired not only the learning of those themselves but also all other students around them or even all student in the class.

When students talked about group activities or related articles, appropriate noise was a good sign and acceptable. However, most students in both the MI and non-MI classes were seated on two sides of the desk, two students on each side, while MI students were asked to work in their group activities with peers sitting by the same desk. Due to the size of desks in the classroom, which was relatively big, 
students on one side of a desk had to raise her/his voice to communicate with peers on the other side, which might be distractive to students of other desks.

In order to minimize negative impact of noise and distracting behaviors in class, both MI and non-MI instructors re-arranged students' seating several times, trying to separate those who talked a lot when sitting close. However, it did not work well as Anna said

"we make friends really fast so we talk to everybody... You get distracted very easily. We can talk about other things other than this...Time goes by very fast."

All interviewees, who complained about class environment, suggested the instructor to be stricter to those distracting behaviors, which they believed could stop or at least minimize distracting behaviors and improve class environment.

Timing and pacing. High school biology MI curriculum was structured to lead students to learn new biology concepts through constructing, validating, implementing, and modifying models around specific concepts. It might take longer time for students with MI to master new concepts than those with direct instruction, particularly when both students and the instructor are not experienced with MI. In this study, both participating MI instructors were not experienced with MI. Bill was in his second-year teaching in high school and his first time of using MI. Amy had a couple of years of experiences in using high school chemistry MI but it was her first time of using high school biology MI. Both Bill and Amy informally complained to 
me about the difficulties in applying MI in their classes. One of the challenges they were facing was timing, particularly when the pacing guide pushed them to finish a specific topic by a deadline. Their complaints were also supported by words from informal interviews with other high school biology MI instructors during or after the high school biology modeling workshops. The observed MI instructor spent about 10 class hours in teaching evolution, which was longer than about 6 class hours spent by the non-MI instructor in teaching evolution. It was also challenging to students when MI was also new to them. Sara complained that "Sometimes you do not have that much time to do everything like lab...That takes a lot of time." It was particularly challenging in a distracting class environment. Anna complained to me that

"If they get put on the spot, and they don't know it, and they don't really try to find out the answer, it kind of holds us back a little bit because she (the instructor) has to explain everything all over again. And we get like, we heard this already. But, what can you do? They didn't pay attention the first time. Now we have to hear it again." Due to the stress from pacing guides and school district oversight, MI instructors, particularly when they were inexperienced in MI, were hesitant in implementing high school biology MI curriculum. This stress negatively impacted MI instructors' attitudes towards implementing MI in their classrooms. Therefore, both students and 
MI instructor need further support, particularly support from the school and district administration, when they were both inexperienced with high school biology MI.

\subsubsection{Instructors' Teaching Practices, Students' Biology and Evolution Identities, and Students' Biology Career Aspirations}

Based on my observation, I found that the MI instructor employed more student-centered teaching than did the non-MI instructor. However, sometimes the MI instructor had to take the control of the class to push students in order to finish a certain topic on time. According to Black and Deci (2000) and Lavigne, Vallerand, and Miquelon (2007), instructors' autonomy support predicted students' perceived competence and interest in learning science, which are two components of science identity and further positively influenced students' pursue of science career. However, students' biology/evolution identities and biology career aspirations in this study were not significantly different between the MI and non-MI classes, which indicated that high school biology MI instructors should provide enough autonomy to students so that students can perceive the autonomy and effectively develop their biology/evolution identities.

The MI instructor encouraged small-group collaboration in her MI class. However, except one group, all other groups did not employ all elements of small-group collaboration (Johnson, Johnson, \& Holubec, 1994). The MI instructor did not explicitly set goals for each group in group activities, and she did not explicitly assign specific roles to each group member to engage them in group 
collaboration. The MI instructor tried but did not have effective strategies to encourage students' promotive interactions so that they could academically and personally support each other. The MI students also did not have good small-group and interpersonal skills, because of which most MI students did not know how to lead a group, communicate with each other, and manage conflicts. For example, many active group members did not want to or even hated to do all the work for other inactive group members. Eva expressed her upset by saying that "because if someone is not giving their all in the group project then, for example, I have to do it. Or me with someone else. We have to end up the project and then he gets the A or she because of us, because of our work, not because they did something about it...I'm not going to do your job...my other group members need to do theirs too"

Anna was mad about her group members for their not participating "I had a group in here with it. They didn't do anything and I had to do everything. It got me mad...I did everything and I deserved the grade and they just got it because they were with me."

Although active group members still completed group tasks no matter other group members participated or not, lack of interpersonal and small-group skills and low participation of inactive group members did lead to negative group dynamics and low group productivity. In this sense, except the only one collaborative group, other 
groups in the MI class did not have more effective small-group collaboration than the non-MI class, which corresponded to the no significant difference in students' biology/evolution identities and biology career aspirations between the MI and non-MI classes.

Both the MI and non-MI instructors tried to lead whole-class discussion, but both failed to involve students in discussion with other classmates about any issues. Although the MI instructor applied Socratic questioning in class, most MI students did not respond well to her questions and did not follow her questions to think more. As to intentionally lack of inquiry closure and seeding, both were not employed in either the MI or non-MI class. The absence or failure use of whole-class discussion, Socratic questioning, intentionally lack of inquiry closure, and seeding in the MI class corresponded to the no significant difference of students' biology/evolution identities and biology career aspirations in the MI class than in the non-MI class.

\subsection{Discussion}

\subsubsection{Students' Low Participation in Small-group Collaboration}

I have several suggestions for the MI instructor to structure small-group collaboration in group MI activities, particularly when some students did not actively participate in group activities, let alone collaborate with other group members, and some students even misused autonomy provided and took the chance to do things off-topic. First, the instructor may benefit from explaining a group task explicitly and providing a clear group goal that requires all group members' efforts 
to reach (Johnson et al., 1994). Group members need to be aware that each member's efforts benefit not only the individual but also the entire group. In this sense, every group member should be committed to the group success and one's own as well. Second, the instructor should explicitly assign a role to each single group member for each specific MI activity so that she/he is accountable for contributing a fair share of the tasks to achieve the group goal (Johnson et al., 1994). If the MI instructor could arrange and implement MI curriculum more effectively, she could save more time and did not have to push her students by taking back their autonomy and taking the control of the class.

\subsubsection{High School Biology MI Curriculum, Workshops, and Instructors}

The high school biology MI curriculum, particularly the biology MI curriculum for $9^{\text {th }}$ and $10^{\text {th }}$ graders, was immature, compared to the high school physics MI curriculum, and still under evaluation and development (Gard, 2015). MI instructional materials for some high school biology topics were still pending. The high school biology MI workshops that I attended and recruited research participants from introduced to attendees the instructional materials for experimental design, classification of life, evolution, energy, and cells. Primarily, the workshop instructor led attending high school biology teachers to collaboratively work on MI activities designed for the topics covered in the workshop. According to our observation during two high school biology modeling workshops, one of which both participating MI instructors attended, how to effectively implement MI in high 
school biology classrooms was not emphasized in the workshop. This observation was also reflected by workshop attendees' words in informal interviews with some of them during or after the workshop. For example, one workshop attendee complained that "I am using MI (materials) but I don't know whether I am using it in a correct way." Another possible reason why not all workshop attendees could effectively implement MI is that they all worked on those MI activities in a student's mode but did not have chances to work in a MI instructor's mode to practice how to implement high school biology MI curriculum. As a matter of fact, the high school biology MI curriculum was new to high school biology MI teachers, including two participants as MI instructors in the study, as well as high school students in biology MI classes. The two MI instructors in the study were both inexperienced in implementing high school biology MI curriculum and so were students in their MI classes in working with MI activities. Therefore, both the MI instructors and their students might be out of their comfort zone in the MI classes, e.g. during the MI evolution class sessions.

I suggest that more training in effectively implementing MI need to be included in high school biology MI workshops so that attendees could learn not only what MI activities could be used for specific biology topics but also how to effectively implement those MI activities to engage students in learning. I also suggest that high school biology modeling workshop attendees should be provided with chances to lead a certain activity in the workshop so that they could better reflect on the use of 
MI activities in a teacher's mode. It would also be helpful to create an accessible platform for high school MI instructors to discuss about their concerns, issues, challenges, ideas, tips, and experiences of implementing high school MI curriculum in various contexts, particularly considering different student demographic background.

\subsubsection{Significant Gain of Evolution Identity in Non-MI Classes}

It was interesting to detect students' significant gain of evolution identity in non-MI classes rather than MI classes. The observed non-MI instructor spoke slower than the MI instructor and even more slower when emphasizing key terms in evolution. When showing videos to students, the non-MI instructor also paused videos to deeper explain the content whenever she was aware that students were confused. The non-MI instructor's strategies of explicitly explaining content knowledge and key terms might make it easier for students to understand the idea of evolution, which might further enhance students' acceptance of evolution and internalize evolution as part of their world view.

\subsubsection{Performed Identity and Narrated Identity}

Although no biology/evolution identity change statistically detected in MI classes, MI students were still performing biology/evolution identities in the MI class. This inconformity suggested that, in a certain stage of learning, students might have already been able to perform biology/evolution identities, but they were not aware of and could not report their biology/evolution identities. It takes time for 
students to internalize their performed biology/evolution identities to be ones that they can perceive and report.

\subsection{Conclusion}

The effect of high school biology MI on students' biology/evolution identity development and positive shift in biology career aspirations highly relied on MI instructors' effective implementation of MI curriculum in classrooms. Low extent of applying modeling discourse management tools along with MI activities are not effective in promoting high school students' biology/evolution identities and biology career aspirations. I suggest MI instructors to fully employ modeling discourse management tools according to the MDM in order to effectively improve students' biology/evolution identities and/or biology career aspirations.

\subsection{Limitation}

A larger sample size is desirable for assessing students' biology/evolution identities and career aspirations. I suggest observing more MI and non-MI high school biology instructors so that researchers could compare high school biology instructors' teaching practices more comprehensively. It would be better for two or three observers to observe simultaneously in each class session. In this sense, researchers could analyze instructors' teaching practices from more perspectives to enhance the trustworthiness of this study. Since high school biology MI curriculum was introduced to south Florida in less than five years ago and yearly workshop has just been hosted since 2015, high school biology instructors were all inexperienced 
in effectively implementing biology MI. It would be worthwhile to collect

longitudinal data on south Florida high school biology MI instructors' teaching

practices and their students' learning outcomes to follow up with their development

in implementing biology MI curriculum.

References (Chapter 3)

American Modeling Teachers Association. (2016). High school biology modeling workshop participant materials. Miami, FL: American Modeling Teachers Association.

Aschbacher, P. R., Li, E., \& Roth, E. J. (2010). Is science me? High school students' identities, participation and aspirations in science, engineering, and medicine. Journal of Research in Science Teaching, 47, 564-582.

Black, A. E., \& Deci, E. L. (2000). The effects of instructors' autonomy support and students' autonomous motivation on learning organic chemistry: A self-determination theory perspective. Science Education, 84, 740-756.

Boaler, J., William, D., \& Zevenbergen, R. (2000). The construction of identity in secondary mathematics education. In Second International Conference on Mathematics Education and Society (pp. 192-202). Montechoro, Portugal.

Breakwell, G. M., \& Beardsell, S. (1992). Gender, parental and peer influences upon science attitudes and activities. Public Understanding of Science, 1(2), 183-197.

Brewe, E. (2008). Modeling theory applied: Modeling Instruction in introductory physics. American Journal of Physics, 76, 1155-1160.

Brewe, E., Kramer, L., \& O’Brien, G. (2009). Modeling instruction: Positive attitudinal shifts in introductory physics measured with CLASS. Physical Review Special Topics - Physics Education Research, 5(1), 1-5.

Brewe, E., Sawtelle, V., Kramer, L. H., O’Brien, G. E., Rodriguez, I., \& Pamelá, P. (2010). Toward equity through participation in Modeling Instruction in introductory university physics. Physical Review Special Topics - Physics Education Research, 6(1), 10106. 
Brickhouse, N. W., Lowery, P., \& Schultz, K. (2000). What kind of girl does science? The construction of school science identities. Journal of Research in Science Teaching, 37, 441-458.

Brickhouse, N. W., \& Potter, J. T. (2001). Young women's scientific identity formation in an urban context. Journal of Research in Science Teaching, 38, 965-980.

Carlone, H. B., \& Johnson, A. (2007). Understanding the science experiences of successful women of color: Science identity as an analytic lens. Journal of Research in Science Teaching, 44, 1187-1218.

Cass, C. A. P., Hazari, Z., Cribbs, J., Sadler, P. M., \& Sonnert, G. (2011). Examining the impact of mathematics identity on the choice of engineering careers for male and female students. In Frontiers in Education Conference (p. F2H-1). Rapid City, SD: IEEE.

Cleaves, A. (2005). The formation of science choices in secondary school. International Journal of Science Education, 27, 471-486.

Desbien, D. M. (2002). Modeling discourse management compared to other classroom management styles in university physics. Arizona State University.

Dukerich, L. (2015). Applying modeling instruction to high school chemistry to improve students' conceptual understanding. Journal of Chemical Education, 92, $1315-1319$.

Durden, J., Brewe, E., \& Kramer, L. H. (2011). "Seeding”: Understanding discourse management in modeling. Jacksonville, FL: AmericanAssociation of Physics Teachers National Meeting.

Gard, A. (2015). Modeling instruction in high school biology. Miami, FL: American Modeling Teachers Association.

Gilmartin, S., Denson, N., Li, E., Bryant, A., \& Aschbacher, P. (2007). Gender ratios in high school science departments: The effect of percent female faculty on multiple dimensions of students' science identities. Journal of Research in Science Teaching, 44, 980-1009. 
Godwin, A., Potvin, G., Hazari, Z., \& Lock, R. (2013). Understanding engineering identity through structural equation modeling. In Proceedings - Frontiers in Education Conference, FIE (pp. 50-56).

Halloun, I. A. (2007). Modeling theory in science education. Dordrecht, Netherlands: Springer.

Hazari, Z., Cass, C., \& Beattie, C. (2015). Obscuring power structures in the physics classroom: Linking teacher positioning, student engagement, and physics identity development. Journal of Research in Science Teaching, 52, 735-762.

Hazari, Z., Sonnert, G., Sadler, P. M., \& Shanahan, M.-C. (2010). Connecting high school physics experiences, outcome expectations, physics identity, and physics career choice: A gender study. Journal of Research in Science Teaching, 47, 978-1003.

Hestenes, D. (1987). Toward a modeling theory of physics instruction. American Journal of Physics, 55, 440-454.

Holland, D., Skinner, D., Lachicotte, W., \& Cain, C. (1998). Identity and agency in cultural worlds. Cambridge, MA: Harvard University Press.

Hull, G. A., \& Greeno, J. G. (2006). Identity and agency in nonschool and school worlds. In Z. Bekerman, N. Burbules, \& D. S. Keller (Eds.), Learning in places: The informal education reader (pp. 77-97). New York, NY: Peter Lang.

Jackson, J., Dukerich, L., \& Hestenes, D. (2008). Modeling instruction : An effective model for science education. Science Educator, 17(1), 10-17.

Johnson, D. W., Johnson, R. T., \& Holubec, E. J. (1994). Coorperative learning in the classroom. Alexandria, VA: Association for Supervision and Curriculum Development.

Lavigne, G. L., Vallerand, R. J., \& Miquelon, P. (2007). A motivational model of persistence in science education: A self-determination theory approach.

European Journal of Psychology of Education, 22, 351-369.

http://doi.org/10.1007/BF03173432

Li, F., \& Hazari, Z. (2017). Developing and validating the Biology Identity and Persistence Survey (BIPS) for use in high schools in south Florida. Manuscript Submitted for Publication. 
Malone, K. L. (2008). Correlations among knowledge structures, force concept inventory, and problem-solving behaviors. Physical Review Special Topics Physics Education Research, 4(2), 1-15.

Manthey, S., \& Brewe, E. (2013). Toward university modeling instruction-biology: Adapting curricular frameworks from physics to biology. CBE Life Sciences Education, 12, 206-214.

Merriam, S. B. (1998). Qualitative research and case study applications in education. San Francisco, CA: Jossey-Bass.

National Research Council. (2009). Learning science in informal environments: People, places, pursuits. Washington, DC: National Academies Press.

National Science Board. (2012). Higher education in science and engineering. In Science and engineering indicators 2012 (pp. 1-39). Arlington, VA: National Academies Press.

National Science Board. (2014). Higher education in science and engineering. In Science and engineering indicators 2014. Arlington, VA: National Academies Press.

O’Brien, M. J., \& Thompson, J. R. (2009). Effectiveness of ninth-grade physics in Maine: Conceptual understanding. The Physics Teacher, 47(4), 234-239.

Papanastasiou, C. (2002). School, teaching and family influence on student attitudes toward science: Based on TIMSS data for Cyprus. Studies in Educational Evaluation, 28(1), 71-86.

Passmore, C., \& Stewart, J. (2002). A modeling approach to teaching evolutionary biology in high schools. Journal of Research in Science Teaching, 39(3), 185-204.

Reichardt, C. S., \& Cook, T. D. (1979). Quantitative and qualitative methods in evaluation research. In C. S. Reichardt \& T. D. Cook (Eds.), Beyond Qualitative versus Quantitative Methods. Thousand Oaks, CA: SAGE.

Renninger, K. A. (2009). Interest and identity development in instruction: An inductive model. Educational Psychologist, 44(2), 105-118. 
Ryan, R. M., \& Deci, E. L. (2000). Self-determination theory and the facilitation of intrinsic motivation, social development, and well-being. The American Psychologist, 55(1), 68-78.

Ryan, R. M., \& Deci, E. L. (2003). On assimilating identities to the self: A self-determination theory perspective on internalization and integrity within cultures. In M. R. Leary \& J. P. Tangney (Eds.), Handbook of Self and Identity (pp. 253-272). New York, NY: Guilford.

Schuchardt, A. M., \& Schunn, C. D. (2015). Modeling scientific processes with mathematics equations enhances student qualitative conceptual understanding and quantitative problem solving. Science Education, 100(2), 290-320.

Schwarz, C., \& Passmore, C. (2012). Preparing for NGSS: Developing and using models. Retrieved May 2, 2017, from http://learningcenter.nsta.org/products/symposia_seminars/ngss/files/Preparingfo rNGSS--DevelopingandUsingModels_9-25-2012.pdf

Shanahan, M. (2009). Identity in science learning: Exploring the attention given to agency and structure in studies of identity. Studies in Science Education, 45(1), $43-64$.

Sherman, R. R., \& Webb, R. B. (1988). Qualitative research in education. London, UK: Routledge.

Strauss, A., \& Corbin, J. (1990). Basics of qualitative research (2nd ed.). Newbury Park, CA: SAGE.

Tai, R. H., Liu, C. Q., Maltese, A. V, \& Fan, X. (2006). Planning early for careers in science. Science, 312, 1143-1144.

Tsai, Y.-M., Kunter, M., Lüdtke, O., Trautwein, U., \& Ryan, R. M. (2008). What makes lessons interesting? The role of situational and individual factors in three school subjects. Journal of Educational Psychology, 100, 460-472.

Yin, R. K. (2014). Case study research: Design and methods (5th Editio). Thousand Oaks, CA: SAGE. 


\section{CHAPTER 4 CONNECTING BIOLOGY MODELING INSTRUCTION PRACTICE AND EVOLUTION CONCEPTUAL UNDERSTANDING: A COMPARATIVE CASE STUDY}

\subsection{Introduction}

A set of biology education researchers and practitioners have worked to develop high school biology Modeling Instruction (MI) curriculum during the past decade (Gard, 2015; Passmore \& Stewart, 2002; Schuchardt \& Schunn, 2015). The MI curriculum is still in development. The high school biology MI curriculum was first developed in a Physics-Chemistry-Biology sequence for $11^{\text {th }}$ graders (Gard, 2015). In 2010, the adapted and modified version of high school biology MI curriculum for $9^{\text {th }}$ and $10^{\text {th }}$ graders in a Biology-Chemistry-Physics sequence started to be developed (Gard, 2015).

Based on modeling theory in science teaching, Passmore and Stewart developed a modeling approach to teach evolution in high schools in order to engage students in modeling the mechanism of evolution (2002). Evolution is the conceptual cornerstone of the modern biology discipline (Dobzhansky, 1973; Mayr, 1982). The importance of evolution education has been recognized by scientific and educational researchers, and educational reform efforts have been put in place to enhance students' understanding of evolution (American Association for the Advancement of Science, 1993; National Academy of Science, 1998; National Research Council, 1996). In terms of the instruction of evolution in high school 
biology classrooms, the National Association of Biology Teachers argued that "teaching biology in an effective and scientifically-honest manner requires classroom discussions and laboratory experiences on evolution" (2000).

\subsection{Efficacy and Practice of MI}

Dye, Cheatham, Rowell, Barlow and Carlton (2013) demonstrated that high school science students in MI classes scored significantly higher in ACT science test and achieved higher average percentage of college science readiness than their counterparts in traditional lecture classes. The efficacy of MI in significantly improving high school students' science academic achievements was also supported by evidence from two studies measuring high school students' conceptual understanding in physics with Force Concept Inventory (FCI; Liang et al., 2012; O’Brien \& Thompson, 2009). Malone (2008) indicated that students in a modeling group employed more expert-like problem-solving skills than their counterparts in a non-modeling group. Brewe and colleagues also reported that MI improved underrepresented students' academic achievements, odds of success, and participation in college introductory physics class (2010).

High school biology MI is conceptualized by Modeling Theory of Science (MTS), Modeling Theory of Instruction (MTI), and Modeling Discourse Management (MDM; Manthey \& Brewe, 2013), among which MTI and MDM particularly conceptualize high school biology MI instructors' teaching practice. The MTS articulates the progress of scientific disciplines, including biology, as an 
ongoing process of constructing, validating, implementing, and modifying models (Halloun, 2007). Science is understood and conceptualized through connecting scientific theories and associated concepts with models (Halloun, 2007; Hestenes, 1987). According to the MTS, the MTI suggests students to learn science through similar and simulated scientific activities in constructing, validating, implementing, and modifying models (Brewe, 2008). The MTI also suggests MI instructors employ student-centered pedagogical strategies and encourage student-student interactions during their students' science learning (Brewe, 2008). In order to support MI instructors' science teaching practices, MDM identifies and suggests a series of discourse management tools (Manthey \& Brewe, 2013), which include small-group collaboration, whole-class discussion, intentional lack of inquiry closure, seeding (Desbien, 2002), and Socratic questioning. Seeding is a pedagogical technique used to introduce new questions/concepts/ideas to a small collaborative group for them to work out their own understanding and interpretation and then introduce the ideas to the whole class (Desbien, 2002; Durden et al., 2011). Through seeding, the small collaborative group can gain and perceive ownership of the idea (Desbien, 2002). It is easier to stimulate a whole-class discussion through seeding when the idea is introduced by peer classmates rather than an authority (Desbien, 2002). According to MDM, MI instructors encourage students to employ tools to build models. These tools include diagrams, maps, pictorial and graphical representations. In biology MI classes, students construct their understanding of the nature of biological topics 
through conducting modeling activities, which simulate biological practices in real-life situations.

\subsection{Research Motivation and Research Questions}

Although high school biology MI curriculum has been evaluated in U.S. high schools for several years (Gard, 2015) and a modeling method was developed and described specifically for teaching evolution in high schools over a decade ago (Passmore \& Stewart, 2002), both MI instructors' teaching practice and MI students' learning outcomes in evolution have yet been examined. MI has been demonstrated as an effective strategy in teaching science (Brewe et al., 2009; Dukerich, 2015; Jackson et al., 2008; O’Brien \& Thompson, 2009). However, due to the younger age of high school biology MI curriculum compared to that of high school physics and chemistry MI curricula, there is a limited amount of published research assessing high school biology MI curriculum, particularly its specific efficacy in teaching evolution to high school students. High school MI instructors' teaching practice is yet to be monitored and evaluated in terms of its relation with students' conceptual understanding in MI science courses, even on high school physics and/or chemistry MI curricula, which have been examined extensively, particularly about students' conceptual understanding (e.g., Dukerich, 2015; O’Brien \& Thompson, 2009). It is critical to evaluate and acknowledge the role of MI instructors' effective teaching practice in implementing MI curriculum in teaching evolution in high school biology classes. I conducted this comparative case study, which included both 
quantitative and qualitative data, to examine and compare high school students' conceptual understanding in evolution in MI and non-MI classes in Biology I courses in south Florida public high schools and to connect students' evolution conceptual understanding with their biology instructors' teaching practices in either MI or non-MI class. I intended to provide suggestions about how to better implement high school biology MI to improve evolution conceptual understanding of public high school students in south Florida. Reported evidence of students' significant improvement of academic achievement in learning science in MI classes supported and stimulated our focus on assessing high school biology MI students' conceptual understanding in evolution and exploring how high school biology MI instructors' teaching practice connected to students' evolution conceptual understanding.

Through this comparative case study, I intend to explore the following research questions: 1) Do high school biology students gain significantly more conceptual understanding in evolution in MI class than in non-MI class? 2) Do high school biology MI instructors' evolution teaching practices along with employed MI evolution activities have connection with the significant difference, if any, in students' evolution conceptual understanding between MI and non-MI classes? 3) If so, what teaching practices have connection with the significant difference, if any, in students' evolution conceptual understanding between MI and non-MI classes? 


\subsection{Methods}

\subsubsection{Participants}

The primary researcher attended two-week-long high school biology MI workshops respectively in the summer of 2015 and 2016. The primary researcher talked with all attendees of the workshop in the summer of 2016 and collected data with a short teacher survey on all attendees' attitudes towards high school biology MI and demographic information. Two high school biology MI instructors were recruited from the Summer 2016 workshop, based on their willingness and criteria including the intention to employ biology MI curriculum in high school Biology I courses in the following academic year and self-efficacy in implementing biology MI curriculum in high school Biology I classrooms. Each one of the two MI instructors was then asked to recruit one non-MI biology instructor in one's own school, who would teach Biology I as well. This sampling strategy was employed to minimize variations between the MI and non-MI instructors from school traits, and to make the MI and non-MI instructors within the same boundary of this comparative case study. In total, I had two MI and two non-MI instructors, each pair of MI and non-MI instructors from the same high school, to participate this study. I then asked each MI or non-MI instructor to recommend two Biology I classes of one's own, based on students' performance, for quantitative data collection. Therefore, I had eight classes of high school Biology I students from two public high schools in south Florida. I selected one pair of MI and non-MI instructors from 
the same high school to collect qualitative data through in-class observation and student interviews. I further asked each one of the MI and non-MI instructors, who were selected for observation, to recommend one class for qualitative data collection.

The first public high school, in which I collected both quantitative and qualitative data, was opened less than one decade ago and had over 1500 students enrolled, including about 35\% White non-Hispanic, 33\% Hispanic of any race, $32 \%$ Black non-Hispanic, and less than $1 \%$ other races. The second public high school, in which I only collected quantitative data, was an urban school in a historically Black neighborhood that serves people of low socioeconomic status and had about 1000 students enrolled, including about $91 \%$ Black non-Hispanic, $8 \%$ Hispanic of any race, and $1 \%$ White non-Hispanic.

The MI instructor in the first school is Amy (pseudonym). Amy is a female Hispanic science teacher with a master's degree in education. She had ten-years of science teaching experience in high schools, including four-years of experience in teaching high school biology, and one-year experience in applying MI in high school chemistry classrooms. The non-MI instructor in the same school is Mia (pseudonym). Mia is a female Hispanic science teacher with a bachelor's degree from a Spanish-speaking country. The MI instructor in the second school is Bill (pseudonym). Bill is a male White science teacher with a Ph.D. in biology. He had one-year experience in teaching biology in high school and no prior MI experience. 
The non-MI instructor in the second school is Grace (pseudonym). Grace is a female Hispanic science teacher.

\subsubsection{Comparative Case Study}

The research purpose of this study was to examine evolution education in high school MI and non-MI Biology I classes in south Florida, in terms of students' evolution conceptual understanding and the instructors' teaching practices, to answer the question of how and/or why students' gain of conceptual understanding in evolution was different (or not different) between the MI and non-MI classes. A case study approach has particular advantage in answering "how" and/or "why" questions (Yin, 2014). Merriam (1998) supported case study research design in "investigating complex social units consisting of multiple variables of potential importance in understanding the phenomenon" (p. 41). Reichardt and Cook (1979) particularly suggested case study as an applicable strategy to assess an educational intervention, due to its function in "describing the context and population of the study, discovering the extent to which the treatment or program has been implemented, providing immediate feedback of a formative type, and the like" and "discovering or confirming the process by which the treatment had the effect that it did" (p. 21). In this study, I employed a comparative case study research design, which can not only describe each single case but also explore the relationship between two cases to answer why students' gains in conceptual understanding in evolution happened differently (or not differently) in one class than in the other. The advantages of a 
comparative case study is its variation across cases, which could provide convincing interpretation, help answer how, where, and why a phenomenon happens in a certain case, and boost the precision, validity, and reliability of research findings (Merriam, 1998). In order to improve the validity and reliability of this study, I collected data from multiple sources to minimize the impact of the researchers' bias.

\subsubsection{Quantitative Analyses}

I collected quantitative data with the Evolution Concept Inventory (ECI) about students' conceptual understanding in evolution in eight high school Biology I classes, two classes from each participating instructor. The ECI is composed of eight selected-response items on evolution, which were adopted from the Modeling Biology Concept Inventory student version 3.0 (MBCI sv 3.0). The MBCI sv 3.0 was validated by its developers and external evaluators in terms of its face and content validity, and its internal reliability (Cronbach's alpha) was 0.70 (M. Howard, personal communication, September 20, 2016). I gauged students' total mean score, item difficulties, item discrimination, and internal reliability to address the validity and reliability of the ECI. I administered the ECI at the beginning and the end of the instructional period of evolution in all eight high school Biology I classes $(n=189)$ to statistically examine students' gain of conceptual understanding in evolution across the MI and non-MI classes. The ECI was administered as a pre- and post-test.

I analyzed the data collected with the ECI to provide statistical evidence on students' conceptual understanding in evolution across the MI and non-MI classes. 
Each item of the ECI had five optional answers, and only one answer was the correct one to the item and all other four answers were incorrect. Students received one point for choosing the correct and only the correct answer and no point for choosing any other wrong answer, choosing multiple answers, or not choosing any answer to each item. Students' score for the ECI was the sum of all points they received from answering each item. First, I conducted paired-sample t-test to examine students' gain of conceptual understanding in evolution by comparing students' scores for the ECI in the pre-test of the ECI at the beginning of the evolution instruction sessions and in the post-test at the end of evolution teaching sessions.

I assesses the predictive power of teaching methods (MI vs non-MI) on students' gain of conceptual understanding in evolution through linear regression analysis on students' evolution conceptual understanding with class type (MI vs non-MI) as the predictor and students' scores for the ECI in the post-test as the outcome, by controlling students' scores for the ECI in the pre-test and some demographic background information as co-variables that had potentially influence on students' gain of conceptual understanding in evolution. I controlled these co-variables in order to control their potential effect on students' gain of conceptual understanding in evolution so that I could fairly compare across the MI and non-MI classes. In the initial evolution conceptual understanding linear regression model, I controlled: 1) students' scores for the ECI in the pre-test before taking class sessions on evolution; 2) students' reported extent of science supporting environment at home 
(an item in the BIPS on a five-point Likert scale from "not at all" to "very much so");

3) the total and the highest of parents'/guardians' highest level of education as the indicator of socioeconomic status (Li, Brewe, Hazari, O’Brien, \& Long, 2017); 4) primary spoken language at home (English or non-English language); 5) students' grade levels (ninth to twelfth grade); and 6) other demographic information including gender, ethnicity (Hispanic or non-Hispanic), and race (dummy variables for White/Caucasian, Black/African American, Asian, American Indian, Pacific Islander, and other). The first covariate controlled for students' prior conceptual understanding in evolution immediately before taking the evolution class sessions, which had potential effect on students' evolution conceptual understanding as the outcome of learning evolution at the end of the evolution class sessions. The second covariate, home environment supporting for science, was controlled due to its potential effect on students' science academic achievements (Schneider \& Lee, 1990; Song \& Hattie, 1984). The third one was parental education level as the indicator of students' household socioeconomic status, which was controlled for its potential effect on students' science academic achievements (Caldas \& Bankston, 1997; Davis-Kean, 2005). Students' primary speaking language, the fourth covariate, was controlled due to the potential effect of language barrier on English Language Learners' (ELLs') science academic achievements (Lee \& Fradd, 1998). The fifth controlled covariate was students' grade levels in high school (in this study, most students were tenth graders while a few of them were of other grades). Other 
covariates were students' gender, ethnicity, and race in case potential differences existed across groups.

\subsubsection{Qualitative Analyses}

I selected one MI class and one non-MI class of regular Biology I from Amy (MI instructor) and Mia (non-MI instructor) for qualitative data collection through in-class observation and semi-structured student interviews. These classes were in the same public high school in south Florida. I employed video-recording and field notes for observational data collection during the observation of all evolution class sessions in both selected MI and non-MI classes. At the beginning of the last evolution class session in both the MI and non-MI classes, a participant solicitation speech was given to recruit students for interview. Five MI students and four non-MI students were recruited and interviewed respectively, after the completion of all their evolution class sessions, about their learning experiences in the evolution class sessions and perceptions of their biology instructors' teaching practices. Each interviewee was interviewed for about 15 to 30 minutes after class in the school. All student interviews were audio-recorded.

The themes of the instructors' teaching practices were compared, based on a constant comparative approach (Sherman \& Webb, 1988; Strauss \& Corbin, 1990), across the MI and non-MI classes in order to understand how and/or why the difference (or no difference) in students' conceptual understanding in evolution happened across the MI and non-MI classes. The video data were viewed several 
times as well as the field notes were read several times to identify patterns of the MI and non-MI instructors' teaching practices and students' performance across the MI and non-MI classes. The interview data were transcribed and coded for themes of students' classroom experiences and perceptions of the instructors' teaching practices. I examined and compared the MI and non-MI instructors' teaching practices, according to the MTI and the MDM, to evaluate how well the MI instructor applied the high school MI curriculum in evolution class sessions and the connection of instructors' teaching practices with students' conceptual understanding in evolution. I focused our observation on in-class activities and discourse management techniques employed by the instructors. I developed the interview protocol after viewing recorded videos once so as to include more pertinent questions.

\subsection{Results}

\subsubsection{Validity and Reliability of the ECI}

The total mean scores for the ECI were 1.92 out of $8(\mathrm{SD}=1.329)$ in the pre-test and 1.99 out of $8(\mathrm{SD}=1.339)$ in the post-test. The Cronbach's alpha for the ECI was 0.202 in the pre-test and 0.209 in the post-test, which indicated low internal reliability of items in the ECI. The exploratory factor analysis (EFA) results demonstrated scattered loadings of items. EFA results in the pre-test indicated that Question 3 and 4 loaded as one sub-concept measure, Question 5 and 6 loaded as one sub-concept measure, and Question 7 and 8 loaded as one sub-concept measure. 
However, EFA results in the post-test indicated that Question 4 and 5 loaded as one sub-concept measure and Question 3 and 7 loaded as one sub-concept measure. The highest Cronbach's alpha of those items loaded as one sub-concept measure was 0.357 of Question 3 and 7 in the post-test. The improved Cronbach's alpha was still lower than the acceptable value of 0.7 . The EFA and Cronbach's alpha results suggested that the ECI was not a valid and reliable research instrument for assessing evolution conceptual understanding of students in this study.

Our validation results of the ECI were dramatically different from those of the developers and evaluator of the MBCI sv 3.0, from which I adopted questions on evolution to compose the ECI. Items in the MBCI were compiled from existing validated sources, including AAAS Project 2061, Biology Concept Inventory, Natural Selection Concept Inventory, VA Standards of Learning End-of-Course Assessments (released items), and National Assessment of Educational Progress (released items). The selected items were reviewed by the evaluator and instrument developers for clarity, completeness, appropriateness, and balance across the content objectives, and some items were modified or replaced for the face and content validity of the MBCI. The first version of the MBCI was piloted with biology MI workshop teachers, and several items with questionable item characteristics were replaced. The second version of the MBCI was piloted again with biology MI workshop teachers, and several items with low difficulty were replaced. The second version was adapted as a student version to test high school biology students. The 
final student version of the MBCI has an internal reliability (Cronbach's alpha) of

0.70 (M. Howard, personal communication, September 20, 2016). Based on the face and content validity of the MBCI reported by the developers and acceptable internal reliability reported by its external evaluator, I adopted items from the MBCI sv 3.0 and composed the ECI.

\subsubsection{Connection between Biology MI and Students' Evolution}

\section{Conceptual Understanding}

To better understand students' gain of evolution conceptual understanding and its connection with high school biology MI curriculum, I qualitatively analyzed data on instructional materials used and instructors' teaching practices in both the MI and non-MI classes in evolution class sessions collected through in-class observation and student interviews. I first describe instructional materials both MI and non-MI instructors employed in their evolution class sessions. Then I describe both MI and non-MI instructors' teaching practices in general. In order to specifically assess the MI instructor's teaching practice, I employed aspects of discourse techniques suggested by the MTI and MDM to analyze and compare teaching practices of the MI and non-MI instructors. The comparison of the MI and non-MI instructors' teaching practices is demonstrated in Table 11.

Instructional materials. The MI instructor utilized primarily instructional materials provided in the biology modeling workshop in the summer of 2016. She initiated the evolution class with an interactive PowerPoint lecture on theories of the 
origin of life. She was not just delivering the content to students; instead, she discussed theories about the origin of life with students by asking questions to stimulate their thinking. She gave students one article on theories of evolution and how scientists tested their theories and discussed the article with students by orally asking them questions. She gave students another article on evidence of evolution and asked each group of students to present their digestion of the article to the whole class. To help students understand natural selection and adaptation, the MI instructor employed an MI activity called "Thirsty Bird simulation.” With the Thirsty Bird simulation activity, the MI students were assigned to use spoons, forks, knives, or pairs of straws to simulate different beaks of finches and explored how finches with different beaks survived based on their capabilities in competing for food, under natural selection. To further develop students' ideas about natural selection and adaptation, the MI instructor discussed with students a scenario of a kind of worms' chance of survival, based on the worms eating out during day or night, and the predators, a kind of birds, feeding during day or night.

The non-MI instructor initiated her evolution class with two videos and she asked students to find two evidences of human's common ancestor with chimpanzee living on the earth six million years ago. She gave students an article and asked students to highlight answers to ten questions about evidence of evolution from the article. She walked around to help students locate the answers. Some students read the article but some did not, particularly when the instructor was answering other 
students' questions. The non-MI instructor then discussed with students about traits that are acquired or hereditary. To help students understand genetic drift and natural selection, the non-MI instructor employed one modeling activity, in which students used cards of red, yellow, or orange as beetles of different colors. Then in each generation, students determined the color of offspring according to different combinations of parents based on given rules to model the process of genetic drift, and removed certain percentage of beetles of specific colors based on the preference of predators to beetles' colors to simulate the mechanism of natural selection. However, usually only one or two students of each group worked on the activity. In order to push students to complete the activity on time, the non-MI instructor walked around to each group and partially or even almost fully did the activity for students and demonstrated the results to them. Then she asked students to present to the entire class their own data, reasoning, and claims about the frequencies of each color of beetles in each generation. The non-MI instructor demonstrated a video about diverse species in Galapagos Islands to discuss with students about evidences of natural selection in real world. When showing videos, the non-MI instructor paused videos periodically to ask relevant questions to students.

In comparison, the instructional materials used in the MI class were more student-centered than those in the non-MI class. The MI instructor also employed student-centered teaching strategy in using her instructional materials. Although the non-MI instructor also used one modeling activity that was student-centered, she 
provided students with much less autonomy in working on the activity than the MI instructor provided to her students.

General description and comparison. Due to the interruption of a high-stakes test, scheduled earlier release, and teaching of other topics for a test, the MI instructor, Ms. Amy, spent nine class sessions to complete teaching evolution, while the non-MI instructor, Ms. Mia, spent four class session to complete teaching evolution. The actual time they spent in teaching evolution was about ten class hours in the MI class and six class hours in the non-MI class. The MI instructor, Ms. Amy, tended to walk around in the classroom and talk with her students extensively. She spoke fast most of time. She was humorous in using verbal and body language to attract students' attention. For example, Sara said that "She is funny, like I said. She just makes it interesting how she teaches it and how passionate she is about her job...like getting us to learn.” Noah expressed the similar perception about Ms. Amy's personality "she does it in a fun way... She explains everything pretty well." He further explained the benefit of the instructor's humor as "when she does jokes about the lesson, you remember those jokes and sometimes those jokes, you remember them and it helps you on the test." Ms. Amy asked more questions in class than did the non-MI instructor either to the whole class or to a specific group about their group activities. She was not always behind the front desk. Instead, she walked around the classroom or sat on a student desk, which made her very close to students. She allowed students to move relatively freely in the classroom to interact 
with other students. She required students to take notes in class and Eva appreciated class notes by saying that "I like how our notes are really organized. We take a lot of notes and the notes help a lot." Taking notes was especially helpful to those who missed a class session, as Anna said, "if you ask someone for the notebook, you kind of get a thought about what they did the day you missed." The non-MI instructor, Ms. Mia, tended to stand behind the front desk, which made her not close to students except those sitting in the desk adjacent to the instructor's front desk. She spoke slower than the MI instructor, especially when speaking out key terms that were important for students to understand relevant concepts. Although the non-MI instructor was not as humorous as the MI instructor in terms of personality, she still tried to make the class fun, which was appreciated by Adam "The way she teaches. She makes it interesting. She makes it intriguing and stuff." She asked less questions than the MI instructor and tended to lecture more. She used "shh" repeatedly to stop students from making too much noise.

In general, the casual teaching style of the MI instructor made the class atmosphere more relaxed and enjoyable in the MI class than in the non-MI class. The humorous personality of the MI instructor and her casual ways of interacting with students were appreciated by students. Compared to the non-MI instructor, the MI instructor interacted with students not like an authority but more like a friend. In this sense, MI students were less anxious and more engaged than their counterparts in the non-MI class, which could contribute to MI and non-MI students' different, if 
any, gains of evolution conceptual understanding (Hodapp, 1982; Hughes \& Kwok, 2007; Lawrence Jr., 1962).

Discourse techniques based on the MTI and MDM. I employed predetermined coding themes of teaching practices derived from the MTI and MDM (Brewe, 2008; Manthey \& Brewe, 2013) in the qualitative analysis of the observational data and student interviews, while allowing for emergence of new themes. I compared the MI and non-MI instructors' teaching practices in order to particularly evaluate how well the MI instructor was implementing the high school evolution MI curriculum by linking with students' evolution conceptual understanding. I compared and identified difference between the MI and non-MI instructors' teaching practices in the following five aspects:

- Student-centered teaching: positioning students in a central role in constructing their own understanding of evolution through providing autonomy to students in learning evolution and acknowledging students' ideas.

- Student-student interactions: encouraging students to interact with peer classmates and learn from each other through employing interactive activities and encouraging group work.

- Small-group collaboration: encouraging students to form small groups and collaboratively working and learning together through setting a common group goal, assigning or helping assign roles to group members, 
encouraging promotive interactions, asking students to evaluate the group work as well as each individual's work.

- Whole-class discussion: involving the whole class in discussion of questions/issues/ideas in learning evolution through providing questions/issues/ideas and stimulating students to think and discuss about.

- Socratic questioning: questioning students and stimulating their deep thinking through opening up questions, revealing embedded assumptions, and logically following implication of thought.

- Seeding: introducing a concept to a selected group to explore and learn by themselves through encouraging the group of students to freely explore a specific concept and present their ideas to the whole class.

I describe teaching practices of the MI and non-MI instructors identified through observational data and student interviews. I intend to decipher and compare the MI and non-MI instructors' teaching practices and link their teaching practices with their students' conceptual understanding in evolution.

Student-centered teaching. The MTI suggests MI instructors allows students a sense of autonomy in science learning in classrooms (Brewe, 2008). It is articulated, according to the MTI, that students should be in the central role in classrooms for them to learn and construct understanding of science.

The MI instructor, Ms. Amy, initially allowed students autonomy in each class session, particularly in activities. For example, Sara described that “we don't just do 
book work or anything she does logs. For us, we actually get to do our own experiments" and she appreciated autonomy in hands-on activities "I just don't like something just reading, especially science. It's better to see it actually like you do your own thing like experiment than just reading." On the contrary, the non-MI instructor, Ms. Mia, tended to take the control of the class to draw attention of students. The MI instructor initiated interactions with students, primarily by asking questions, more often than did the non-MI instructor. Both the MI and non-MI instructors employed in-class activities; however, the MI instructor usually allowed and encouraged students to work as a group by themselves to complete tasks after providing brief instructions on the activity while the non-MI instructor usually led the activities and guided students to follow step by step. One MI student, Eva, appreciated MI activities by saying that

"I liked that activity. Activities like that catch my attention a lot...activities that make you work and like think and at the same time is fun...it doesn't make the class boring. Like, it catches my attention and I actually learn."

MI students were allowed to walk around in the classrooms and talk with peers. Non-MI students were not allowed to walk around although they did, which made the class environment noisy but the non-MI instructor had no effective strategy to handle distracting behaviors. Ms. Amy was very attentive especially when students asked questions or has problems in completing group tasks. When students raised 
questions, sometimes she gave direct answers and sometimes she encouraged students to find solutions by themselves. Sara appreciated Ms. Amy's assistance by saying that

“If you need help or you don't understand something, she will tell you...she will give you better instruction than just the paper... If she sees you struggle, she will come and like 'oh, do this' to help us." Fewer students asked the non-MI instructor questions although she did provide direct help. MI students were not always engaged in group activities, and a few students were constantly off-task. In these cases, the MI instructor did not have effective strategies to engage students in group work besides verbally encouraging participation and asking about their task progress, which actually did not function. Occasionally, she had to separate a pair or group of off-task students by rearranging their seats. Even though MI students were not engaged as expected, non-MI students were much less engaged in activities. The MI instructor once assigned an article for students to read and answer questions accordingly. However, most students could not answer related questions. Consequently, the MI instructor had to identify and extract information for students to answer the questions. The non-MI instructor never asked students to read by themselves. Both the MI and non-MI instructors employed videos in class but in different ways. The MI instructor showed videos to students uninterruptedly until the end for students to extract information from videos, 
while the non-MI instructor stopped the video periodically to explain the concept just demonstrated with more details.

In general, the MI instructor provided more autonomy to students than did the non-MI instructor. Although, in a few cases the MI instructor had to take the control of the class by pushing students to complete some tasks in order to catch up with the school district pacing guide. There were more student-centered events happened in the MI class than in the non-MI class. MI students also perceived more autonomy provided by the instructor than their counterparts in the non-MI class did. More student-centered teaching employed and autonomy provided to students could contribute to students' more gain of evolution conceptual understanding (Black \& Deci, 2000; Grolnick \& Ryan, 1987).

Student-student interactions and small-group collaboration. The MTI suggested instructors to encourage student-student interaction in class to allow students to learn from and help each other through promotive interactions (Brewe, 2008). MDM suggests structuring group-based classrooms and encouraging students to collaboratively work in groups on activities. MI instructors are suggested to encourage students to interdepend on each other to pursue a common group goal, play specific roles in group activities, support each other academically as well as personally, and work in a group-mode with necessary small-group skills.

Since all activities that the MI students did were developed purposely for small-group collaboration, the MI students were initially asked to form groups of 
four or five by sitting in the same desk. Although the non-MI students also physically sat in the similar group structure as the MI students did, they did not work in groups except in one activity they were asked to work in pairs. One MI group used small-group collaboration more effectively compared to other groups in the MI class. All members of this group were involved and played different roles in each group activity. They shared ideas, discussed about solutions, and make decisions together. In other groups of the MI class, students preferred to collaborate with friends. For example, Eva articulated that "If I'm sitting with like my friends and they know the answer, yeah, I ask them and they explain it to me" and Anna explained her feeling when working with friends by saying that "if you don't get something, you can always ask someone else and get their opinion on things. If you're stressed out, you can laugh with someone." However, if students were not sitting and working with friends, those groups were less dynamic. In these cases, some students (usually one or two each group) became less active or even inactive. Students' promotive interactions happened less frequently in these cases. Even though some active students tried to communicate and encourage less active or inactive students to participate by assigning tasks to the inactive peer group members, those inactive students, in most cases, just did the assigned jobs passively without enough efforts or even did not work at all. Most active students had to do all the work in order to receive credit. Since the non-MI class was not group-based, all except one activities were done individually. The only activity that the non-MI 
students worked in pairs was card-simulation of natural selection and genetic drift according to colors of beetles. This was the only activity in the non-MI class during which I explicitly identified meaningful student-student interactions and small-group collaborations between students in a pair. Very few meaningful student-student interactions were identified in the non-MI class in all other cases. Most interactions happened between students in the non-MI class were about off-topic things, which distracted those who wanted to learn. The non-MI instructor required students to work individually in almost all activities. Although some students tried to ask for help from others, very few students were willing to provide meaningful academic support to others. For example, Adam complained that

"They ask you for work. They never work and then they ask you to do all the work for them, and it distracts you a lot because they come up to you and start asking you."

In general, student interactions and collaborations were rare and even not encouraged by the non-MI instructor. Even though effective small-group collaboration in the MI class happened mostly in one group and relatively rarely in other groups, student-student interactions and small-group collaborations still happened more in the MI class than in the non-MI class in general.

Although small-group collaboration did not happen as frequently as expected according to the MDM, the MI instructor still successfully encouraged a certain extent of collaboration in students group activities, compared to almost no student 
collaboration in the non-MI class. Meaningful student-student interaction also happened more in the MI class and much less in the non-MI class. The different in student-student interaction and small-group collaboration between the MI and non-MI classes could contribute to the difference of students' gain of evolution conceptual understanding between the MI and non-MI classes.

Whole-class discussion and Socratic questioning. One recommended strategy is to initiate and encourage discussion of some questions/topics/ideas among the whole class of students. Students are allowed to construct their understanding through whole-class discussion. Socratic questioning is the technique suggested for MI instructors to propel whole-class discussion and stimulate students' deeper thinking by opening up questions, following out students' logical implication of thought, and uncovering assumptions.

The MI instructor, Ms. Amy, initiated whole-class discussion once following each group's whiteboard presentation on evidence of evolution. The instructor requested the audience to ask questions after each group's whiteboard presentation and encouraged the entire class to discuss around the questions. Although students paid more attention to peers' presentations than to the instructor's lectures, very few MI students were involved in whole-class discussion by asking questions and negotiating with peers. Most MI students were not involved in whole-class discussion by just listening to the instructor and peers. The non-MI instructor initiated whole-class discussion several times by asking questions for the whole 
class. In most cases only one student who sat in the desk adjacent to the front desk was engaged by actively answering the instructor's questions and expressed his ideas. A few other students occasionally answered the instructor's questions. However, the questioning-answering interactions only happened between participating students with the instructor, not between students, which means there was almost no whole-class discussion in the non-MI class. The MI instructor also employed Socratic questioning to raise questions for the presenting group of students to stimulate their re-thinking of their work. As to the Socratic questioning, usually only a few students could follow the instructor's questions to think deeper, explore the specific topic, and distinguish what they knew from what they did not know. Most other students were not engaged by either passively listening or doing thing off-topic. The non-MI instructor did not employ Socratic questioning technique. She usually asked closed-ended questions.

In summary, there were only a few cases of whole-class discussion happened in the MI class, and the MI instructor's Socratic questioning only engaged a few students to think deeper in very few cases. However, considering almost no whole-class discussion happened in the non-MI class and the non-MI instructor did not employ Socratic questioning technique, whole-class discussion still happened more frequently and the Socratic questioning still worked out better in the MI class than in the non-MI class. The employment of whole-class discussion and Socratic 
questioning in the MI class could contribute to students' gain of evolution conceptual understanding.

\subsection{Discussion}

\subsubsection{Validity and Reliability of the ECI}

Our EFA results demonstrated that items in the ECI loaded differently across the pre- and post-test and were not internally reliable. One possible explanation for the results was that the ECI was administered simultaneously with other assessments, and students usually started to work on the ECI after completing other assessments, so students were pushed by the instructors to complete the ECI quickly in order to save time for the class teaching. In that situation, students were hard to put enough efforts to answer all questions in the ECI carefully. Since they were told that the ECI scores would not affect their class grades, they have just randomly selected answers for each item in the ECI so as not to be pushed by the instructors any more. Their possible careless performance under pressure might result in low correctness rates and selecting answers which was not capability-based.

\subsubsection{Extent of High School Biology MI Implementation and Conceptual Understanding}

In this study, the MI instructor was still new and inexperienced with the high school biology MI curriculum. Although she had one-year experience with high school chemistry MI, it was her first semester implementing biology MI in this study. As she complained to the primary researcher once after class, she felt it very 
challenging to implement biology MI curriculum as well as follow the school district pacing guide. She said that it was particularly difficult to plan MI lessons when occasional early release and high-stakes tests cost her class sessions. However, even though the MI instructor did not employ all modeling discourse management tools effectively as suggested and expected by the MDM, she still took advantage of the MI curriculum, particularly the MI evolution instructional materials, and surpassed the non-MI instructor more or less in instructional materials used and teaching practices in aspects evaluated in the results section.

\subsection{Limitation and Future Directions}

The sample size of this study was 189 . I evaluate the validity and reliability of the ECI based on this sample size, which is not big enough. In order to better assess the validity and reliability of the ECI, larger sample size is needed for collecting more data for analysis. If the assessment administration was more controlled by the researchers and not affected by the instructors, data would be able to illustrate the validity and reliability of the ECI more accurately.

References (Chapter 4)

American Association for the Advancement of Science. (1993). Benchmarks for science literacy: A project 2061 report. New York, NY: Oxford University Press.

Black, A. E., \& Deci, E. L. (2000). The effects of instructors' autonomy support and students' autonomous motivation on learning organic chemistry: A self-determination theory perspective. Science Education, 84, 740-756. 
Brewe, E. (2008). Modeling theory applied: Modeling Instruction in introductory physics. American Journal of Physics, 76, 1155-1160.

Brewe, E., Kramer, L., \& O’Brien, G. (2009). Modeling instruction: Positive attitudinal shifts in introductory physics measured with CLASS. Physical Review Special Topics - Physics Education Research, 5(1), 1-5.

Brewe, E., Sawtelle, V., Kramer, L. H., O’Brien, G. E., Rodriguez, I., \& Pamelá, P. (2010). Toward equity through participation in Modeling Instruction in introductory university physics. Physical Review Special Topics - Physics Education Research, 6(1), 10106.

Caldas, S. J., \& Bankston, C. (1997). Effect of school population socioeconomic status on individual academic achievement. The Journal of Educational Research, 90(5), 269-277.

Davis-Kean, P. E. (2005). The influence of parent education and family income on child achievement: The indirect role of parental expectations and the home environment. Journal of Family Psychology, 19(2), 294-304.

Desbien, D. M. (2002). Modeling discourse management compared to other classroom management styles in university physics. Arizona State University.

Dobzhansky, T. (1973). Nothing in biology makes sense except in the light of evolution. The American Biology Teacher, 35(3), 125-129.

Dukerich, L. (2015). Applying modeling instruction to high school chemistry to improve students' conceptual understanding. Journal of Chemical Education, 92, $1315-1319$.

Durden, J., Brewe, E., \& Kramer, L. H. (2011). "Seeding”: Understanding discourse management in modeling. Jacksonville, FL: AmericanAssociation of Physics Teachers National Meeting.

Dye, J., Cheatham, T., Rowell, G. H., Barlow, A., \& Carlton, R. (2013). The impact of modeling instruction within the inverted curriculum on student achievement in science. Electronic Journal of Science Education, 17(2), 1-19.

Gard, A. (2015). Modeling instruction in high school biology. Miami, FL: American Modeling Teachers Association. 
Grolnick, W. S., \& Ryan, R. M. (1987). Autonomy in children's learning: An experimental and individual difference investigation. Journal of Personality and Social Psychology, 52, 890-898. http://doi.org/10.1037/0022-3514.52.5.890

Halloun, I. A. (2007). Modeling theory in science education. Dordrecht, Netherlands: Springer.

Hestenes, D. (1987). Toward a modeling theory of physics instruction. American Journal of Physics, 55, 440-454.

Hodapp, V. (1982). Causal inference from nonexperimental research on anxiety and educational achievement. Series in Clinical \& Community Psychology: Achievement, Stress, \& Anxiety, 355-372.

Hughes, J., \& Kwok, O. (2007). Influence of student-teacher and parent-teacher relationships on lower achieving readers' engagement and achievement in the primary grades. Journal of Educational Psychology, 99(1), 39-51.

Jackson, J., Dukerich, L., \& Hestenes, D. (2008). Modeling instruction : An effective model for science education. Science Educator, 17(1), 10-17.

Lawrence Jr., S. W. (1962). The effects of anxiety, achievement motivation, and task importance upon performance on an intelligence test. Journal of Educational Psychology, 53(3), 150-156. http://doi.org/10.1037/h0045204

Lee, O., \& Fradd, S. H. (1998). Science for all, including students from non-English-language backgrounds. Educational Researcher, 27(4), 12-21.

Liang, L. L., Fulmer, G. W., Majerich, D. M., Clevenstine, R., \& Howanski, R. (2012). The effects of a model-based physics curriculum program with a physics first approach: A causal-comparative study. Journal of Science Education and Technology, 21, 114-124.

Malone, K. L. (2008). Correlations among knowledge structures, force concept inventory, and problem-solving behaviors. Physical Review Special Topics Physics Education Research, 4(2), 1-15.

Manthey, S., \& Brewe, E. (2013). Toward university modeling instruction-biology: Adapting curricular frameworks from physics to biology. CBE Life Sciences Education, 12, 206-214. 
Mayr, E. (1982). The growth of biological thought. Cambridge, MA: Harvard University Press.

Merriam, S. B. (1998). Qualitative research and case study applications in education. San Francisco, CA: Jossey-Bass.

National Academy of Science. (1998). Teaching about evolution and the nature of science. Washington, DC: National Academies Press.

National Association of Biology Teachers. (2000). Statement on teaching evoluton. In Voices for Evolution (p. 154). National Center for Science Education.

National Research Council. (1996). National science education standards. Washington, DC: National Academies Press.

O’Brien, M. J., \& Thompson, J. R. (2009). Effectiveness of ninth-grade physics in Maine: Conceptual understanding. The Physics Teacher, 47(4), 234-239.

Passmore, C., \& Stewart, J. (2002). A modeling approach to teaching evolutionary biology in high schools. Journal of Research in Science Teaching, 39(3), 185-204.

Reichardt, C. S., \& Cook, T. D. (1979). Quantitative and qualitative methods in evaluation research. In C. S. Reichardt \& T. D. Cook (Eds.), Beyond Qualitative versus Quantitative Methods. Thousand Oaks, CA: SAGE.

Schneider, B., \& Lee, Y. (1990). A Model for academic success: The school and home environment of East Asian students. Anthropology \& Education Quarterly, 21(4), 358-377.

Schuchardt, A. M., \& Schunn, C. D. (2015). Modeling scientific processes with mathematics equations enhances student qualitative conceptual understanding and quantitative problem solving. Science Education, 100(2), 290-320.

Sherman, R. R., \& Webb, R. B. (1988). Qualitative research in education. London, UK: Routledge.

Song, I.-S., \& Hattie, J. (1984). Home environment, self-concept, and academic achievement: A causal modeling approach. Journal of Educational Psychology, $76,1269-1281$. 
Strauss, A., \& Corbin, J. (1990). Basics of qualitative research (2nd ed.). Newbury Park, CA: SAGE.

Yin, R. K. (2014). Case study research : Design and methods (5th Editio). Thousand Oaks, CA: SAGE. 


\section{CHAPTER 5 CONCLUSIONS}

\subsection{Summary of Research Findings}

This dissertation study developed a research instrument, the BIPS, and then focused on examining students' learning outcomes and evaluating and comparing instructors' teaching practices in both MI and non-MI high school Biology I classes. The first part of the dissertation study developed and validated the BIPS for its use in the second part of the dissertation study to gauge high school students' biology identities, evolution identities, and career aspirations (Chapter 2). The second part of the dissertation study focused on students' biology/evolution identities and career aspirations, and connected them with instructors' teaching practices (Chapter 3). The third part of the dissertation study focused on students' conceptual understanding in evolution and its connection with instructors' teaching practices (Chapter 4). These three linked studies worked together to evaluate the implementation of high school biology MI curriculum in south Florida and provide suggestions for better implementation of high school biology MI curriculum in south Florida.

\subsubsection{Validity and Reliability of the BIPS}

Chapter 2 developed the BIPS and assessed the validity and reliability of the BIPS. To develop the BIPS, I first adapted science identity statements from a survey study on the mathematics and physics identities of college students (Godwin et al., 2016) to make biology identity statements for the first section of the BIPS.

Evolution identity statements in the second section of the BIPS were rephrased from 
the biology identity statements, particularly statements about students' recognition with evolution, to conform with mindset of high school students in south Florida. The third section of the BIPS is about students' career aspirations in several biology-related fields, non-biology-related fields, and non-science-related fields. Each item is under an 11-point Likert scale to capture nuance between students' career aspirations. The fourth section of the BIPS is to collect students' demographic information, which is used for data analysis.

The BIPS was first reviewed and validated by an expert in science identity to address its face and content validity. The face and content validity of the BIPS was also addressed through cognitive interviews with three high school students. Qualitative data from the science identity expert and student interviewees support the BIPS as a valid instrument in covering the concept it was designed to measure and representing all components of targeted constructs. The confirmatory factor analysis (CFA) was applied to statistically assess the construct validity of the BIPS. After removing four problematic evolution identity statements, the final version of the BIPS was supported by the CFA results as a valid instrument in measuring biology/evolution identity based on the science identity conceptual framework employed in this study (Carlone \& Johnson, 2007; Hazari et al., 2010). The reliability of the BIPS was assessed through Cronbach's alpha for its internal reliability and through test-retest reliability for its stability. The Cronbach's alpha results demonstrated excellent internal reliability of the BIPS in measuring biology 
identity and evolution identity. The test-retest reliability analysis suggested that the BIPS was stable in measuring biology identity, evolution identity, and aspirations in biology-related careers. Due to sample students were taking other science courses (e.g. physics) and possibly other non-science courses, statements in measuring students' career aspirations in non-biology-related fields were not stable. In general, both qualitative and quantitative data supported the BIPS as a valid and reliable research instrument in measuring high school students' biology identities, evolution identities, and biology career aspirations, which was then employed for quantitative data collection in Chapter 3.

\subsubsection{Connections between Teaching Practice, Biology and Evolution}

\section{Identity, and Career Aspirations}

In the second part of the dissertation study, I did not detect significant difference in students' biology identities, evolution identities, and career aspirations between MI and non-MI students. However, after analyzing both the MI and non-MI instructors' teaching practices, I successfully identified connections between instructors' teaching practices and students' biology/evolution identities and career aspirations. The MI instructor did not employ intentional lack of inquiry closure and seeding, which are two pedagogical techniques that would involve students in expert-like activities. Intentional lack of inquiry closure and seeding might be two critical pedagogical techniques the MI should apply so as to promote students' gain of biology/evolution identities, and aspirations in biology-related careers. The MI 
instructor encouraged whole-class discussion and also used Socratic questioning to stimulate students' deeper thinking; however, she failed to engage students to participate in whole-class discussion, and her students failed to follow her Socratic questioning to think more and deeper on questions/ideas. As a result, although the MI instructor initially used whole-class discussion and Socratic questioning as two important pedagogical techniques, these two techniques did not function well and make difference between the MI and non-Mi classes. The MI instructor successfully employ student-centered teaching strategy and encouraged student-student interactions and students' small-group collaboration, compared to the teacher-centered teaching and much less meaningful interactions and collaboration between students in the non-MI class. However, it seemed that employing student-centered teaching and encouraging student-student interaction and small-group collaboration was not enough to improve students' more gain of biology/evolution identities and aspirations in biology careers in MI classes than in non-MI classes. Another remarkable finding was that the MI instructor did not employed activities about evidence of evolution suggested in the high school biology MI materials, which might impact the MI students' understanding and/or acceptance of evolution, and contribute to their insignificant development of evolution identity, particularly their recognition with evolution. 


\subsubsection{Connections between Teaching Practice and Conceptual Understanding in Evolution}

Both the MI evolution activities and how the MI instructor implemented the MI evolution activities might contribute to students' gain of conceptual understanding in evolution. The MI instructor employed more student-centered teaching, particularly during in-class MI activities, than the non-MI instructor did. The MI activities require small-group collaboration, which was also encouraged by the MI instructor in this study. In the small-group collaboration environment, meaningful student-student interactions were significantly more in the MI class than in the no-MI class.

\subsection{Implications of the Dissertation Research}

\subsubsection{Implications for High School Biology MI Workshops}

The two participating MI instructors, Amy and Bill, were both recruited in the high school biology MI workshop in the summer of 2016. They were both new to the high school biology MI curriculum and attended the workshop for the first time. According to observation of Amy's class, and informal talk with Bill and some other attendees of the workshop in the summer of 2016, they were all struggling in implementing high school biology MI in two aspects: 1) implementing biology MI in a timely manner; 2) implementing biology MI effectively. I suggest that high school biology MI workshops need to involve attendees in leading MI activities in "teacher mode," not just in "student mode" as is currently the practice. Then this 
activity leader's performance would be discussed within the whole workshop. In this way, workshop attendees would have ideas about not only what are high school biology MI activities but also how to implement MI activities effectively.

\subsection{Directions for Future Work}

This dissertation study evaluated high school biology MI curriculum through a comparative case study approach by comparing students' learning outcomes and instructors' teaching practices in evolution class sessions in MI classes with those in non-MI classes. To further evaluate high school biology MI curriculum as a whole unit in terms of biology identity development, future work is to collect data on students' biology identity through the entire academic year. The long period of data collection on biology identity would allow me to capture nuances of students' biology identity development. A study through an entire academic year also allowed me to examine students' conceptual understanding in biology in general, which would be beneficial for the argument on the implementation of biology MI curriculum in high schools.

Since high school biology MI curriculum is still new to high school biology instructors in south Florida, MI instructors in south Florida are still inexperienced in effectively implement biology MI curriculum in high school biology classrooms. A longitudinal study would be able to monitor and assess biology MI instructors' progress in developing their capabilities in implementing high school biology MI curriculum. Data on biology MI instructors' development and how they improve 
their MI capability would help design more efficient biology MI workshops for high school biology instructors and provide suggestions for high school biology MI instructors in their classroom teaching practices.

\section{References (Chapter 5)}

Carlone, H. B., \& Johnson, A. (2007). Understanding the science experiences of successful women of color: Science identity as an analytic lens. Journal of Research in Science Teaching, 44, 1187-1218.

Godwin, A., Potvin, G., Hazari, Z., \& Lock, R. (2016). Identity, critical agency, and engineering: An affective model for predicting engineering as a career choice. Journal of Engineering Education, 105(2), 312-340.

Hazari, Z., Sonnert, G., Sadler, P. M., \& Shanahan, M.-C. (2010). Connecting high school physics experiences, outcome expectations, physics identity, and physics career choice: A gender study. Journal of Research in Science Teaching, 47, 978-1003. 


\section{APPENDIX A}

This appendix includes the final version of the Biology Identity and Persistence Survey (BIPS) given to students to evaluate their biology identities, evolution identities, and career aspirations. I dropped Statement $2 \mathrm{c}, 2 \mathrm{~d}, 2 \mathrm{i}$, and $2 \mathrm{j}$ from the original version of the BIPS according to the confirmatory factor analysis results.

\section{Biology Identity and Persistence Survey - BIPS}

1. To what extent do you agree or disagree with the following statements?

a) I see myself as a biology person

b) My family sees me as a biology person

c) My friends/classmates see me as a biology person

d) My biology teachers see me as a biology person

e) I am confident that I can understand biology in class

f) I am confident that I can understand biology outside of class

g) I can do well on exams in biology

h) I understand concepts I have studied in biology

i) I can overcome setbacks in biology

j) Others ask me for help in biology

k) I am interested in learning more about biology

1) Topics in biology excite my curiosity

m) I enjoy learning about biology

2. To what extent do you agree or disagree with the following statements?

a) I see myself as an advocate for evolution

b) Evolution fits in how I see the world

c) I am confident that I can understand evolution in class

d) I am confident that I can understand evolution outside of class

e) I can do well on exams in evolution

f) I understand concepts I have studied in evolution

g) I am interested in learning more about evolution

h) Topics in evolution excite my curiosity

i) I enjoy learning about evolution

3. Please rate the LIKELIHOOD of you choosing a career in:

a) Medical professional (e.g., doctor, dentist, vet.)

b) Health professional (e.g., nursing, pharmacy) 

c) Biologist
d) Earth/Environmental scientist
e) Other biology-related field
f) Other science-related field
g) Non-science-related field 


\section{APPENDIX B}

This appendix includes the Evolution Concept Inventory assessment given to students to assess their conceptual understanding in evolution.

\section{Evolution Concept Inventory}

1. Natural selection produces evolutionary change by ...

a. Changing the frequency of various versions of genes.

b. Reducing the number of new mutations.

c. Producing genes needed for new environments.

d. Reducing the effects of detrimental versions of genes.

e. Increasing the number of new mutations.

2. What is the primary change that occurs gradually over time in a population?

a. The traits of each individual organism in the population gradually change.

b. The proportions of organisms having different traits in the population change.

c. Successful behaviors learned by certain individuals are passed on to offspring.

d. Individual organisms change their traits to be more like successful individuals in the population.

e. Mutations occur to meet the needs of the organism as the environment changes.

3. A species of bird ate many types of seeds, each type coming from a different species of tree. The birds' beaks varied in size, with some individuals having slightly smaller beaks and others having slightly larger beaks.

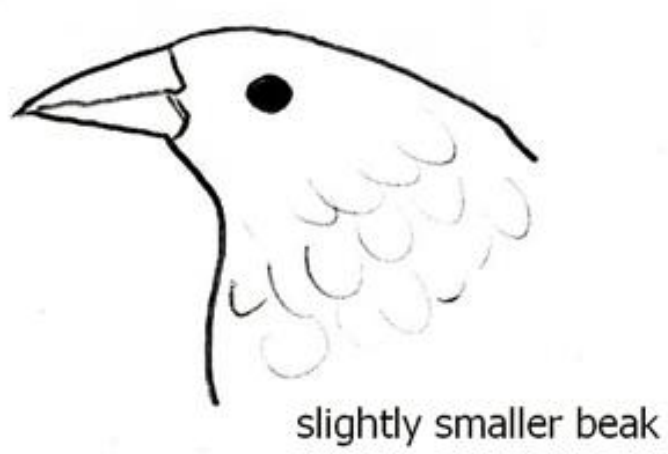

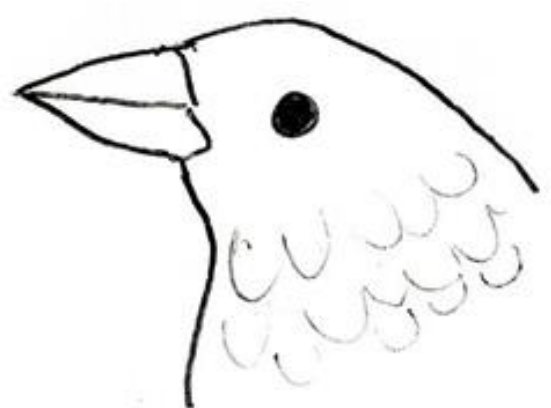

slightly larger beak 
A few years went by without much rain, and the only species of tree that survived had large seeds. Many generations later, almost all the birds had the slightly larger beaks. How is this best explained?

a. The birds with larger beaks were better at eating the large seeds than those with smaller beaks, so only the birds with larger beaks got enough food to survive, reproduce, and pass the trait of large beaks to the next generation.

b. The birds with larger beaks learned to get their food from the trees with large seeds. This behavior was passed down to subsequent generations, enabling the birds with larger beaks to survive better than the birds with smaller beaks.

c. The birds with smaller beaks had to work harder than those with larger beaks to crack open the large seeds. The more they used their beaks, the larger their beaks became, so they were able to get enough food to survive, reproduce, and pass the traits of large beaks to the next generation.

d. The birds with smaller beaks grew their beaks so that they would be better able to eat the large seeds and get enough food to survive, reproduce, and pass the trait of larger beaks to the next generation.

e. It was a chance occurrence that all the individual birds' beaks in the next generation were larger. They were therefore able to eat the large seeds and get enough food to survive, reproduce, and pass the trait of large beaks to the next generation.

4. What could cause a population living today to differ from their ancestors many generations ago?

a. An environmental change could affect which inherited traits are most helpful, and therefore which individuals are more likely to survive and reproduce.

b. Mutations could alter inherited traits, which are subsequently passed down to offspring.

c. Genetic drift could alter the allele frequency of the population.

d. $a$ and $b$ are correct.

e. a, b, and c are correct.

5. Biologists have been growing a population of bacteria on a media containing an antibiotic and then switching the bacteria to media without the antibiotic. They have continued doing this for a thousand generations of the bacteria. The biologists noticed that initially very few bacteria survived, but now almost $100 \%$ of the bacteria survive (i.e., are resistant to the antibiotic). The best explanation is that: 
a. The environment (the media with the antibiotic) caused the bacteria to become resistant to the antibiotic. Each generation more bacteria changed and so now more survive.

b. The environment (the media with the antibiotic) caused the bacteria to become resistant to the antibiotic. These bacteria survived and reproduced more than nonresistant bacteria and so now more survive.

c. Initially, some bacteria were resistant to the antibiotic and some weren't. The environment (the media with the antibiotic) allowed those that were resistant to survive and reproduce better than the nonresistant bacteria and so now more survive.

d. Initially, some bacteria were resistant to the antibiotic and some weren't. Over time, the environment (the media with the antibiotic) stimulated other bacteria to develop resistance as well and so now more survive.

e. Initially, some bacteria received a weaker dose of the antibiotic and were able to survive. Their initial exposure stimulated a resistance to further exposures, even at higher levels. This enhanced resistance was passed on to subsequent generations.

6. Three different species of lizards found on the Canary Islands are similar to one species found on the African continent to the east of the islands. Scientists infer that at some time long ago, lizards of the African species were taken from the African continent to the Canary Islands on floating tree trunks washed out to sea. What could cause the one species of lizard to change into three species over time?

a. Two groups of lizards were initially separated and remained isolated. Each developed into a separate species. Eventually, the populations began to mingle and the interbreeding produced the third species.

b. Groups of lizards encountered different island environments so the lizards needed to become new species with different traits in order to survive.

c. Groups of lizards must have been geographically isolated from other groups, and random genetic changes must have accumulated in these isolated lizard populations over time, resulting in different species.

d. There may be minor variations, but they are more likely to actually be three sub-species of the single original species.

e. In order to survive, different groups of lizards needed to adapt to the different islands, and so all organisms in each group gradually evolved to become a new lizard species. 
7. According to fossil records and recent published observations, two species of leaf-eating beetles (species A and B) have existed on an isolated island in the Pacific Ocean for over 100,000 years. In 1964, a third species of leaf-eating beetle (species C) was accidentally introduced on the island. The population size of each species has been regularly monitored as shown in the graph below.

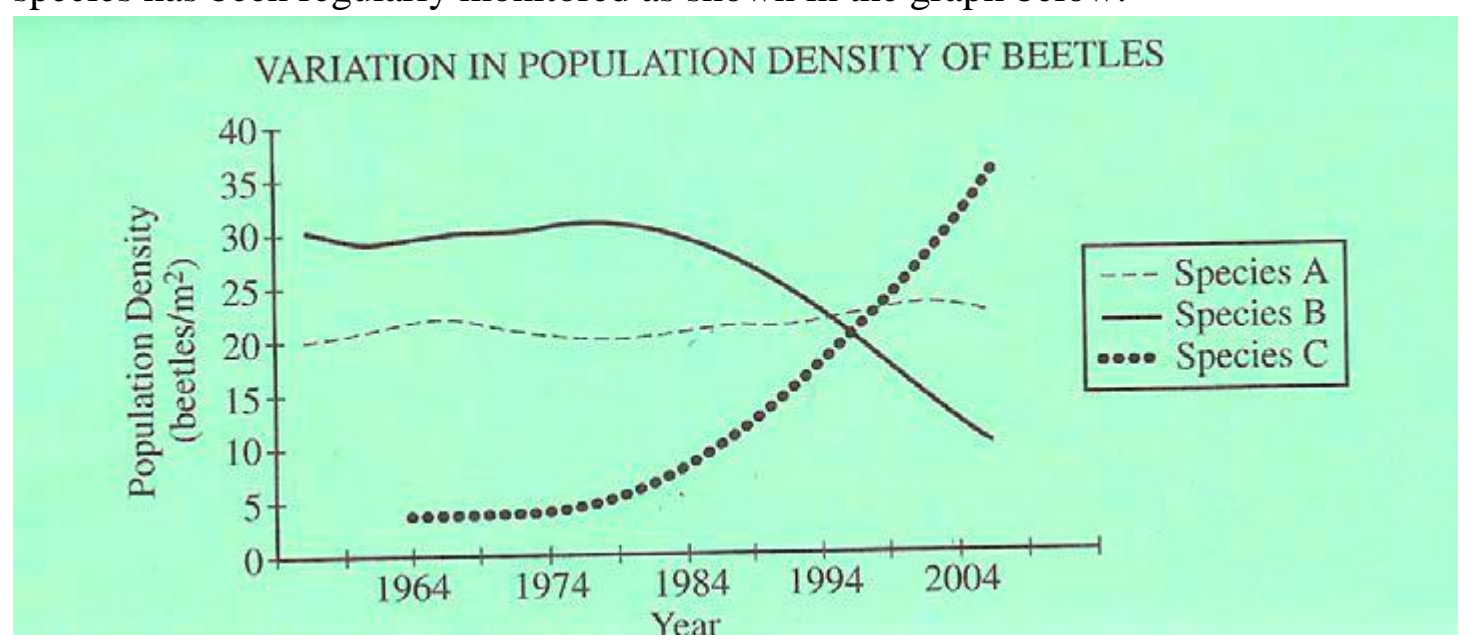

The best explanation for the decline in species B's numbers and the increase in species C's numbers is:

a. There was more water available for species $C$ than species $B$

b. There was no competition between species $\mathrm{C}$ and species $\mathrm{A}$

c. Species B was about to decline in numbers prior to the introduction of Species C

d. Species B and Species $\mathrm{C}$ compete for the same resources

e. Species A and Species $\mathrm{C}$ compete for the same resources

8. Darwin's theory of evolution by natural selection states that evolution occurs because:

a. Natural selection acts on variation in a population.

b. Variation in a population is produced by natural selection.

c. Some organisms in a population are selected because they are the strongest in the environment.

d. The more intelligent organisms are best suited for a particular environment.

e. Changes in an individual's genetic material are usually harmful. 


\section{FENG LI}

Born, Yangzhou, Jiangsu, China

2002

B.S., Biotechnology

Shanghai Ocean University

Shanghai, China

2014-2017

Graduate Teaching Assistant

Florida International University

Miami, Florida

2015-2017

Ph.D. Candidate

Florida International University

Miami, Florida

\section{PUBLICATIONS AND PRESENTATIONS}

Li, F. (April 2014). The effectiveness of Modeling Instruction on the academic achievement and learning attitudes of undergraduate students in an introductory biology lab class. Paper presented at 2014 Annual Graduate Student Appreciation Week Scholarly Forum. Miami, FL: Florida International University.

Li, F. \& Jiang, X. (May 2014). Modeling Instruction as scaffolding to ESL students in high school biology classes. Paper presented at the Sunshine State TESOL 2014 conference. St. Petersburg, FL.

Li, F., Hazari, Z., Sonnert, G., \& Sadler, P. M. (July 2014). The examination of the relationship between high school biology experiences, career outcome expectations, biology identity, and biology career choice. Poster presented at Society for the Advancement of Biology Education Research 2014 National Meeting. Twin Cities, MN.

Li, F. (2015). Theoretical foundations of developing Modeling Instruction curriculum for college biology courses. In S. M. Nielsen (Ed.), Proceedings of the 14th Annual South Florida Education Research Conference (pp. 23-31). Miami, FL. http://digitalcommons.fiu.edu/cgi/viewcontent.cgi? article=1481\&context=sferc 
Li, F., \& Jiang, X. (July 2015). High school biology-related experiences of three non-science major undergraduate students. Roundtable session conducted at Society for the Advancement of Biology Education Research 2015 National Meeting. Twin Cities, MN.

Li, F., \& Hazari, Z. (July 2016). Biology Identity and Persistence Survey (BIPS): An instrument for assessing students' biology identities and aspirations in biology. Paper presented at Society for the Advancement of Biology Education Research 2016 National Meeting. Twin Cities, MN.

Li, F., \& Jiang, X. (2016). Non-science major undergraduate students' high school science experiences: An exploratory case study. The Qualitative Report, 21(11), 2015-2035.

Jiang, X., Li, F., \& Wang, C. (April 2017). Chinese English teachers' perceptions of their professional development: A mixed-methods case study. Manuscript revised and resubmitted to Teacher Development.

Li, F., \& Hazari, Z. (May 2017). Developing and validating the Biology Identity and Persistence Survey (BIPS) for use in high schools in south Florida. Manuscript submitted to CBE-Life Science Education and currently under revision.

Li, F., Brewe, E., Hazari, Z., O’Brien, G.E., \& Long, H. (July 2017). Deciphering High School Biology Modeling Instruction Practice: A Comparative Case Study. Paper presented at Society for the Advancement of Biology Education Research 2017 National Meeting. Twin Cities, MN. 